\title{
Ultrasonic tissue characterization of the heart
}

Citation for published version (APA):

Tak, T. (1989). Ultrasonic tissue characterization of the heart. [Doctoral Thesis, Maastricht University]. Rijksuniversiteit Limburg. https://doi.org/10.26481/dis.19890512tt

Document status and date:

Published: 01/01/1989

DOI:

10.26481/dis.19890512tt

Document Version:

Publisher's PDF, also known as Version of record

\section{Please check the document version of this publication:}

- A submitted manuscript is the version of the article upon submission and before peer-review. There can be important differences between the submitted version and the official published version of record.

People interested in the research are advised to contact the author for the final version of the publication, or visit the DOI to the publisher's website.

- The final author version and the galley proof are versions of the publication after peer review.

- The final published version features the final layout of the paper including the volume, issue and page numbers.

Link to publication

\footnotetext{
General rights rights.

- You may freely distribute the URL identifying the publication in the public portal. please follow below link for the End User Agreement:

www.umlib.nl/taverne-license

Take down policy

If you believe that this document breaches copyright please contact us at:

repository@maastrichtuniversity.nl

providing details and we will investigate your claim.
}

Copyright and moral rights for the publications made accessible in the public portal are retained by the authors and/or other copyright owners and it is a condition of accessing publications that users recognise and abide by the legal requirements associated with these

- Users may download and print one copy of any publication from the public portal for the purpose of private study or research.

- You may not further distribute the material or use it for any profit-making activity or commercial gain

If the publication is distributed under the terms of Article $25 \mathrm{fa}$ of the Dutch Copyright Act, indicated by the "Taverne" license above, 
Part of this work was awarded:

The first prize and Governor's Trophy at the Annual Young Investigators Forum, American College of Physicians, Southern California and Nevada Scientific Meeting, La Jolla, San Diego, California. March 20th. 1988. 
ULTRASONIC TISSUE CHARACTERIZATION OF THE HEART 



\section{ULTRASONIC TISSUE CHARACTERIZATION OF THE HEART}

\section{PROEFSCHRIFT}

ter verkriging van de grad van doctor aan de Ruksuniversitet Limburg te Maastricht, op gezag van de Rector Magnificas, Prof. Dr. F.M.M. Bonke, volgens het beskit van het College van Dekanen,

in het openbaar te verdedigen

op vrijdag, 12 mei 1989 , on 14.00 wur

door

\section{TAHIR TAK}

geboren te Lahore, Pakistan 
Promotor:

Co-promotor:

Beoordelingscommissie: Prof. Dr. R.S. Reneman (voorzitter)

Prof. Dr. F.I.M. Bonke

Prof. Dr. R. Erbel (Joh. Gutenberg Universität,

Mainz, West Duitsland)

Dr. J.P.M. Hamer (Rijksuniversiteit Groningen)

Prof. Dr. O.C.K.M. Penn

Financial support by the Netherlands Heart Foundation for the publication of this thesis is gratefully acknowledged. A part of the publication costs were sponsored by Smith, Kline and French Pharmaceuticals, Rijswijk, The Netherlands. 
To claim that we understand something, we must understand the rudiments.

$$
\text { Aristotle }
$$

..... Dedicated to my father and to the memory of my mother. 



\section{CONTENTS}

Chapter 1: General Introduction 1

Chapter 2: Identification of textural differences of the mitral leaflets in subsets of patients with mitral valve prolapse

Chapter 3: Value of digital image processing of two-dimensional echocardiograms in differentiating active from chronic vegetations of infective endocarditis

Chapter 4: Ultrasonic tissue characterization of acute canine myocardial infarction.

Chapter 5: Evidence of decreased tissue density in mitral valves with severe myxomatous degeneration and increased tissue density in rheumatic mitral valves: In vitro observations

Chapter 6: Ultrasonic tissue characterization methods in the diagnosis of coronary artery disease

Chapter 7: Detection of early myocardial tissue changes in acute canine myocardial infarction by ultrasonic tissue characterization methods.

Chapter 8: Appraisal of the research performed. 



\section{Chapter 1}

\section{INTRODUCTION}

Since the earliest work of Edler and Hertz ${ }^{1}$ who recorded mitral valve motion with ultrasound, echocardiography has become well established as a useful tool in the evaluation of cardiovascular disease. The advent of two-dimensional echocardiography has further added to its applications. ${ }^{2}$ Ultrasound, by definition, is sound with frequency greater than 20 thousand cycles per second, above the audible range. The suitability of ultrasound for medical diagnosis depends essentially on the characteristics. of tissue interfaces which reflect ultrasound.

Ultrasound energy propagates in the form of a mechanical disturbance, or pressure wave, through a medium. The most common way these waveforms have been produced has been through the pulsing of Piezo electric crystal transducers. When the crystal is electronically pulsed, it oscillates mechanically in an expanding and contracting motion that produces a pressure wave. This wave then propagates into the object of interest (a patient or test object) where it interacts with the object to produce echoes. These echoes, or backscattered signal, are the result of the interactions between the waveform and the many acoustical characteristics of the object of interrogation and, therefore, contain the information that is needed to image the object as well as other information that may be related to the state of the tissue.

\section{M-mode Echocardiography}

When the ultrasonic energy returns as an echo and strikes the transducer a radiofrequency is created, which will be processed and displayed on an oscilloscope in time-motion or M-mode. This type of recording is best suited for the constantly moving heart structures. ${ }^{3}$ The principle of $\mathrm{M}$ mode display is shown in Figure 1. The position of the echoes which originate from the different interfaces of the heart structures is continuously plotted against time yielding its motion pattern.

The M-mode echocardiogram is documented with a stripchart recorder 


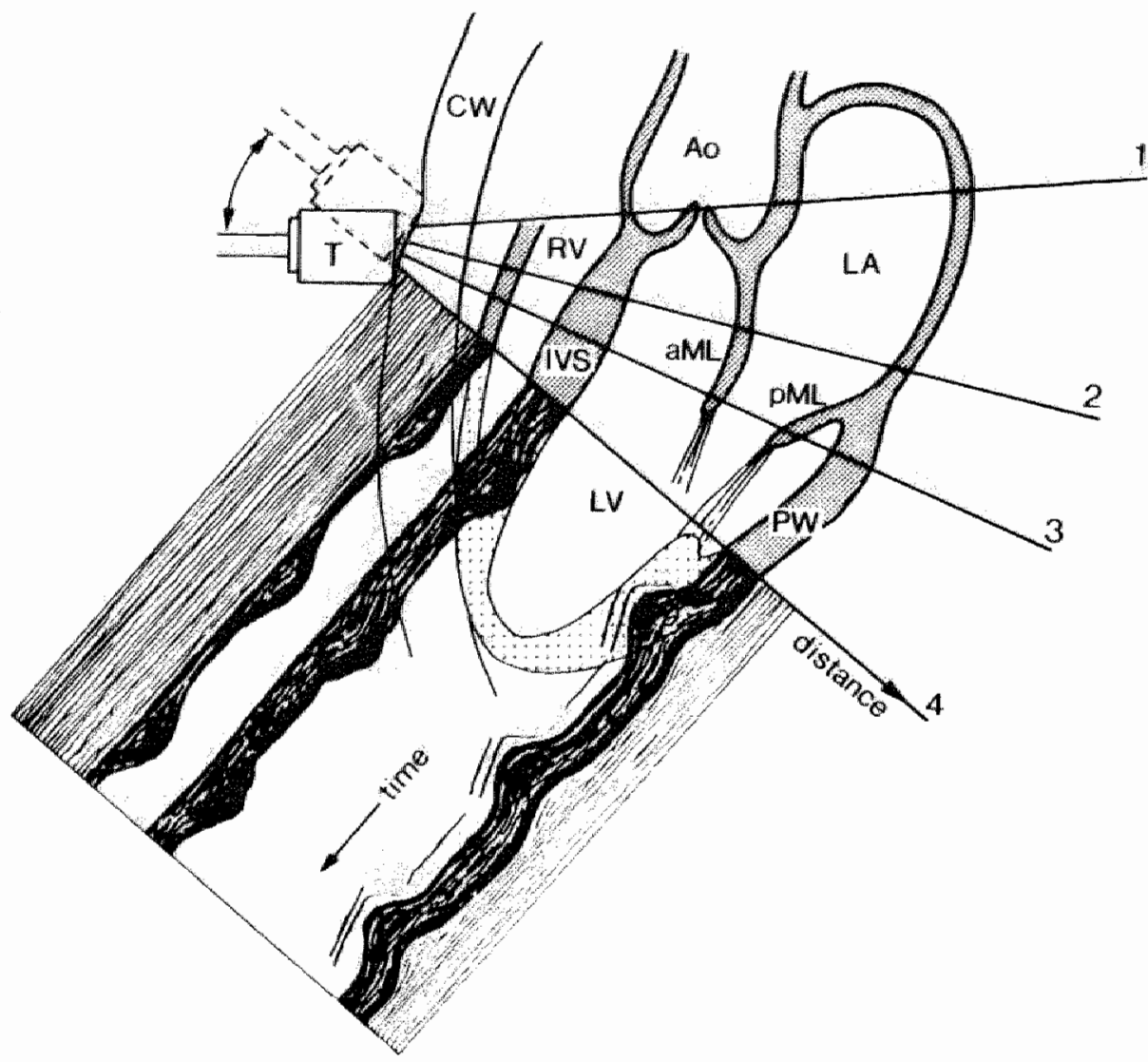

Figure 1: Schematic cross-section of the heart, parallel to the long axis of the left ventricle (LV), showing the structure which the sound beam passes when the transducer $(T)$ is placed in a left parasternal acoustic position (third of fourth intercostal space) and is directed (4) at the left ventricular cavity (long axis plane).

Ao: aorta; CW: chest wall.; aML: anterior mitral leaflet; IVS: interventricular septum; pML: posterior mitral leaflet; LA: left atrium; PW: posterior wall; RV: right ventricle.

which provides a hard copy of the M-mode data along with the electrocardiogram. phonocardiogram, etc. (Figure 2).

\section{2-Dimensional Echocardiography}

Real time, two-dimensional echocardiographic visualization of cardiac anatomical features has now been available for diagnostic cardiology 


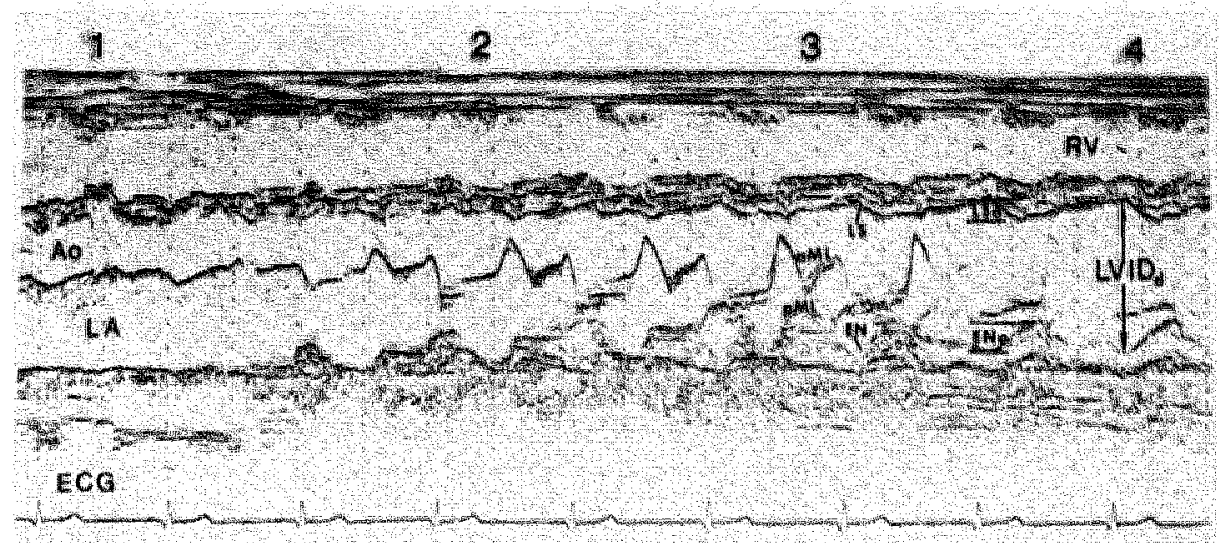

Figure 2: M-mode scan from a normal person. The direction of the sound beam labelled 1 to 4 in Figure 1 corresponds to the area labelled 1 to 4 in this M-mode scan. ENa: amplitude of posterior wall endocardium; LSa: amplitude of left septal endocardium; LVIDd: diastolic left ventricular internal diameter.

For abbreviations see Figure 1.

since the early seventies. The images obtained with a commercially available two-dimensional echocardiographic system are displayed on an oscilloscope and are stored on video tape for subsequent analysis. Utilizing a Polaroid camera, hard copies of stop frame images can be obtained (Figures 3-5).

Two-dimensional echocardiographic examinations are performed with the patient in the supine or left lateral decubitus position. The latter is preferable, because the heart shifts laterally from beneath the sternum. Examination of the left ventricle begins by placing the transducer in the left parasternal region (Figure 6), usually in the third or fourth left intercostal space. An identical acoustical window to that used for $\mathrm{M}$ mode scanning of the heart is thus utilized. From this position, an image of the heart along its long- and short-axis can be obtained. A parasternal long-axis view of the left ventricle usually reveals portions of the aortic root, left atrium, mitral valve leaflets and the base of the left ventricle (Figure $3 \mathrm{~A}$ ). From this position, it is not possible to visualize the cardiac apex.

Short-axis views of the left ventricle are obtained by rotating the transducer clockwise, so that the plane of the ultrasonic beam is approximately perpendicular to the plane of the long-axis of the left 
A
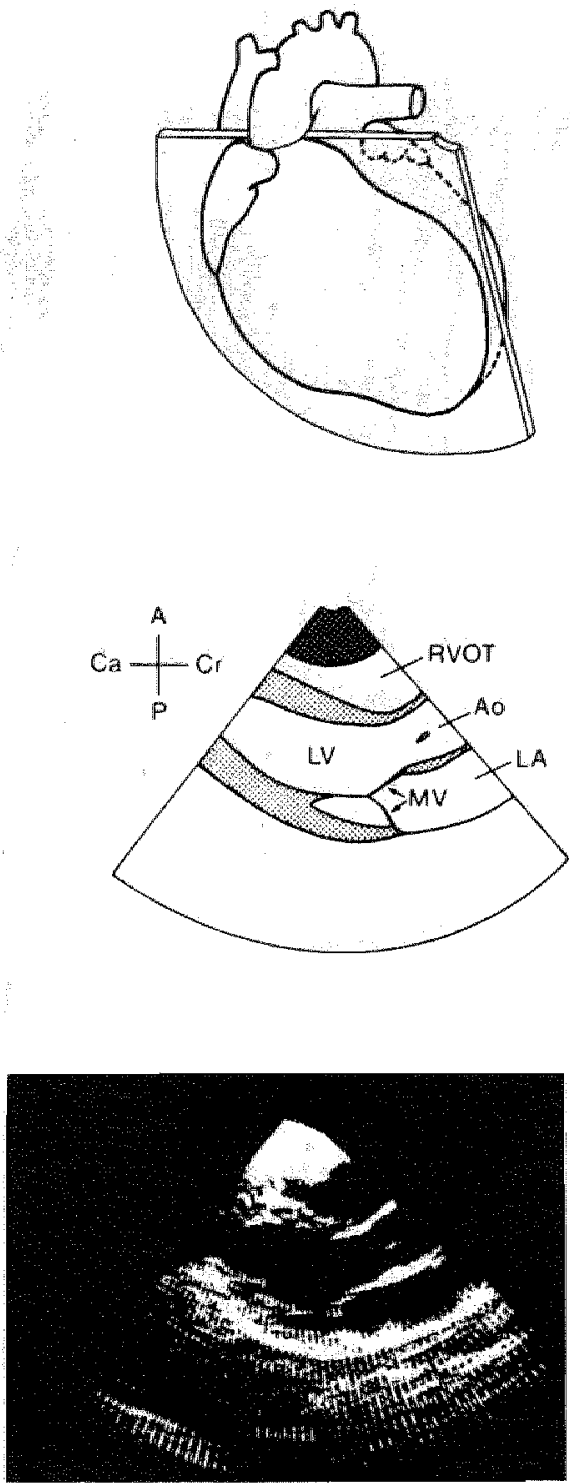

B
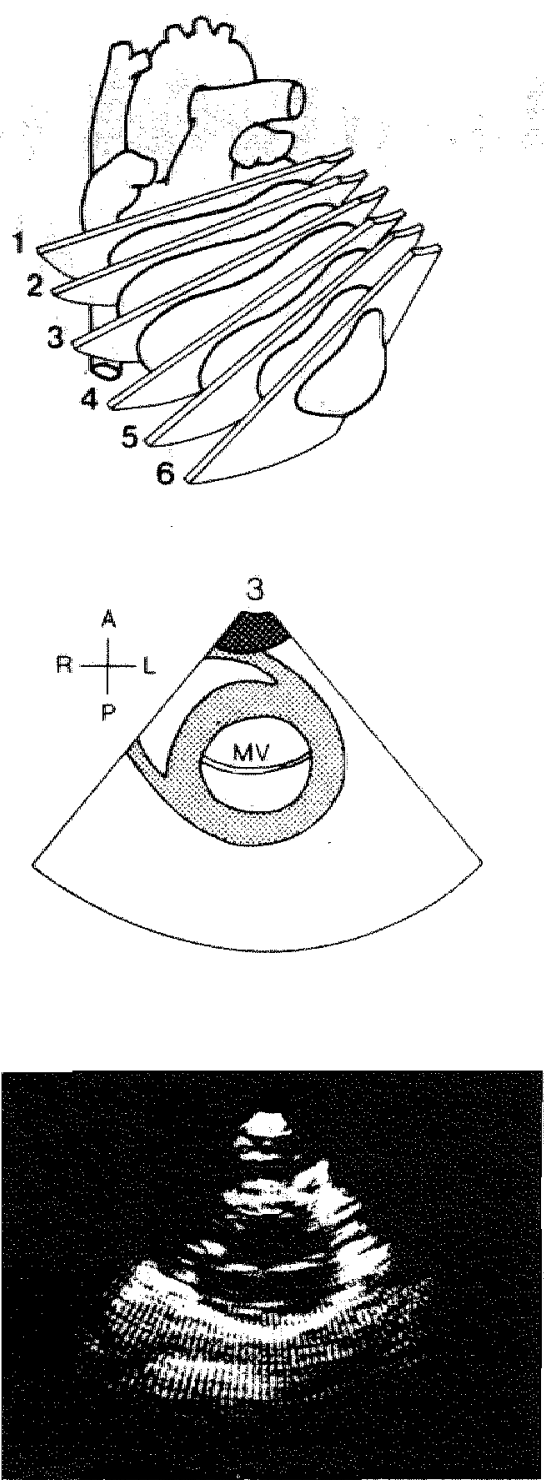

Figure 3: Transducer position, schematic diagram and stop frame of a parasternal (A) long-and (B) short-axis echocardiogram of the heart in a normal person. For details see text. A: anterior; Ca: caudall; Cr: cranial; L: left; $M V$ : mitral valve; $R$ : right; $R$ VOT: right ventricular outflow tract; $\mathrm{P}$ : posterior. For abbreviations see Figure 1. 
A

a

0

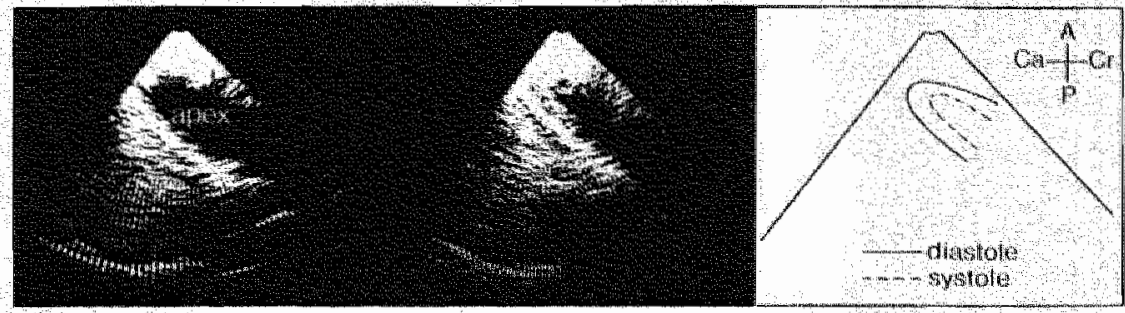

Figure 4: Diastolic and systolic parasternal long axis echocardiograms of a normal cardiac apex. The diagram shows the diastolic and systolic cardiac line.

$4 \mathrm{C}$
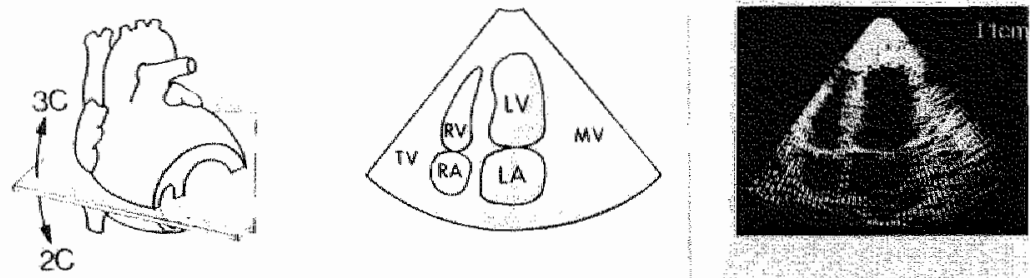

$2 \mathrm{C}$
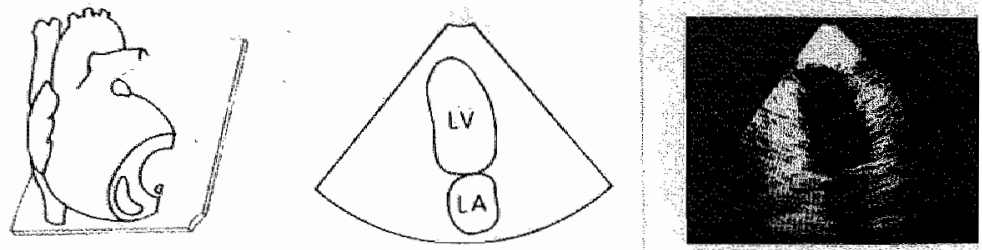

30
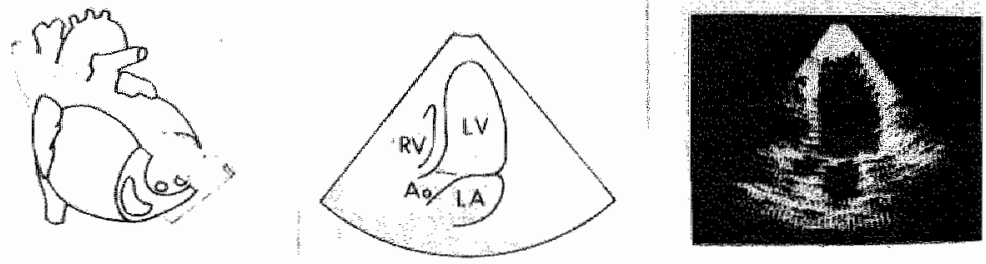

Figure 5: Apical transducer position together with corresponding diagram and stop frame of two $(2 \mathrm{C})$, three $(3 \mathrm{C})$ and four $(4 \mathrm{C})$ chamber view. $\mathrm{RA}$ : right atrium; $T$ : transpid valve. $\mathbb{R} V$ : right ventricle; $L V$ : left ventricle; $L A$ : left atrium; $M V$ : mitral valve; $\mathrm{AO}$ : Aorta. 


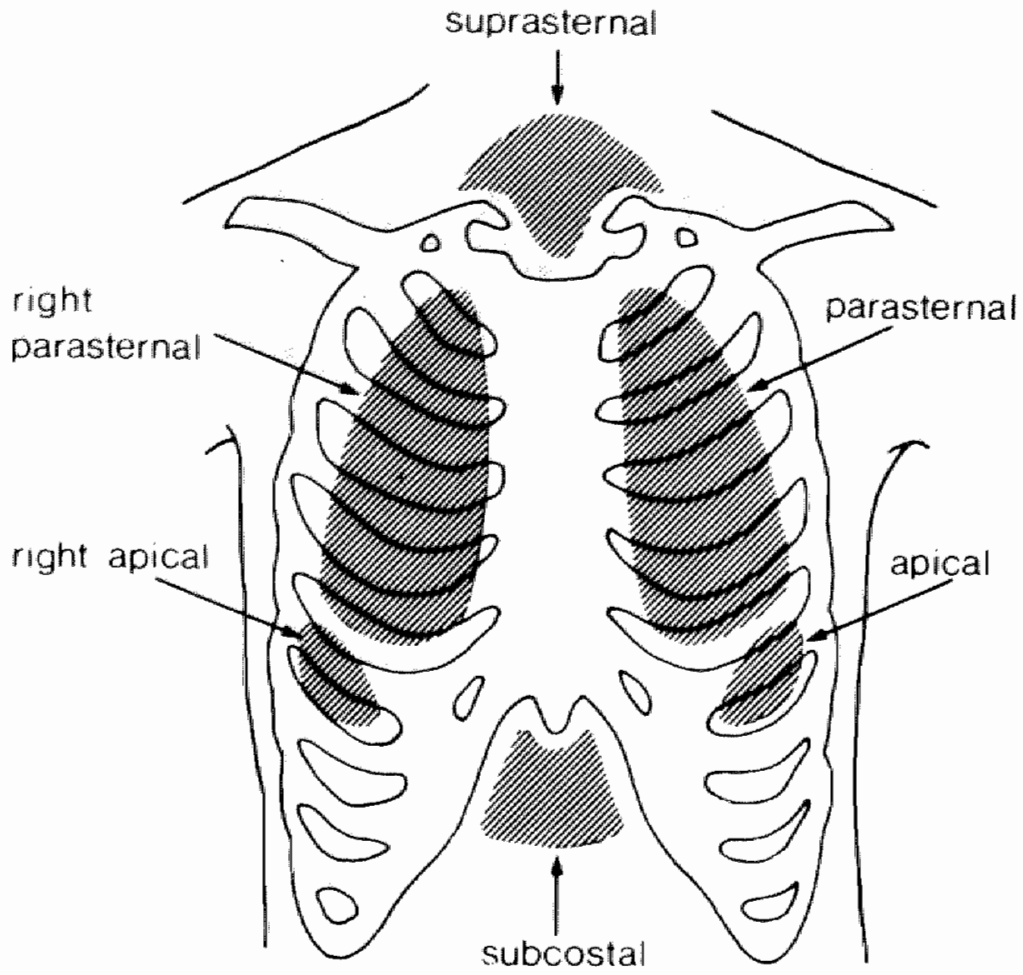

Figure 6: Schematic diagram of the standard nomenclature of the various transucer positions on the chest wall.

ventricle. With the transducer perpendicular to the chest wall a short-axis image of the left ventricle is obtained at the level of the mitral valve (Figure 3B). From this position, the transducer is tilted upward to the base of the heart and downwards to the region of the papillary muscles. Cross sections of the cardiac apex can only be obtained by moving the transducer down the chest wall and placing it over, or in the immediate vicinity of the point of maximal apical impulse. Figure 4 shows parasternal long-axis echocardiograms of the cardiax apex in a normal person.

From the apical location, a cross-section is obtained which displays all four cardiac chambers (Figure 5). This four-chamber view is of particular value in patients with coronary artery disease, since it displays the interventricular septum to a large extent. A two and three-chamber view is obtained by rotating this transducer approximately 60 degrees 
clockwise and counter- clockwise, respectively (Figure 5). This apical approach is of particular value in patients with acute and chronic myocardial infarction, as the apex of the left ventricle is often involved.4.5

In summary, the tomographic sections obtained by two-dimensional echocardiography, display the cardiac anatomy, ${ }^{6}$ and provide excellent information about size, shape and wall dynamics of the entire ventricle. 7,8

\section{ULTRASONIC TISSUE CHARACTERIZATION IN CARDIOLOGY}

The standard clinical applications of echocardiography involve display of the smooth surfaces of the heart, such as the endocardium, epicardium and valve leaflets. A relatively new area in cardiac ultrasound is the attempt to evaluate myocardial tissue composition and/or structure based on the acoustic properties of the heart. The rationale for this area of study which is termed ultrasonic tissue characterization is that ultrasound interacts (is absorbed or reflected) differently with abnormal myocardium than with normal myocardium. Several approaches to the evaluation of tissue composition with ultrasound include the display of acoustically abnormal tissue using gray scale or color encoding, the measurement of classical acoustic variables (such as backscatter and attenuation) and computer-based analysis of ultrasound signals and images. Promising results have been obtained through the use of ultrasound tissue characterization methods to identify ischemia, acute and chromic myocardial infarction, cardiomyopathies, myocardial contusion and intracardiac masses. Certain structural abnormalities of the myocardium may be associated with alterations in the character of reflected ultrasound. For example, calcified valvular or annular tissue exhibits a bright, homogeneous appearance"; the ventricular septum in patients with hypertrophic cardiomyopathy displays an unusual pattern of echo amplitudes ${ }^{10}$; amyloid infiltrated myocardium has been described as "sparkling" ", and scarred myocardium occasionally is recognized as an area of intense echoes. ${ }^{12}$ These and other similar observations give impetus to the attempt to identify abnormal myocardial structure based upon the analysis of myocardial acoustic properties i.e. ultrasonic tissue characterization. ${ }^{13-15}$

In summary, ultrasonic tissue characterization can be defined as:

1. The assessment of certain physical attributes of a volume of tissue by evaluation of the characteristics of ultrasound that is propagated through or is reflected by the tissue.

2. The study of the relation of these attributes to potential disease processes in the tissue.

The field of ultrasonic tissue characterization has been applied to 
abnormalities of eye, ${ }^{16}$ liver $^{17}$ and breast. ${ }^{18}$ Evaluation of myocardial acoustic properties has been more difficult but several recent observations suggest that tissue characterization by ultrasound may soon be of routine clinical use. Before further discussing the specific approaches to ultrasound tissue characterization, a few definitions are in order:

Acoustic velocity $(c)$ is related to the density $(p)$ and compressibility $(B)$ of the tissue through which ultrasound is propagating. The relationship can be expressed as:

$$
c=(p B)^{-1 / 2}
$$

Characteristic acoustic impedance $(Z)$ is defined as the product of density and acoustic velocity:

$$
\mathrm{Z}=\mathrm{pc}
$$

Absorption coefficient $\left(\alpha_{A}\right)$ is an index of the amount of ultrasonic energy lost by conversion to other forms of energy, chiefly heat.

Scattering cross section per unit volume $\left(\alpha_{\mathrm{S}}\right)$ is an index of the ultrasonic energy lost by being redirected (reflected or scattered) away from the direction of the propagating ultrasound beam, due to inhomogeneities in the tissue.

Attenuation coefficient $\left(\alpha_{\mathrm{T}}\right)$ is an index of the total energy loss per unit distance as the ultrasound beam propagates through tissue. The attenuation coefficient is the sum of the absorption coefficient and scattering cross section per unit volume:

$$
\alpha_{T}=\alpha_{A}+\alpha_{S}
$$

Thus, the attenuation of ultrasound by myocardium is due both to absorption and scattering and can be represented as:

$$
A(z)=A_{0} e^{-\alpha z}
$$

where $A(z)$ is the amplitude of a plane wave propagating in the $z$ direction and $\alpha_{\mathrm{T}}$ is the attenuation coefficient (including the effects of both absorption and scattering). Different workers have calculated the attenuation coefficient in various fashions, ${ }^{3,19}$ Similarly, ultrasound backscatter measurements have been derived in various ways. ${ }^{20,21}$ Suffice it to say that the various approaches to ultrasound tissue characterization have largely been developed based on the display or measurement of uitrasound attenuation or scattering in soft tissue such as the myocar- 
dium. It is important to note that acoustic velocity, attenuation and scattering (and indices derived from them) are importantly affected by other variables such as the temperature of the specimen and the angle with which the ultrasound beam meets the muscle fiber. Regarding this last point, since materials such as heart muscle have well-defined and varying fiber directions, the velocity, scattering and attenuation may all be anisotropic (i.e. depend upon the direction of the fibers in relation to that of the ultrasonic beam).

A detailed description of the qualitative and quantitative methods used in cardiac tissue characterization is discussed in Chapter 6. Although a large number of methods have been developed to extract information on tissue structure from transmitted or reflected ultrasound, three broad categories exist:

\section{Visual Methods}

Peculiar regional patterns (texture) of ultrasound reflection have been commonly noted in hypertrophic cardiomyopathy ${ }^{22}$ and amyloidosis. ${ }^{1 "}$

A variety of observations have been made utillizing qualitative or quantitative analysis of image displays. The strength of these methods lies in their relative simplicity and their dependence, in general, upon the use of standard or nearly standard echocardiographic imaging systems. The main disadvantage of display-based methods consists of their dependence on imaging system adjustments such as overall gain, time-gaincompensation, compression curves and post-processing gray scale transfer functions. Thus, since these imaging system adjustments can greatly alter image appearance, it is important to note the settings at the initial examination and use the same setting for serial or follow-up studies in the same individual. It should be noted that the use of color encoding of echocardiographic signals is an approach to visual tissue characterization which seeks to increase human perception of regional differences in echo reflectivity, through the use of different colors for differing echo amplitudes.

A color encoded echocardiogram is one in which variations in echo amplitude are displayed as variations in color intensity and hue, instead of variations in gray. The rationale for using color is based on the ability of the human visual system to distinguish a larger number of colors than of shades of gray.

\section{Measurement of Acoustic Variables}

A vast literature has been compiled on ultrasonic velocity, attenuation and scattering from tissues. ${ }^{23,24}$ Many of these measurements have been 
performed in vitro. However, one must be aware of the influence of temperature and other variables on these acoustic parameters. ${ }^{25}$ Furthermore, attempts to quantify ultrasound interactions with biological tissue are affected by several physical phenomena inherent in the ultrasound imaging process. A good example of these phenomena is the occurrence of phase cancellation or "speckle" in ultrasound imaging. ${ }^{26,27}$ Despite these caveats, it should be acknowledged that a growing number of observations suggest that in vivo measurements of attenuation and especially of backscatter, may be used to characterize various myocardial abnormalities. One example is that of the now well accepted alteration in tissue acoustic properties caused by acute myocardial infarction. The acoustic impedance, ${ }^{28}$ attenuation ${ }^{29}$ and backscatter ${ }^{30}$ of ultrasound by myocardial tissue all change within hours of experimental coronary occlusion in the dog. Thus, measurements of acoustic variables appears to be a very promising method of tissue characterization.

\section{Digital Image/Signal Analysis}

A third fundamentally different approach to the ultrasound characterization of tissue composition consists neither of evalluation of image displays nor of measurement of the "classic" acoustic variables such as attenuation or backscatter. Instead, the rationale of digital signal/image analysis is that sufficient information is available in the "pattern" of ultrasound signals or images to differentiate different tissue types and different pathological condition of a given tissue type. Thus, this empirical approach has been referred to as "tissue signature", since the goal of signal and image analysis is the categorization of tissue abnormalities based on characteristic patterns of ultrasound reflection. A large literature exists using digital signal analysis in the evaluation of diseases of other organs such as eye ${ }^{16}$ and breast. ${ }^{18}$ A more modest experience has been garnered in cardiac tissue characterization using digital image or signal analysis, but initiall results have been promising. Specifically, quantitative analysis of the 2D distribution of echo amplitudes (referred to as tissue texture) has been shown capable of identifying a variety of abnormalities including acute ischemic and nonischemic injury in dogs, ${ }^{30-32}$ chronic cardiomyopathies, ${ }^{33}$ mitral valve prolapse, ${ }^{34,35}$ and infective endocarditis. ${ }^{36}$ Analysis of the overall distribution of echo amplitudes has also proved usefull in identifying the nature of intracardiac masses (thrombi) in humans. ${ }^{22}$ 
Promising data on ultrasonic tissue characterization have been obtained so far. Although much of the previous work on tissue characterization was empirical, recently some interesting and reproducible clinical results have been obtained. It is likely that tissue characterization may soon make a routine contribution to clinical diagnosis in cardiovascular diseases.

This thesis is a compilation of studies concerning the application of ultrasonic tissue characterization both in the experimental and clinical setting. Much data are available today concerning the application of ultrasonic tissue characterization methods in the detection of cardiovascular disease. Limited studies, however, have focussed on color encoded two-dimensional echocardiography and quantification of changes in differentiating between various disease states of the cardiac tissue..$^{32,34-36}$ Color encoding has the advantage over conventional gray-scale imaging because the eye can distinguish considerably more colors than shades of gray. Differentiation of subtle differences of gray-level is not an easy task, even for the experienced echocardiographer. Quantification of mean pixel intensity of color encoded two-dimensional echocardiographic images adds more strength to the applicability of ultrasonic tissue characterization methods in the detection of cardiovascular disease.

\section{References}

1. Edler I, Hertz CH: Use of ultrasonic reflectosicope for continuous recording of movements of heart walls. Kungl Fysiogr Sallad i Lund Forhand"1 1954; $24: 5$.

2. Kotter MN, Mintz GS, Segal BL. et all: Clinical uses of two-dimensional echocardiography. Am J Cardiol 1980; 45:1061-1082.

3. Roelandt J: Practical echocardiography. Research Studies Press, Forest Grove, 1977.

4. Savage RM, Wagner GS, Ideker RE, Podolsky SA, Hacket DB: Correllation of post-mortem anatomic findings with electrockardiographic changes in patients with myocardial infarction: retrospective study of patients with typical anterior and posterior infarcts. Circulation 1977; 55:279-285.

5. Gorlin RM, Klein MD, Sulliwan JM: Prospective correlative study of ventricular aneurysm. Am J Med 1967; 42:512-531

6. Tajik AJ, Seward JB, Hagler DJ, Mair DD, Lie JT: Two-dimensional real-time ultrasonic imaging of the heart and great vessels. Mayo Clin Proc 1978, 53:271-303.

7. Kisslo JA, Robertson D, Gilbert BW, Von Ramm OT, Beckar VA: A comparison of real-time, tho-dimensional echocardiography and cineangiography in detecting left ventricular asymergy. Circulation 1977; 55:134-141

8. Weyman AE, Peskoe SM, Williams ES, Dillon JC, Feigenbaum H: Detection of left ventricular aneurysm by cross-sectional echocardiography. Circulation 1976; $54: 936-944$ 
9. Feigenbaum $\mathrm{H}$ : Echocardiography; 4 th Edition, Philadelphia, 1986.

10. Martin RP, Rakowski H, French J, Popp RL: Idiopathic hypertrophic subaortic stenosis vicwed by wide-angle, phased-array echocardiography. Circulation 1979; 1206-1217.

11. Siquira-Filho AG, Cunha CLP, Tajik AJ, Seward JB, Schattenberg TT, Giuliani ER: M-mode and two-dimensional echocardiographic features in cardiac: amyloidosis. Circulation 1981; 69:188-196.

12. Rasmussen $\mathrm{S}$, Corya $\mathrm{BC}$, Feigenbaum H, Knoebel $\mathrm{SB}$ : Detection of myocardial scar tissue by M-mode echocardiography. Circulation 1978; 57:230-237.

13. Chivers RC: Tissue characterization. Ultrasound Med Biol 1981; 7:1-20.

14. Linzer $M$ (ed): Ultrasonic tissue characterization II: National Bureau of Standards, Spec. Pub1 525. Washington: U.S. Government Printing Office, 1979.

15. Skorton DJ, Collins SM: Characterization of myocardial structure with ultrasound. In: Greenleaf J (ed). Tissue characterization with ultrasound. Boca Raton: CRC Press Inc., 1986; 123-146.

16. Lizxi FL, Coleman DJ: Ultrasonic spectrum analysis in ophthalmology. In: White DW (ed) Recent advances in ultrasound in biomedicine. Oregon: Research studies press; 1977; 117-129.

17. Parker KJ, Waag RC: Measurement of ultrasonic attenuation within regions selected from B-scan images. IEEE Trans Biomed Eng 1983; 30:431-437.

18. Finette $\mathrm{S}$, Bleier $\mathrm{A}$, Swindell $\mathrm{W}$ : Breast tissue classification using ultrasound and pattern recognition techniques 1, II. Ultrasonic Imaging 1983; 5:55-86.

19. Jones JP: Computers in ultrasound. Radiographics $1985 ; 5: 105-119$.

20. Nils-Rune Lundström: Echocardiography in congenital heart disease. Elsevier/ Noord Holland, Biomedical Press, 1978.

21. Chang S, $\mathbb{L}$ Feigenbaum H: Subxiphoid echocardiography. J Clin Ultrasound $1973 ; \mathrm{I}: 14$.

22. Green SE, Joynt LF, Fitzgerald PJ, Rubenson DS, Popp RL: In vivo ultrasonic tissue characterization of human intracardiac masses. Am J Cardiol 1983; $51: 231-236$.

23. Gross SA, Johnston RL, Dunn F: Comprehensive compiliation of empirical ultrasonic properties of mammalian tissues. J Acoust Soc Am 1978; 64:423-457.

24. Chivers RC, Parry RJ: Ultrasonic velocity and attenuation in mammlian tissues. J Acoust Soc Am 1978; 63:940-953.

25. Nasoni $R C$, Bowen $T$, Connor WG, Sholes $R R$ : In vivo temperature dependence of ultrasound speed in tissue and its application to noninvasilve temperature monitoring. Ultrasonic Imaging 1979; 1:34-43.

26. Burckhardt $\mathrm{CB}$ : Speckle in ultrasound B-mode scans. IEEE Transonics Ultrasonics $1978 ; 25: 1-6$.

27. Abbott JG, Thurnstone $\mathrm{F}$ L: Acoustic speckle: Theory and experimental analysis. Ultrasonic Imaging 1979; 1:303-324.

28. Namery $J$ Lele PP: Ultrasonic detection of myocardial infarction in dog. In: Proceedings of IEEE Ultrasonics Symposium 1972; 491-494.

29. Mimbs JW, O'Donnel $M$, Miller JG, Sobel $B E$ : Changes in ultrasonic attenuation indicative of early myocardial ischemic injury. Am J Physiol 1979; $236 \mathrm{H} 340-344$.

30. McPherson DD, Ageward PE, Knosp BM, Eltoft DA, Beam JA, Kieso RA, Kerber RE, Collins SM, Skorton DJ: Ultrasound characterization of acute myocardial ischemia by polar texture analysis. Circulation 1984; (suppl II); 70:396. (abstr.) 
31. Skorton DJ, Collins SM, Nichols I, Pandian NG, Bean JA, Kerber RE: Quantitative texture analysis of 2-dimensional echocardiography: Application to the diagnosis of experimental myocardial contusion. Circulation $1983 ; 68217$. 223.

32. Tak $T$, Gamage $N$, Lin SL, Gerbaudo $V$, Collett $P$, Rahimtoola $S H$, Chandraratna PAN: Echocardiographic textural changes and nuclear magnetic resonance parameters in acute canine myocardial infarction. Circulation 1986; 74(Suppl II); III-270. (abstr)

33. Perez JE, Barzilai B, Madaras EI, Glueck RM, Saffitz JE, Johnston P, Miller JG, Sobel BE: Applicability of ultrasonic tissue characterization for longitudinal assessment and differentiation of calcification and fibrosis in cardiomyopathy. $J$ An Coll Cardiol 1984; 4:88-95.

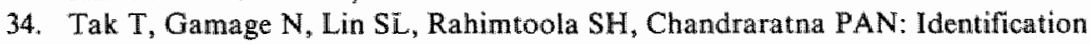
of textural differences in subsets of patients with mitral valve prolapse. Am J Cardiol 1987; 60:917-919.

35. Tak $T$, Chandrasoma $P$, Carlish $R$, Rahimtoola $S$, Chandraratna PAN: Decreased tissue density in mitral valves with severe myxomatous degemeration and increased tissue density in rheumatic mitral valwes: In vitro observations. Am J Noninvasive Cardiol. 1988; $2: 205-208$.

36. Tak T, Rahimtoola SH, Kumar A, Gamage $N$, Chandraratna PAN: Value of digital image processing of 2 -dimensional echocardiograms in differentiating "active" from "chronic" vegetations of infective endocarditis. Circulation 1988; 78: 116-123. 


\section{Chapter 2}

\section{IDENTIFICATION OF TEXTURAL DIFFERENCES OF THE MITRAL LEAFLETS IN SUBSETS OF PATIENTS WITH MITRAL VALVE PROLAPSE}

Tahir Tak, M.D., Nimal Gamage, M.D., Shoa-Lin Lin, M.D., Shahbudin H. Rahimtoola, M.B., F.R.C.P., and P.A.N. Chandraratna, M.D., M.R.C.P.

From the Section of Cardiology, Department of Medicine, Los Angeles County-University of Southern California Medical center, University of Southern California School of Medicine, Los Angeles, California.

\section{SUMMARY}

We previously described a subset of patients with mitral valve prolapse and thickened mitral leaflets (MVP-TL) who had an increased incidence of severe mitral regurgitation. To assess whether textural differences exist between patients with MVP-TL and mitral regurgitation and those with nonthickened leaflets (MVP-NTL), 2-dimensional echocardiography was done on 10 normal subjects, 10 patients with MVP-NTL and 7 patients with MVP-TL and severe mitral regurgitation. The 2-dimensional echocardiographic image was digitized, and the mean pixel intensity of the mitral leaflet (PI-ML) and the posterior wall of the aorta (PI-Ao) was determined. To negate the effects of changes in gain settings, PI-ML was expressed as a ratio of PI-Ao.

The PI-ML in the normal group was $29.0 \pm 4.0$ and the ratio of the mean pixel intensity of mitral leaflet to that of the aortic root was $0.92 \pm 0.03$. In the group MVP-NTL, the PI-ML was $29.5 \pm 2.1$ and the ratio of mean pixel intensity of mitral leaflet to that of the aortic root was $0.86 \pm 0.02$. In the group MVP-TL, the PI-ML was $22.1 \pm 4.8$ and the ratio of mean pixel intensity of mitral leaflet to that of the aortic root 
$0.53 \pm 0.09$. The PI-ML and the ratio of the mean pixel intensity of mitral leaflet to that of the aortic root were both significantly lower in the group MVP-TL when compared to MVP-NTL and the control group.

We conclude that the lower PI-ML in patients with MVP-TL is probably caused by more extensive myxomatous change of the mitral leaflets. Digital imaging enables differentiation of subsets of patients with MVP based on the differences in the mean pixel intensity.

Key Words: Mitral Valve Prolapse, Echocardiography, Digital Image Processing, Mitral Regurgitation.

\section{Introduction}

Mitral valve prolapse (MVP) is a common condition seen frequently in young adults. ${ }^{1}$ Its prevalence is reported to range from 5 to $20 \%$ in the general population. ${ }^{1-3}$ Although most patients with MVP have a benign clinical course, in some patients significant cardiovascular complications develop, such as cerebral embolic events, progressive mitral regurgitation and infective endocarditis. ${ }^{4}$ Some patients with MVP have abnormally thickened mitral leaflets on echocardiography and are reported to have a higher incidence of cardiovascular complications, including severe mitral regurgitation. ${ }^{5}$ The present study was undertaken to ascertain whether textural differences of the mitral leaflets in subsets of patients with MVP can be differentiated by digital image processing of 2-dimensional (2-D) echocardiograms.

\section{Materials and methods}

Between 1983 and 1986, MVP was diagnosed by 2-D echocardiography in 7 patients with clinical evidence of severe mitral regurgitation as defined by a loud holosystolic murmur and a third heart sound. This group consisted of 3 men and 4 women, mean age 65 years (range 40 to 82 years). Two-dimensional echocardiographic examination revealed MVP and thickened mitral leaflets in this subset of patients.

Ten patients ( 3 men, 7 women) mean age 30 years (range 20 to 48 years), had a midsystolic click and late systolic murmur on physical examination. On 2-D echocardiographic examination, MVP and nonthickened mitral leaflets were seen in this group.

A third group consisting of 10 healthy volunteers ( 5 men, 5 women), mean age 57 years (range 49 to 69 years), had normal findings on physical examination and 2-D echocardiography.

Prolapse of the mitral valve was diagnosed by 2-D echocardiograms only during sinus beats and was defined as protrusion of one or both 
mitral leaflets beyond the plane of the mitral annulus into the left atrium during systole. ${ }^{\epsilon}$ One patient with leaflets thickened by MVP underwent angiography and subsequent mitral valve replacement for severe mitral regurgitation.

The leaflets were considered to be thickened when they were more than $5.1 \mathrm{~mm}$ in absolute thickness (by using a pair of calipers) or when the ratio of mitral thickness to posterior aortic wall root thickness was more than 1.4 in the parasternal long-axis view. The latter criterion was used to negate the effects of different gain settings used for different patients. The thickness of the mitral leaflets was measured at its thickest point in diastole (onset of QRS complex), whereas the thickness of the posterior wall of the aortic root was measured near its origin.

Data were analyzed using analysis of variance. $P$ values $<0.05$ were considered significant.

\section{Image acquisition system:}

Selected series of videotaped images were digitized using a Diasonics Cardio Revue Center. The Cardio Revue Center has a JVC model VHS videocassette recorder and a Sony model video motion analyzer. The Cardio Revue Center consists of, among other elements, a Datacube model VG-120 video frame digitizer, a keyboard and a cathode ray tube display. The Dacacube model VG-120 digitizes a full field of analog video data with a resolution of 320 horizontal by 240 vertical picture elements (pixels) by 64 gray levels.

Two-dimensional echocardiograms were standardized because ultrasound machines and videotape recorders vary in regard to video signal level. To negate the effects of these variations, a standard video signal was presented to the image digitizer using a video processing amplifier and an osiclloscope. Each digitized video frame was transmitted through a highspeed serial data link to a second computer for further processing.

Pixel intensity at any given location could be ascertained using a highresolution light pen. The computer had the capability to average pixels at any given area of interest. The number of pixels averaged and mean pixel intensity of the areas studied could be displayed. When pixel averaging, we tried to avoid specular reflections from the leading and trailing edges of the valve. To negate the effects of gain settings, the ratio of the mean pixel intensity of the mitral valwe to that of the posterior wall of the aortic root was determined. Mean pixel intensity of the mitral leaflet was measured from a diastolic frame obtained at the onset of the QRS on the electrocardiogram. 
Table 1: Summary of Findings

\begin{tabular}{|c|c|c|c|c|c|c|c|}
\hline \multirow[b]{2}{*}{ Group } & \multirow[b]{2}{*}{$\begin{array}{c}\text { No. of } \\
\text { Pis }\end{array}$} & \multirow[b]{2}{*}{$\begin{array}{c}\text { Mean } \\
\text { Age } \\
(y r s)\end{array}$} & \multicolumn{3}{|c|}{ Thickness (mm) } & \multicolumn{2}{|c|}{ Mean Pixel Value } \\
\hline & & & ML & $\mathrm{AO}$ & ML/Ao & PI-ML & $\begin{array}{l}\text { PI-ML/ } \\
\text { PI-AO }\end{array}$ \\
\hline Narmal & 10 & $57 \pm 8$ & $\begin{array}{r}3.70 \\
+0.90\end{array}$ & $\begin{array}{r}3.90 \\
\pm 0.30\end{array}$ & $\begin{array}{r}0.95 \\
\pm 0.20\end{array}$ & $\begin{array}{r}29.00 \\
\pm 4.10\end{array}$ & $\begin{array}{r}0.92 \\
\pm 0.30\end{array}$ \\
\hline MVP-NTL & 10 & $32 \pm 6$ & $\begin{array}{r}3.90 \\
+1.30\end{array}$ & $\begin{array}{r}4.00 \\
\pm 1.10\end{array}$ & $\begin{array}{r}0.98 \\
\pm 0.10\end{array}$ & $\begin{array}{r}29.50 \\
+\quad 2.10\end{array}$ & $\begin{array}{r}0.86 \\
\pm 0.20\end{array}$ \\
\hline MVP-TL & 7 & $65 \pm 9$ & $\begin{aligned} & 7.00^{*} \\
\pm & 1.70\end{aligned}$ & $\begin{array}{r}4.00 \\
+0.90\end{array}$ & $\begin{aligned} & 1.80^{\circ} \\
\pm & 0.40\end{aligned}$ & $\begin{array}{c}22.12^{*} \\
\pm 4.80\end{array}$ & $\begin{array}{r}0.53^{*} \\
\pm 0.10\end{array}$ \\
\hline
\end{tabular}

$*$ P $<0.05$ vi MVP-NTL and normal group (by analysis of variance).

Values are mean \pm standard deviation.

$A O=$ aortic root (posterior wall); $M L=$ mitral leaflet; $M L / A O=$ ratio of $M L$ to $A o$; MVP-NTL = mitral valve prolapse and nonthickened MLs; MVP-TL $=$ MVP and thickened MLs; PI-ML = pixel intensity of ML; PI-ML/Pi-Ao = ratio of pixel intensity of ML to Ao.

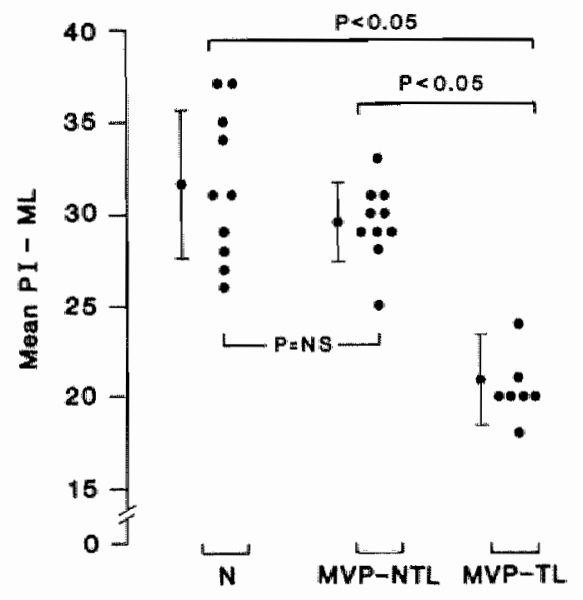

Figure 1. Mean pixel intensity (PI) (t standard deviation) of mitral leaflets in normal persons (N) and 2 subsets of patients with mitral walve prolapse. MVP-TL $=$ MVP and thickened mital leaflets; $:$ IVP-NTL $=$ MVP and nonthickened leaflets; $N S=$ not significant. 


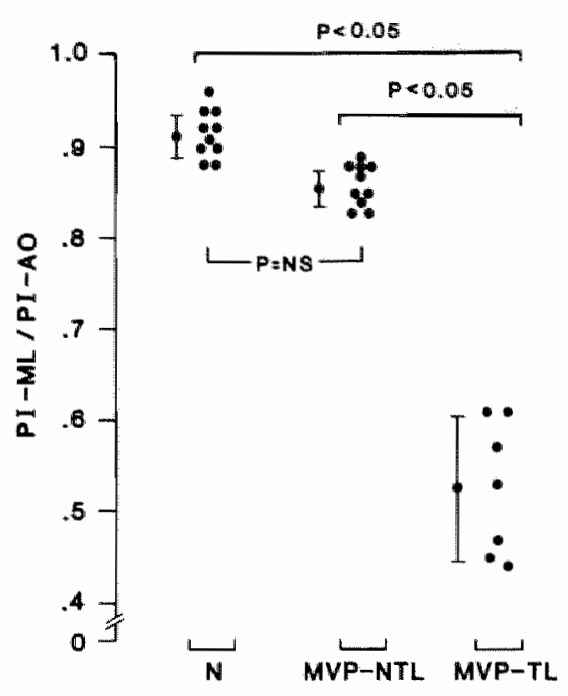

Figure 2. Ratio of pixel intensity (PI) of mitral leaflet and posterior aortic root wall ( \pm standard daviation) in normal subjects $(N)$ and subsets of patients with mitral valve prolapse (MVP). NS = not significant.

\section{Results}

The data are summarized in Table I. Mean pixel intensity of the mitral leaflet in the normal group was 29.0 and the ratio of pixel intensity of the mitral leaflet to that of the aortic root was 0.92 (Fig. 1 and 2). In the group with MVP and nonthickened leaflets, mean pixel intensity of the mitral leaflet was 30.0 and the ratio of pixel intensity of mitral leaflet to that of the aortic root 0.86 . In patients with MVP and thickened leaflets, mean pixel intensity of the mitral leaflet was 22.1 and the mean ratio of pixel intensity of mitral leaflet to that of the aortic root 0.53 .

Statistical analysis revealed a significantly lower pixel intensity of mitral leaflet and the ratio of pixel intensity of mitral leaflet to that of the aortic root in the group with MVP and thickened leaflets as compared tot those with MVP and nonthickened leaflet and normall control subjects ( $\mathrm{p}$ $<0.05$ ). However, no significant differences existed between those with MVP and nonthickened leaflets and normal control subjects (Fig. 1).

\section{Discussion}

Since MVP is a common condition with a benign prognosis in most patients, identification of a subset of patients with an increased incidence 
of cardiovascular abnormalities is important. In a previous study, we showed that patients with MVP and thickened leaflets had a higher incidence of severe $\mathrm{MR}$, tricuspid valve prolapse and aortic root abnormalities. ${ }^{5}$ Subsequent studies by Nishimura ${ }^{4}$ and Barletta ${ }^{7}$ and their coworkers show that patients with MVP and thickened mitral leaflets have a higher incidence of infective endocarditis, sudden death and cerebral thromboembolic events. In this study, we further attempted to characterize the thickened mitral leaflets in patients with MVP in a select group with MVP and severe mitral regurgitation by applying digital image processing techniques.

Our study shows that the mitral valves of patients with MVP and thickened leaflets have lower tissue density and significantly lower mean pixel values than those in normal subjects and those with MVP and nonthickened leaflets. To negate the effects of gain settings, the ratio of the mean pixel intensity of the mitral valve to that of the posterior wall of the aorta was determined. The ratio of pixel intensity of the mitral leaflet to that of the aortic root was also significantly lower in the group of patients with MVP and thickened leaflets.

Thickening of the mitral valve leaflets may occur in a variety of conditions including rheumatic mitral valve disease and MVP. We previously showed that the pixel intensity of rheumatic mitral valves is higher than that of normal mitral leaflets, probably because of increased fibrous tissue and calcification in rheumatic valves. ${ }^{8}$ In contrast to rheumatic valves, the thickened leaflets in patients with MVP and severe mitral regurgitation had a pixel intensity less than that of normal valves. This is probably because of extensive myxomatous degeneration with increased water content resulting in reduced tissue density of these valves. King et $a l^{9}$ observed that the density of valves excised at the time of mitral valve replacement for mitral regurgitation and severe MVP was lower than the density of normal valves. These data also indicate that severe myxomatous degeneration of the mitral valve is associated with decreased tissue density.

\section{REFERENCES}

1. Markiewicz W, Stoner J, London E, Hunt SA, Popp RL. Mitral valve prolapse in 100 presumably healthy females. Circullation 1976;53:464-473.

2. Procacci PM, Savran SV, Schreiter SL, Bryson AL. Prevalence of clinical mitral valve prolapse in 1169 young women. N Engl J Med 1976;294:1086-1088.

3. Davies MJ, Moore PB, Braimbridge MV. The floppy mitral valve. Study of incidence, pathology, and complications in surgical, necropsy, and forensic material. Br Heart J 1978,$40 ; 468-481$.

4. Nishimura RA, Mcgoon MD, Shub C, Miller F, Ilstrup D, Tajik AJ. 
Echocardiographically documented mitrall valve prolapse. Long term follow-up of 237 patients. N Engl J Med 313;21:1305-1309.

5. Chandraratna PAN, Nimalasuriya A, Kawanishi DT, Duncun P, Rosin B, Rahimtoola SH. Identification of increased frequency of cardiovascular abnormalities associated with mitral valve prolapse by 2-dimensional echocardiography. Am J Cardiol 1984;54:1283-1285.

6. Morganroth J, Mardelli J, Naito M, Chin CC. Apical cross-sectional echocardiography: standard for diagnosis of idiopathic mitral valve prolapse syndrome. Chest 1981;79:23-28.

7. Barletta GA, Cogliardi R, Benvenuti L, Fantini F. Cerebral ischemic attacks as a complication of aortic and mitral walve prolapse. Stroke 1985;16:219-223.

8. Chandraratna PAN, Minagoe S, Nimalasuriya A, Rosin B, Rahimtoola SH. Quantitative estimation of textural differences in thickened mitral leaflets of rheumatic mitral stenosis and mitrall valve prolapse by digital image processing (abstr). Circulation 1984;4:70:suppl II:II-405.

9. King BD, Clark MA, Baba N, Kilman JW, Wooley CF. "Myxomatous" mitral valves: collagen dissolution as the primary defect. Circulation 1982;66-288-296. 



\section{Chapter 3}

\section{VALUE OF DIGITAL IMAGE PROCESSING OF TWO-DIMEN- SIONAL ECHOCARDIOGRAMS IN DIFFERENTIATING ACTIVE FROM CHRONIC VEGETATIONS OF INFECTIVE ENDOCARDITIS}

Tahir Tak, M.D., Shahbudin H. Rahimtoola, M.B., F.R.C.P., Anil Kumar, M.D., Nimal Gamage, M.D., and P.A.N. Chandraratna, M.D., M.R.C.P.

From the Section of Cardiology, Department of Medicine, Los Angeles County-University of Southern California Medical Center, University of Southern California School of Medicine, Los Angeles, California.

\section{SUMMARY}

The ability of a computer-based image digitizing system to differentiate "active" from "chronic" valvular vegetation was evaluated. Twenty-two patients with newly diagnosed infective endocarditis were studied prospectively by serial two-dimensional echocardiograms. Two comparable images (active and chronic) from the same patient taken several weeks apart (range 4-17 weeks) after initiation of therapy were obtained at end diastole with identical gain settings. The images were digitized, magnified, and displayed on a high-resolution color monitor. The mean pixel intensity of the valvular vegetation in the active stage was $20.6 \pm 3.6$ (mean $\pm S D$ ), which increased to $34.4 \pm 4.3$ in the chronic stage $(\mathrm{p}<0.01)$. Because there was some overlap of values, an additional standardization procedure was used in the last eight patients. In these eight patients, the mean pixel intensity of the vegetations in the active stage was $17.5 \pm 1.1$, and it increased at 4 weeks to $25.0 \pm 1.2(\mathrm{p}<0.05)$ and further increased in the chronic stage to $33.6 \pm 3.1(p<0.05)$. There was no overlap of values between the active and chronic stages. Three clinical states are of 
particular interest: 1) The mean pixel intensity of the vegetation remained unchanged ( 23 vs. 24 ) in one patient who did not respond to antibiotic therapy 2) The mean pixel intensity of the vegetation fell from 35 to 24 when one patient developed reinfection of the same valve, and with treatment, mean pixel intensity once again increased to 34. 3) The mean pixel intensity of the wegetations in five patients with culture negative

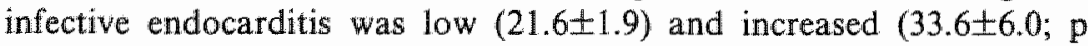
$<0.05$ ) during the chronic stage. The mean vegetation size was $0.73 \pm 0.30$ $\mathrm{cm}^{2}$ in the active stage and decreased to $0.56 \pm 0.24 \mathrm{~cm}^{2}(\mathrm{p}<0.05)$ in the chronic stage; however, in six of 22 patients $(27 \%)$, vegetation size did not decrease with clinical cure. We conclude that digital image processing of two-dimensional echocardiograms can differentiate active from chronic vegetations of infective endocarditis and is a promising new technique that has the potential of being a useful clinical tool in selected patients with infective endocarditis, for example, in those in whom there is a need to distinguish active from cured infective endocarditis.

Keywords: Infective Endocarditis, Two-dimensional echocardiography, Valvular disease, Ultrasonic tissue characterization.

\section{Introdluction}

Infective endocarditis (IE) most often involves the cardiac valves and can be detected by $\mathrm{M}$-mode and two-dimensional echocardiography; the sensitivity of M-mode and two-dimensional echocardiograph for the diagnosis of IE has ranged from $34 \%$ to $80 \%{ }^{1-7}$ In the majority of patients, valvular vegetations (VEG) that are visualized on the initial echocardiography persist after successful antibiotic treatment of $\mathrm{IE}^{7} \mathrm{~A}$ non-invasive method that could distinguish "active" from "chronic" VEG of IE is sometimes highly desirable, for example, when a clinical response to antibiotic therapy is inconclusive and the diagnosis of recurrent endocarditis is uncertain or when blood cultures remain negative.

The purpose of this study was to evaluate the ability of a computerassisted image digitizing system to differentiate active from chronic valvular VEG of IE.

\section{Patients and methods}

\section{Patient Selection}

In this prospective study, 22 patients with a clinical diagnosis of IE (for 
criteria and clinical details see below) with complete and good quality two-dimensional echocardiograms and with well-defined VEG on native valves were included. None of these patients had a previous history of IE. However, one patient from this group subsequently had recurrent endocarditis on the same valve (tricuspid valve) and had a second series of echocardiograms performed during the second admission. For purposes of the study, we have referred to VEG at the time of admission as "active" and those after bacteriological cure as "chronic." Bacteria were cultured from blood in 17 of the 22 patients (Table 1). Staphylococcus aureus was isolated in eight patients, Staphylococcus epidermidis in one patient, Streptococcus viridans in six patients, Streptococcus pneumoni in one patient, and Hemophilus influenza in one patient. Five patients had negative blood cultures. The prodromal symptoms of lethargy and fever before admission ranged from 1 to 3 weeks.

There were 13 men and nine women with a mean age of 35.6 years (range, 21-69 years) The VEG were located on the mitral valve in eight patients, the tricuspid valve in ten patients, and the aortic valve in four patients.

In 17 patients with positive blood cultures, the diagnosis of IE was based on: general malaise, fever, new regurgitant cardiac murmur, three or more abnormal blood chemistries (elevated erythrocyte sedimentation rate, leucocytosis, circulating immune complexes, and anemia), and

Table 1: Clinical Features of Patients With Infective Endocarditis

Clinical feature

Chills:

General malaise

Fever

Splenomegaly

Cardiac murmur

Anemia

Positive blood culture

Elevated ESR

Leucocytosis

CIC
Active

$\begin{array}{rr}18 & 0 \\ 22 & 0 \\ 22 & 0 \\ 6 & 1 \\ 22 & 22 \\ 21 & 1 \\ 17 & 0 \\ 22 & 0 \\ 22 & 0 \\ 8 & 0\end{array}$

Active, valvular wegetations observed at time of clinical admission; Chronic, valvullar vegetations observed after bacteriological cure. ESR, Erythrocyte sedimentation rate. CIC, Circulating immune complexes. 
positive blood cultures. In the five patients with negative blood cultures, the diagnosis of IE was based on general malaise, fever, a new regurgitant murmur, and three or more abnormal blood chemistries (elevated erythrocyte sedimentation rate, leucocytosis, circulating immune complexes, and anemia).

\section{Echocardiographic Examination}

Serial two-dimensional echocardiographic images were performed in each patient. A complete two-dimensional echocardiographic examination consisting of a parasternal long-axis view of the left ventricle, parasternal short-axis and parasternal long-axis view of the right ventricle, apical four-chamber view, and apical two-chamber view, with a 2.25-MHz transducer and an IREX Meridian echocardiographic machine (New Jersey) was performed and recorded on a standard VHS videocassette tape.

Two comparable images (which maximally visualized the valve leaflets) from the same patient, taken several weeks apart with a mean period of 9 weeks (range, 4-17 weeks) after initiation of therapy and from the same echocardiographic window and in the same phase of the cardiac cycle (end diastole), were digitized, magnified, and displayed on a highresolution color monitor. The mean pixel intensity (MPI) of the VEG was obtained by painting the VEG with a light pen. Specular reflections from the leading and trailing edges of the VEG were excluded. The first study, which was considered for analysis (active phase), was performed on the day of admission to the hospital in 12 patients, 1 day after admission in three patients, 2 days after admission in six patients, and 3 days after admission in one patient. The study considered for analysis (chronic phase) was performed after a mean period of 8 weeks (range, 4-17 weeks) after hospitalization and initiation of antibiotic treatment. The crosssectional areas of the VEG were measured digitally on the echocardiographic machine (IREX Meridian) at end diastole (onset of QRS on electrocardiogram) by two independent observers.

\section{Standardization of Two-Dimensional Echocardiograms}

To enable comparison of serial studies, standardization of twodimensional echocardiograms was performed. This was done by recording the time-again compensation settings and other controls on the echocardiographic machine at the time of the first study, by keeping these settings identical in subsequent studies in a particular patient, and by presenting a standard video signal to the image digitizer with a video processing amplifier and an oscilloscope. 


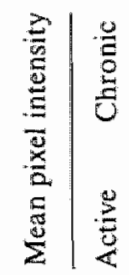

4⿻上丨

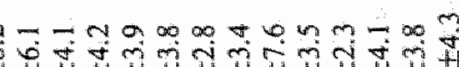
$H+H+H+H+H+H+H+H+H+H+H+H+H$ m

त 0 m $\mathrm{N}+\mathrm{f}$ क त.

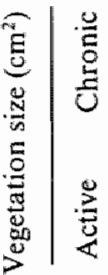

ทำชัต $000000000-00-000000000$ in

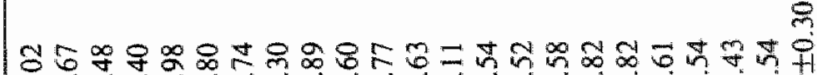

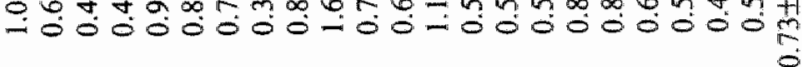

オ

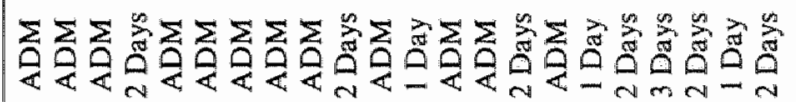

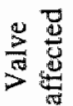

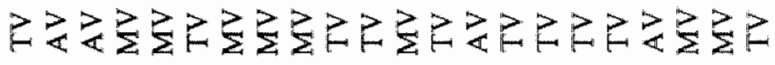

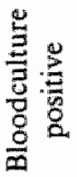

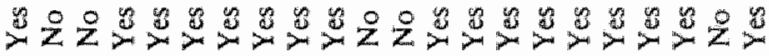

$\stackrel{8}{\infty}$

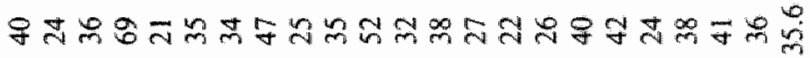


Since MPI values in the first 14 patients did not reliably distinguish between active and chronic vegetations, we devised an additional procedure for standardizing gain settings for the initial echocardiographic study. The procedure consisted of turning the gain settings on the echocardiographic machine down to zero and then gradually increasing the gain until the valve leaflet first became visible. This gain setting was noted, and the echocardiogram was performed. The same gain settings were then used for subsequent studies in the same patient.

\section{Data Analysis System}

Selected series of videotaped images were digitized with a Diasonics Cardio Revue Center (Diasonics Inc., Milpitas California). The Cardio Revue Center has a JVC model BR-6400U VHS videocassette recorder and a Sony model SVM-1010 Video Motion Analyzer. The Cardio Revue Center consists of a magnetic videodisk, a Polaroid camera, and an 8080based microcomputer incorporating a five-megabyte hard disk, a Datacube model VG-120 video frame digitizer and a graphic display controller, dual 5-inch floppy disk drives, a dot-matrix printer, a keyboard, and a cathode ray tube display. The Datacube model VG-120 digitizes a full field of analog video data (RS-170 E1A standard analog signal) with a resolution of 320 horizontal by 240 vertical picture elements (pixels) by 64 gray levels, and it downloads the binary result of on-board random access memory in real time while simultaneously converting the binary data in the random access memory back into analog video data viewable on a monitor. In addition, the microprocessor has read and write access to any single pixel contained in the on-board random access memory. Standardization was accomplished with a video processing amplifier and an oscilloscope.

Each digitized video frame was transmitted through a high-speed serial data link to a second computer for further processing. This computer, a Compupro model (Oakland Airport, California) $816 / \mathrm{B}$, is an 8085/8088based microcomputer incorporating $64 \mathrm{kbytes}$ of random access memory, dual 8-inch 1.2-megabyte floppy disk drives, a Scion Microangelo color graphics subsystem, a red, green, and blue high-resolution video display monitor, and a high-resolution light pen. The digitized video frames were stored on floppy disks after transfer from the Cardio Revue Center and could be retrieved at any time thereafter for redisplay or processing. The Microangelo system stored digitized video images with a resolution of 480 horizontal by 512 vertical pixels.

The pixel intensity of any given location could be ascertained with a high-resolution light pen. The computer had the capability to average 
pixels at any given area of interest such as valvular leaflets or the myocardium. The number of pixels averaged and the MPI (value) of the areas studied could be displayed. When averaging pixels, we tried to avoid specular reflections. Sixty-four colors indicated pixel intensity or pixel value; blue and green color represented low pixel values, while yellow and red color represented high pixel values.

The MPI of the VEG, pixel histograms showing the relative frequency of occurrence of pixels, and pixel maps showing a three-dimensional representation of the pixels in the VEG were obtained in all patients.

The VEG size was measured by digital analysis with an IREX Meridian echocardiographic machine at end diastole (onset of QRS complex) in the same view in which the image was digitized. To determine intraobserver and interobserver repeatability of measurement of VEG area, two independent observers measured VEG size, and one observer measured it on two occasions. To determine intraobserver and interobserver repeatability of measurement of MPI, two independent observers measured MPI, and one observer measured it on two occasions.

A paired Student's $t$ test was used to evaluate significance of results. For repeated measures, analysis of variance was used (Table 3).

\section{Results}

The salient clinical features of the patients during the active and chronic phases are summarized in Table 1. One hundred and five twodimensional echocardipgrams examinations were performed (mean, 4.7 /patient) at intervals ranging from time of admission to hospitalization and initiation of antibiotic therapy and to 17 weeks later. Digital imaging processing was performed on all echocardiograms. An unprocessed echocardiogram (black and white) of a patient with tricuspid valve VEG (patient 10, Table 2) is shown in Figure 1. The color picture, pixel histograms, and pixel maps of the VEG from te same patient are shown in Fïgures 2, 3, and 4, respectively.

The details of the specific valve that was affected, timing of MPI during the active and chronic phases, and the MPI are listed in Table 2. The MPIs of the VEG in the active and chronic stages were $20.6 \pm 3.6$ vs. $34.4 \pm 4.3$ (mean \pm SD), $p<0.01$ (Figure 5). The MPI of the last eight patients who were studied with a special standardization procedure (See "Materials and Methods") showed an increase from time of hospital admission to 4 weeks later $(17.5 \pm 1.1$ vs. $25.0 \pm 1.2, \mathrm{p}<0.05)$ and a further increase to the chronic stage $(25.0 \pm 1.2$ vs. $33.6 \pm 3.1, \mathrm{p}<0.05)$ (Figure 6 , Table 3). There was no overlap of values between the active and chronic stages for those patients with standardized initial gain settings. 

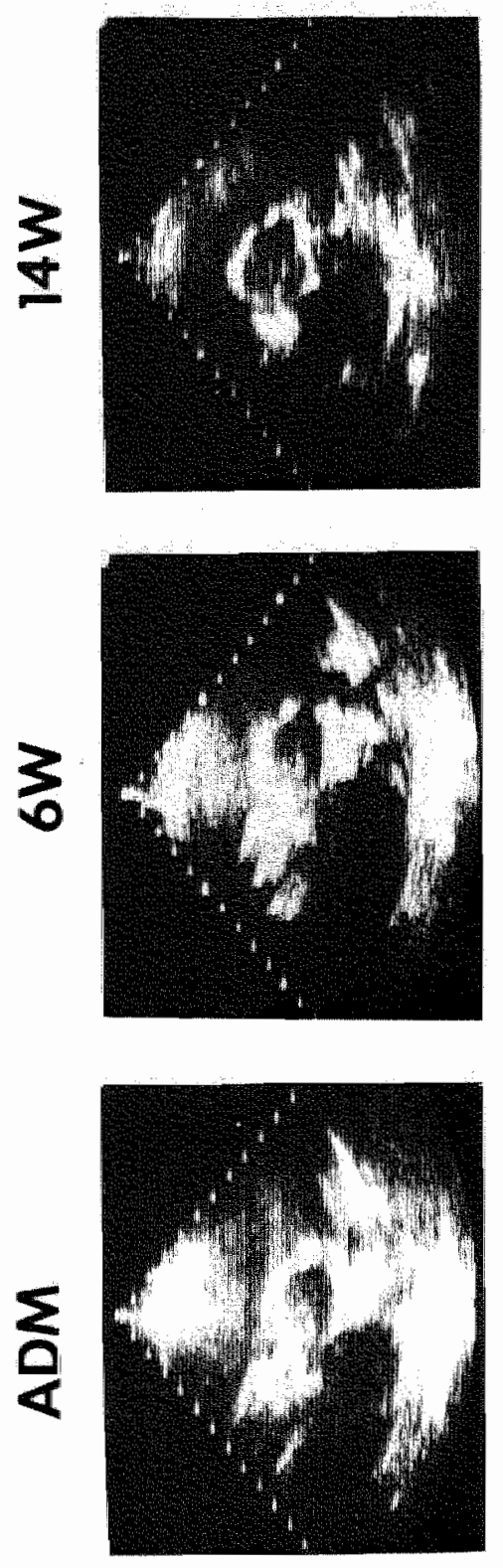

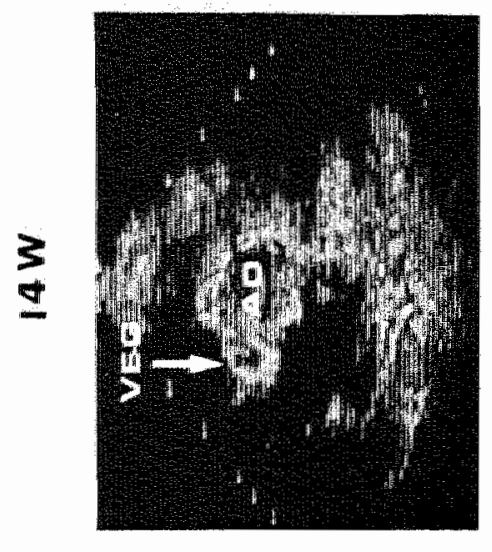

$\frac{0}{11}$

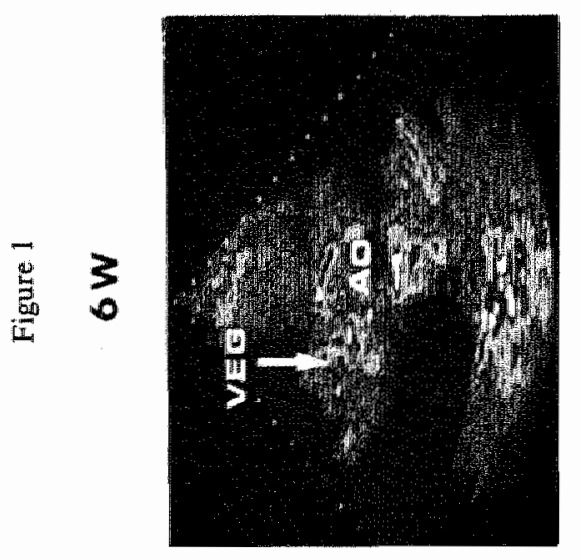

管

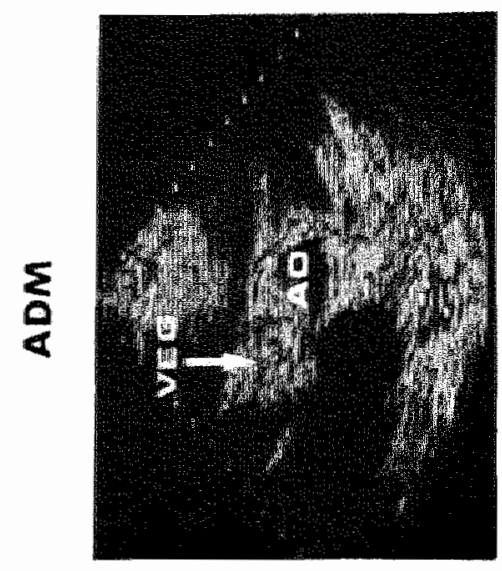

$\frac{0}{\frac{1}{5}}$ 
One patient did not respond to antibiotic therapy for 4 weeeks (patient 12 ) and required surgery. In this patient, the MPI remained consistently low (MPI, 23 vs. 24) throughout the 4 weeks after the initiation of therapy. Another patient (patient 13) had recurrent IE on the tricuspid valve. In this patient, the MPI of the VEG increased from 18 to 35 after treatment of the initial infection. After recurrence of infection, the MPI decreased to 24 , and with cure of the reinfection, the MPI increased once again to 34 (Figure 7). The pixel map after recurrence of infection was characterized by green and yellow (representing low pixel intensity) superimposed on the preexisting red area (Figure 8). In the five patients (patients 2, 3, 11, 12, and 21; Table 2) with culture negative endocarditis,

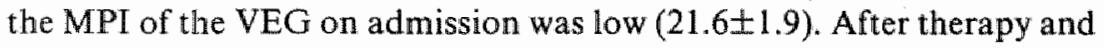
clincal cure, the MPI increased to $33.6 \pm 6.0$ ( $\mathrm{p}<0.05$ ); the pixel maps changed from predominantly blue and green (active stage) to red and yellow (chronic stage).

The mean VEG size was $0.73 \pm 0.30 \mathrm{~cm}^{2}$ in active vs. $0.55 \pm 0.24 \mathrm{~cm}^{2}$ in the chromic stage $(\mathrm{p}<0.05)$. in six patients who were clinically cured of $I E$, the VEG size showed a slight increase in the chronic versus active stage $\left(0.66 \pm 0.3 \mathrm{~cm}^{2}\right.$ vs. $0.69 \pm 0.4 \mathrm{~cm}^{2}, \mathrm{p}=$ NS); however, the MPI showed a significant increase in this period, which was consistent with clinical cure of the IE.

The intraobserver and interobserver repeatability of the measured VEG size revealed correlation coefficeints of $r=0.95$ and $r=0.96$, respectively. The standard error of the estimate (SEE) for interobserver and intraobserver repeatability of measurement of VEG sizes was 0.07 $\mathrm{cm}^{2}$ and $0.05 \mathrm{~cm}^{2}$, respectively.

The correlation coefficient for intraobserver repeatability of MPI in the active stage was $r=0.95(\mathrm{SEE}=1.2, \mathrm{p}<0.05)$; the correlation coefficient for interobserver repeatability was $r=0.89$ (SEE $=1.8, \mathrm{p}<0.05)$. The correlation coefficient for intraobserver repeatability of MPI in the chronic stage was $r=0.92(\mathrm{SEE}=1.9, \mathrm{p}<0.05)$; the correlation coefficient for interobserver repeatability was $r=0.83$ (SEE $=2.7, \mathrm{p}$ $<0.05$ ).

- Figure 1: Unprocessed two-dimensional echocardiographic image (black and white) of a valvular vegetation of patient referred to in Figure 2. Note that differences of gray level are not as apparent as in the color encoded image.

- Figure 2: Example of valvular wegetation (VEG) (in color) on the tricuspid valye (TV) showing the mean pixel intensity (MPI) at admission, at 6 weeks and at 14 weeks. With bacteriological cure, the mean pixel intensity of the VEG gradually increased from 19 to 40 . A black and white image of the vegetation in the same patient is shown in Figure 1. 


\section{Discussion}

The clinical usefulness of two-dimensional echocardiopgram in the diagnosis of IE has already been established. $3,5,8,9$ Vegetations on the aortic and mitral valves were first described echocardiographically by Dillon et al in 1973." Although previous investigators had noted an increase in intensity of VEG after bacteriological cure, no attempt was made to keep the echocardiographic gain settings constant. ${ }^{11,12}$ Since changes in gain settings may produce striking changes in the intensity of VEG and because the above observation were subjective, no firm conclusions could be drawn from these studies. ${ }^{714-17}$ The 22 patients presented in this study constitute a consecutive series of patients with a clinical diagnosis of IE on native valves; they were selected by strict criteria and were followed on prospective basis. All recording variables on the echocardiographic machine were noted at the time of the initial study and were kept identical in follow-up studies.

In the first 14 patients, there was a partial overlap of data points between the active and chronic VEG probably due to the use of excessive gain setting (without standardization) at the time of the first echocardiogram. We therefore instituted a standardization procedure for setting the gain for the first echocardiogram machine down to zero, and then the gain was gradually increased until the valve leaflet first became visible in each patient. This gain setting was noted, and the echocardiogram was performed. The same gain settings were used for subsequent studies in the same patient. Eight patients were studied with this standardization technique. There was no overlap between the MPI in the active and chronic VEG in this group. Because we studied these eight patients weekly, we first observed a statistically significant increase in the MPI of the VEG 4 weeks after beginning therapy (Table 3).

A fresh VEG of IE consists of neutrophils, clumps of bacteria or fungi coated with erythrocytes, fibrin, and platelet thrombi. $13,18,19$ This mass is attached to the degenerated native valve tissue. After therapy and during the process of bacteriological cure, the composition of the VEG changes; that is, polymorphonuclear leukocytes invade the area, and eventually, the infective organism disappears. Thereafter, fibroblasts infiltrate the area, and the VEG undergo fibrosis, collagen deposition, hyalinization, and calcification. The remnant of the VEG is finally covered with a layer of endothelium. These pathological changes probably account for the increase in the pixel intensity that we observed in chronic VEG. 


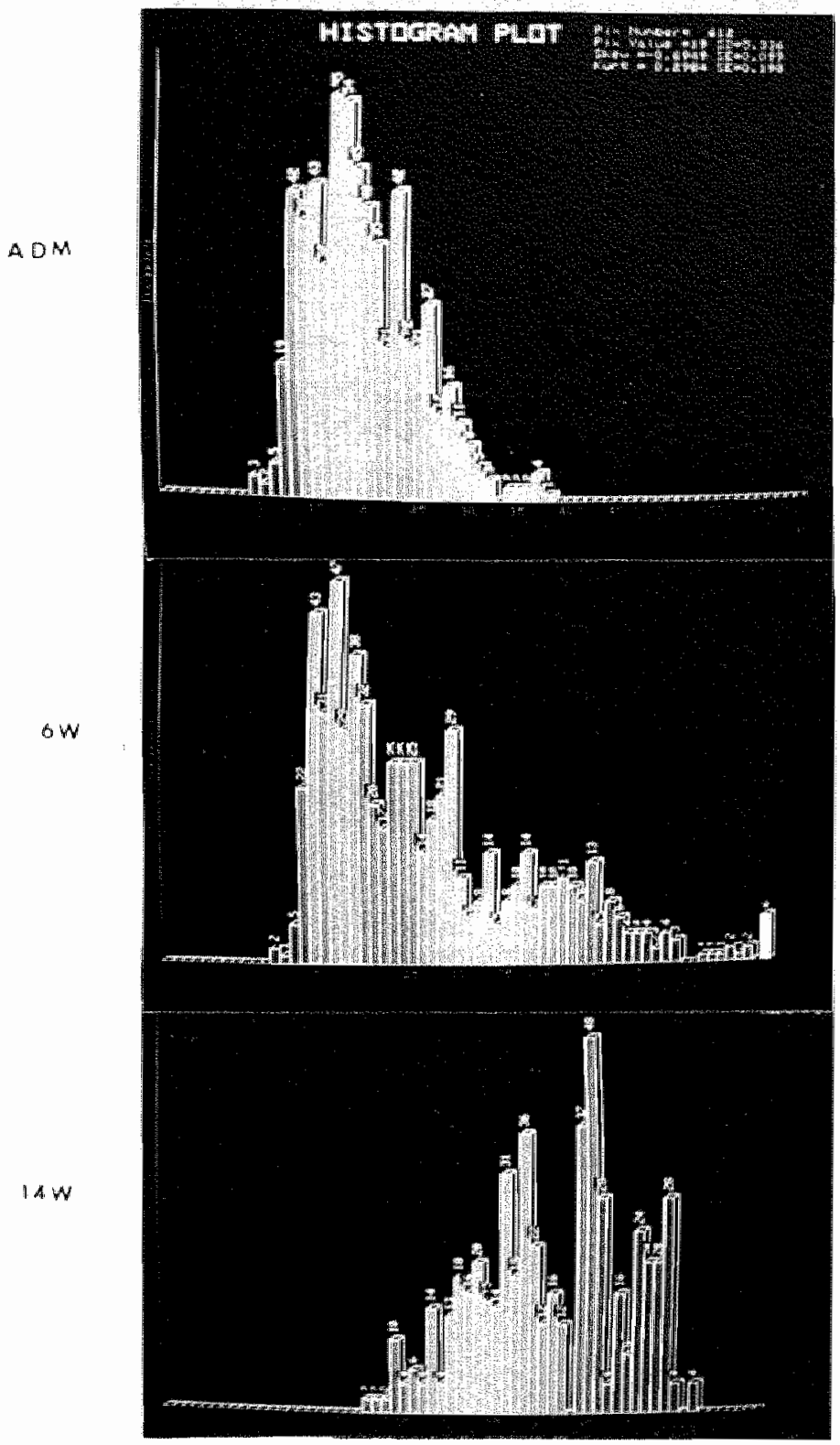

Figure 3: Representative example of pixel histograms obtained in the patient referred to in Figure 1 at the time of admission (ADM), at 6 weeks (6W) and at 14 weeks $(14 \mathrm{~W})$. Note the relative preponderance of blue/green bars (representing low pixel values) on admission and the relative increase in red bars (representing high pixel values) at the end of 14 weeks. 

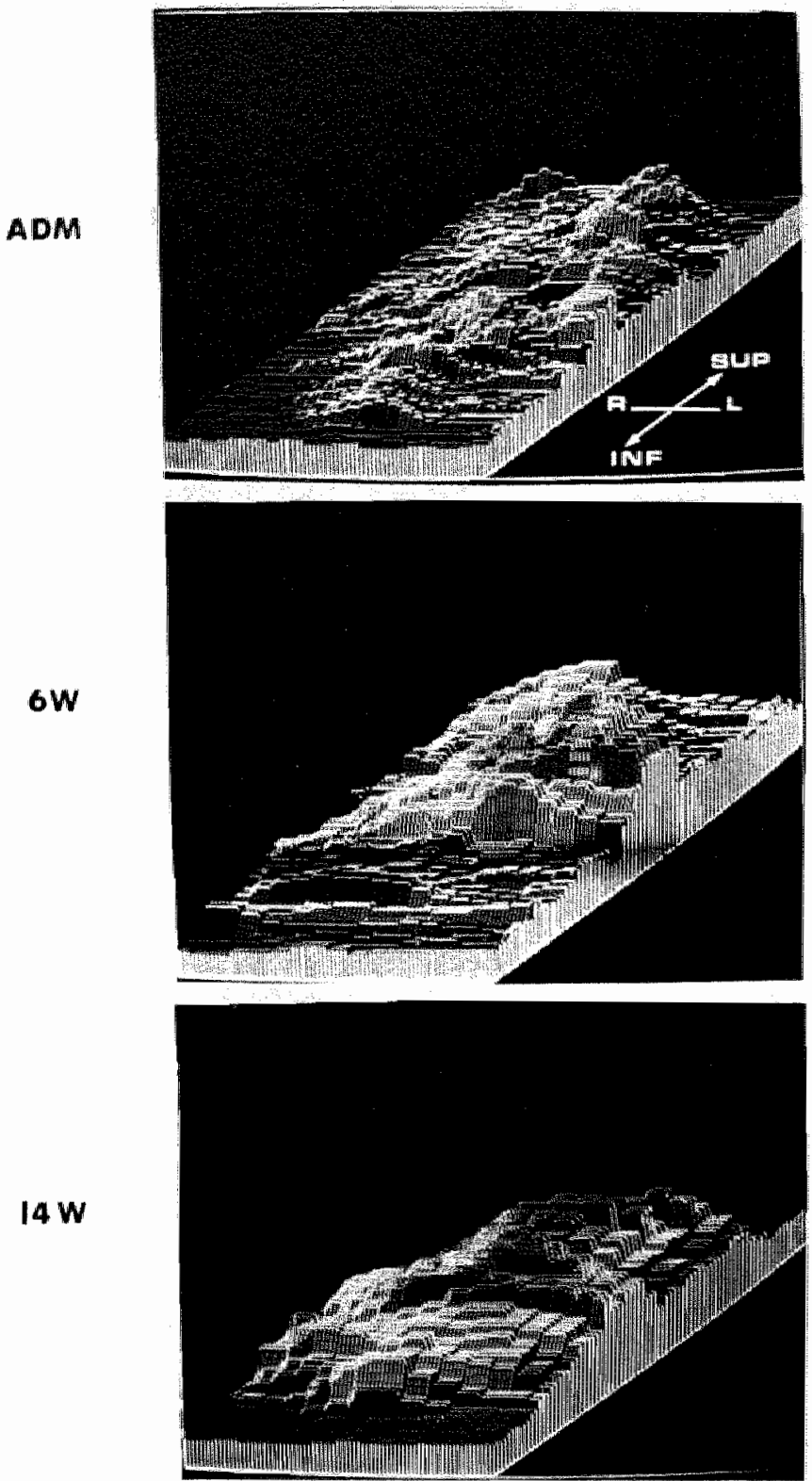

Figure 4: Representative example of pixel maps obtained in the patient referred to in Figure 1 at the time of admission (ADM), at 6 weeks (6W) and at 14 weeks (14W). There is a preponderance of blue/green pixels (representing low pixel values) on admission, and the increase in red pixels (representing high pixel values) at the end of 14 weeks. Note, images at $6 \mathrm{~W}$ and $14 \mathrm{~W}$ were originally magnified $\times 3$. 


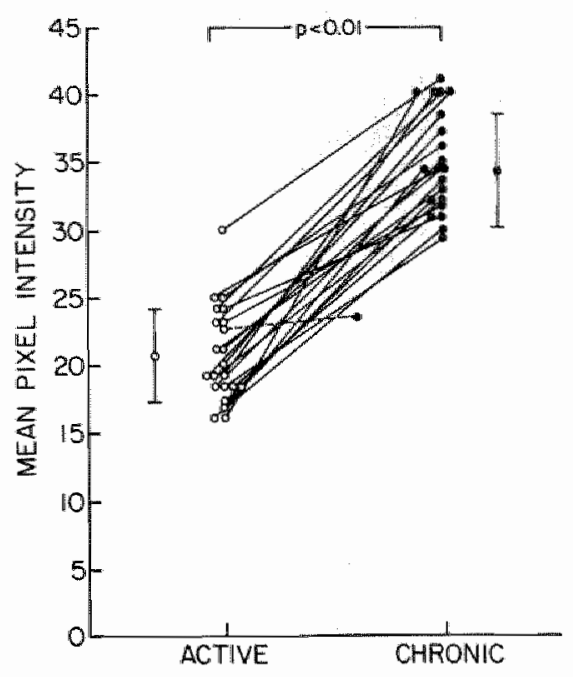

Figure 5: Mean pixel intensity in the "active" and "chronic" stage of VEG in all patients ( $N=22$ ) with infective endocarditis. Mean valueststandard deviation are displayed. The increase was significant at the 0.01 level $0 \ldots-0$, the mean pixel intensity in one patient who did not respond to antibiotic therapy and required surgery.

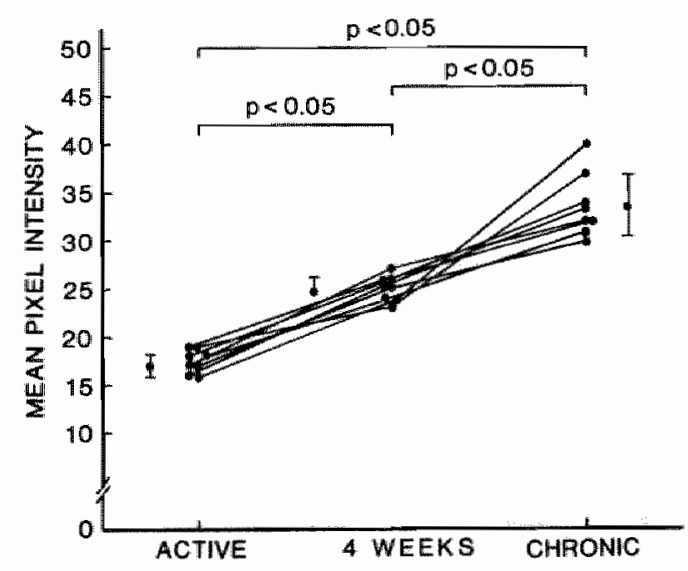

Figure 6: Plot of mean pixel intensity in the "active" and "chronic" stage and at 4 weeks following initiation of antibiotic therapy in 8 patients, who were studied using a new standardization technique. Mean valueststandard deviation are displayed. The increase was significant at the 0.05 lewel. 
Table 3: Data From Standardized Echocardiographic Images

\begin{tabular}{|c|c|c|c|c|c|}
\hline \multirow[b]{2}{*}{ Patient } & \multicolumn{5}{|c|}{ Mean Pixel Intensity } \\
\hline & ADM & 2 Weeks & 3 Weeks & 4 Weeks & Chronic \\
\hline 15 & 18 & 16 & 16 & 25 & 31 \\
\hline 16 & 17 & 16 & 18 & 26 & 30 \\
\hline 17 & 16 & 15 & 16 & 24 & 40 \\
\hline 18 & 18 & 19 & 19 & 24 & 34 \\
\hline 19 & 19 & 18 & $\ldots$ & 26 & 32 \\
\hline 20 & 17 & 16 & 17 & 27 & 32 \\
\hline 21 & 19 & 18 & 17 & 23 & 37 \\
\hline 22 & 16 & 17 & 17 & 25 & 33 \\
\hline MeantSSD & 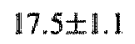 & $16.9 \pm 1.2$ & $17.1 \pm 0.9$ & $25.0 \pm 1.2^{*}$ & $33.6 \pm 3.1+$ \\
\hline
\end{tabular}

Mean pixel intensity in eight patients studied with the standardization technique.

$A D M$, on admission; 2,3 , and 4 weeks after initiation of therapy; Chronic, after 4 weeks of initiation of therapy.

$* \mathrm{P}<0.05 ; 4$ Weeks vs. Admission, 2, and 3 Weeks; and $+\mathrm{P}<0.05$ : Chronic vs. admission, 2,3 , and 4 Weeks by analysis of variance.

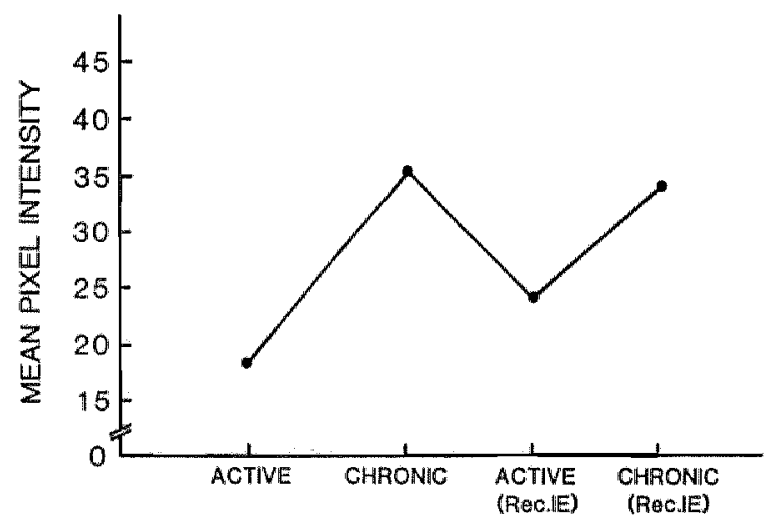

Figure 7: Plot of mean pixel intensity (MPI) in 1 patient with recurrent infective endocarditis (Rec. IE). Note that there is an increase in MPI in the chronic phase of the first episode of endocarditis. In the active phase of Rec. IE there is a striking decrease in MPI, which increases during the chronic phase of Rec. IE. 

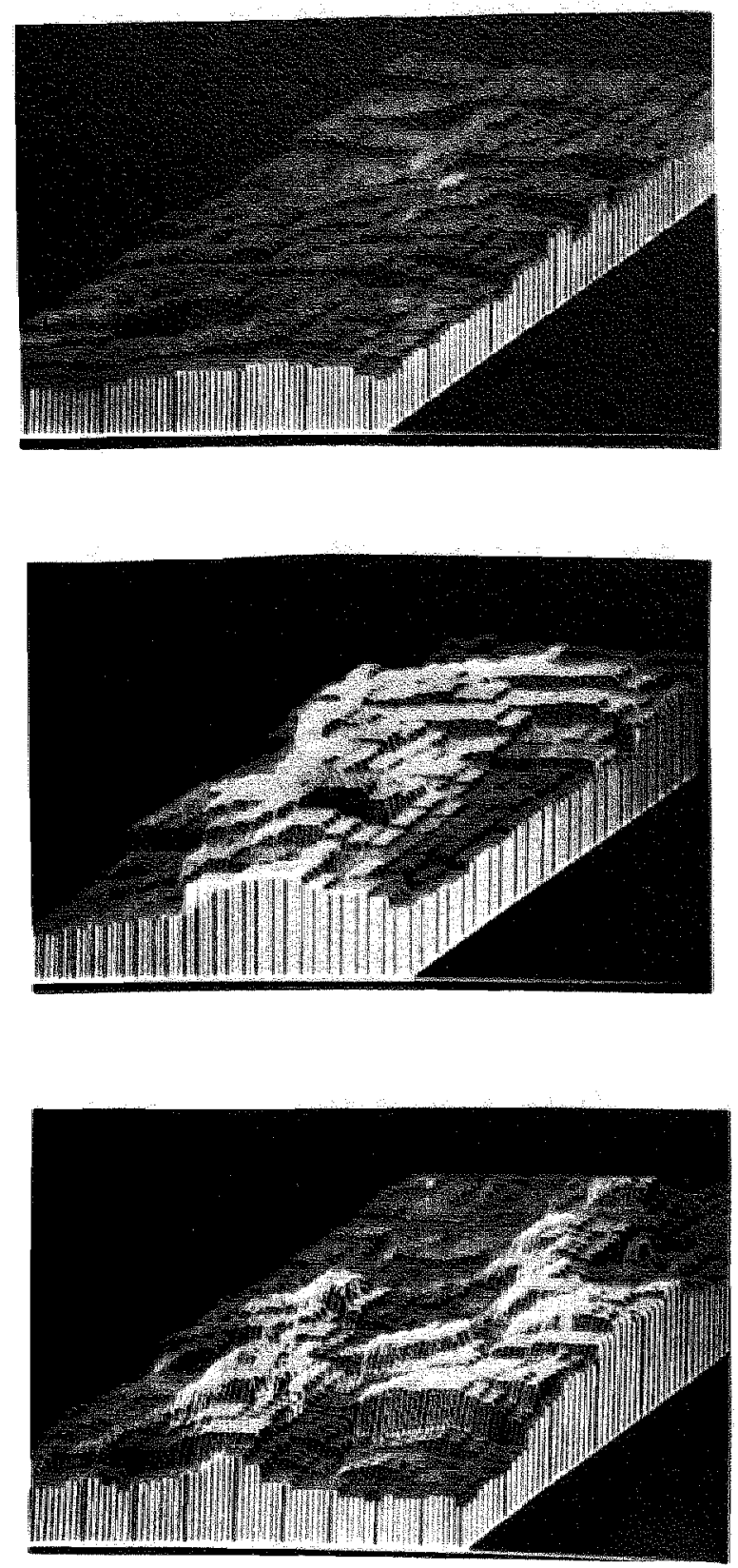

Figure 8: Pixel maps of vegetation in patients with recurrent infection. Panel A: "Active" stage (MPI, 18) Panel B: "Chronic" stage (MPI, 35); Panel C: After recurrence of infection (MPI, 24). Note, images A and B were originally magnified $\times 2$. 
This study indicates that VEG of IE show a gradual increase in the MPI with clinical cure. The sequential acquisition of baseline pixel intensities, pixel maps, and pixel histograms of the VEG may likely be of clinical value. Several patients in this series illustrate the potential clinical value of this line of investigation, 1) One patient did not respond to antibiotic therapy and needed surgical treatment; the MPI remained persistently low. The pixel map showed a preponderance of green (llow pixel intensity) during the entire period of antibiotic therapy. This suggests that failure of MPI to increase is a sign of persistent infection. 2) One patient in our series with recurrent endocarditis showed a reduced MPI in the active stage of recurrent infection compared with the value obtained during the chronic phase of the first infection. This patient showed a pixel map in the chronic stage (i.e., before recurrence) characterized by red and yellow (high pixel intensity); the pixel map of the VEG after recurrence of infection showed a green area (low pixel intensity) superimposed on a preexisting red area, which was suggestive of recurrent endocarditis. These findings suggest that recurrence of active IE changes the MPI and pixel map. 3) In patients with culture-negative IE, the MPI increased with therapy, indicating that the VEG was in active phase initially. Although thee cultures were negative, these patients clinically had active endocarditis. These three clinical examples indicate that measurement of MPI, pixel histograms, and pixel maps have the potential of assessing antibiotic response in patients with IE, of diagnosing active VEG that are superimposed on healed VEG, and of diagnosing active VEG in culture-negative IE.

In this study, we also observed a reduction of the mean VEG size (Table 2) from the active to the chronic stage. However, in six of $22(27 \%)$ patients, the VEG showed a slight increase compared with the active stage. Other investigators have noted either an increase in VEG size, ${ }^{10,11}$ a decrease in VEG size, ${ }^{20}$ or no change in VEG size ${ }^{3}$ after therapy and bacteriological cure. Other reports have shown no apparent correlation between the clinical response and change in VEG size during treatment of IE. ${ }^{14,15,21}$ assessing the efficacy of antibiotic treatment.

In summary, we observed an increase in MPI of valvular VEG after clinical cure of IE. This is probably attributable to an increase in density of the VEG during the chronic phase. A significant increase in MPI first occurred 4 weeks after initiation of therapy. In the three clinical situations of uncontrolled infection, reinfection, and culture-negative $\mathbb{I E}$, pixel averaging and pixel maps provided clinically useful information. The mean VEG size decreased in size with clinical cure in only $73 \%$ of patients. We believe digital image processing of two-dimensional echocardiograms of VEG is a promising new technique that could 
provide additional diagnostic information of clinical value in selected patients with IE.

\section{REFERENCES}

1. Hoche JP, King DL: Sensitivity and specificity of echocardiography in the diagnosis of infective endocarditis, in White D, Lyons EA (eds): Ultrasound in Medicime. Plenum Publishing, New York, 1978, vol 4: p. 9-14.

2. Gura GM, Tajik AJ, Seward JB: Correlation of initial echocardiographic findings with bacterial endocarditis (abstract). Circulation 1978;58:II-232.

3. Wann LS, Hallam CC, Dillon $\mathbb{J C}$, Weyman AE, Feigenbaum $\mathrm{H}$ : Comparison of M-mode and cross-sectional echocardiography in infective endocarditis. Circulation $1979 ; 60: 728-733$.

4. Wann LS, Dillon JC. Weyman AE, Feigenbaum H: Echocardiography in bacterial endocarditis. N Engl J Med 1976;295:135-139.

5. Mintz GS, Kotler MN, Segal BL. Parry WR: Comparison of 2-dimensional and M-mode echocardiography in the evaluation of patients with infective endocarditis: Am J Cardiol 1979:43:738-744.

6. Thomson KR, Nanda NC, Gramiak R: The reliability of echocardiography in the diagnosis of infective endocarditis. Radiology 1977;125:473 476.

7. Gilbert BW, Haney RS, Crawford F, McClellan J, Gallis HA, Johnson ML, Kisslo JA: Two-dimensional echocardiographic assessment of vegetative endocarditis. Circulation 1977;55:346-353.

8. Roy P, Tajik AJ, Giuliani ER, Schattenberg TT, Gau GT, Frye RL: Spectrum of echocardiographic findings in bacterial endocarditis. Circulation 1976;53:474-482.

9. Kisslo J, Von Ramm OT, Haney R, Jones $\mathbb{R}$, Juk SS, Behar VS: Echocardiographic evaluation of tricuspid valve endocarditis: An M-mode and 2 dimensional study. Am J Cardiol 1976:38:502-507.

10. Dillon JC, Feigenbaum H, Konecke LL, Davies RH, Chang S: Echocardiographic manifestations of valvular wegetations. Am Heart J 973;36:698-704.

11. Dillon JC: Echocardiography in valvular vegetations. Am J Med 1977;62:856-862.

12. Andy $J J$, Sheikh $M N$, Ali N, Barnes BO, Fox LM, Curry CL, Roberts WC: Echocardiographic observations in opiate addicts with active infective endocarditis. Am J Cardiol 1977;40:17-23.

13. Stafford A, Wann LS, Dillon JC, Weyman AE, Feigenbaum H: Serial echocardiographic appearance of healing bacterial vegetations. Am J Cardiol 1979:44:754-760.

14. Stewart JA, Silimperi D, Harris P, Wise NK, Fraker TD, Kisslo JA: Echocardiographic documentation of wegetative lesions in infective endocarditis: Clinical implications. Circulation 1980;61:374-380.

15. Berger M, Delfin LA, Jelweh M, Goldberg $\mathrm{E}$ : Two-dimensional echocardiographic findings in right-sided infective endocarditis. Circulation 1980;61:855-861.

16. Martin RP, Meltzer RS, Chia BL, Stinson EB, Rakowski $H_{n}$ Popp RL: Clinical utility of $2 \mathrm{D}$ echocardiography in infective endocarditis. Am $J$ Cardiol $1980 ; 46: 379-385$.

17. Boucher CA, Fallon JT, Myers GS, Hutler AM, Buckley MJ: The value and limitations of echocardiography in recording mitral valve vegetations. Am Heart J $1977 ; 94: 37-43$.

18. Correll HL, Lubitz JM, Lindert MCF; Bacterial endocarditis: Clinicopatho- 
logical studies of untreated, treated and cured patients. Ann Intern Med $1951 ; 35 ; 45 ; 58$

19. Roberts $W C$, Buchbinder NA: Healed left-sided infective endocarditis: A clinicopathological study of 59 patients. Am J Cardiol 1977;40:876-888.

20. Lewin RF", Sidi $Y$, Hermoni $Y$, Zafrir N, Dean $H$, Glazer $Y$, Pinkhas J, Agmon I: Serial two-dimensional echocardiography in infective endocarditis of the pulmonic walve. Isr J Med Sci 1983;19:53-57.

21. Berger M, Gallerstein PE, Benhuri $P$, Bhalla P, Goldberg E: Evaluation of aortic valve endocarditis by 2-dimensional echocardiography. Chest 1981;80:61-67. 


\section{Chapter 4}

\section{ULTRASONIC TISSUE CHARACTERIZATION OF ACUTE CANINE MYOCARDIAL INFARCTION.}

Tahir Tak, M.D., Shoa-Lin Lin, M.D., Nimal Gamage, M.D., Corry Mahler, M.D., Stephen N. Steen, Sc.D, M.D., Patrick Colletti, M.D., Shahbudin H. Rahimtoola, M.B., F.R.C.P., and P.A.N. Chandraratna, M.D., M.R.C.P.

From the Section of Cardiology, Departments of Medicine, Anesthesiology, and Radiology, Los Angeles County-University of Southern California Medical Center, University of Southern California School of Medicine, Los Angeles, California.

\section{SUMMARY}

This study assessed changes in left ventricular (LV) texture on 2dimensional echocardiography (2DE) after experimental myocardial infarction (MI). In 13 dogs, the left anterior descending coronary artery (LAD) was occluded (OC) for 3 hours, followed by 1 hour of reperfusion (REP) and sacrifice. 2DE were performed pre-LAD OC, 3 hours post-OC and 1 hour after REP by placing a $5 \mathrm{MHz}$ transducer on the chest wall. After sacrifice, triphenyl tetrazolium chloride (TTC) staining was performed on $1 \mathrm{~cm}$. thick LV cross-sectional slices. Five dogs served as controls (shams). 2DE were digitized and in the region of LV asynergy (area of ML), and adjacent normal area, the mean pixel intensities $( \pm S D)$ were calculated.

There was no significant change in the mean pixel intensity in the lateral (22.8 \pm 1.3 and $23.4 \pm 1.8)$ and anteroseptal $(23.2 \pm 1.9)$ regions from 0 through 4 hours in sham-operated dogs. In dogs undergoing LAD occlusion, the mean pixel intensity from the pre- to post-occlusion 
period: 1) Showed no significant change in the lateral (normal) area, $24.4 \pm 2.7$ vs $24.7 \pm 2.9 ; 2$ ) In the area of wall motion abnormality (area of myocardial infarction) the mean pixel intensity increased from $24.5 \pm 2.7$ to $33.7 \pm 4.5, p<0.01$. There was no significant change in the mean pixel intensity between the 3-hour post-occlusion and post-REP period in either the lateral (normal) or anteroseptal areas of $\mathrm{LV}$; and 3 ) The area of $\mathrm{LV}$ asynergy corresponded to the area of myocardial infarction on TTC stain.

Our study demonstrates that: 1) $2 \mathrm{DE}$ showed increased mean pixel intensity in the area of MI; reperfusion did not alter these changes; and 2) The area of myocardial infarction on TTC corresponded to the area of LV asynergy seen by $2 \mathrm{DE}$.

Key Words: Echocardiography, Myocardial Infarction, Ultrasonic Tissue Characterization, Triphenyl Tetrazolium Chloride.

\section{Introduction}

Echocardiography has been used extensively for the evaluation of left ventricular function in patients with myocardial infarction. It is now well established that decreased regional wall motion occurs in the presence of ischemia and infarction ${ }^{1-6}$. Other investigators have noted decreased wall thickening and wall thinning in ischemic and infarcted tissue $5,7,8$.

Thus, these echocardiographic findings are not specific for infarction and cannot distinguish ischemic from infarcted tissue which limits to some extent their clinical utility. Digital image processing of $2 \mathrm{D}$ echocardiograms has been shown to differentiate between normal and healed myocardial infarction in patients ${ }^{9}$. The objective of the present study were to assess whether digital image processing of $2 \mathrm{D}$ echocardiograms would detect changes in mean pixel intensity in the setting of an acute myocardial infarction induced in dogs.

\section{Methods}

\section{Animal Preparation:}

Eighteen adult mongrel dogs (10 males, 8 females) weighing between 30-50 kilograms were used in this study. The study protocol was approved by the Animal Ethics Review Board of the University of Southern California School of Medicine, Los Angeles. The dogs were studied in agreement with the regulations stipulated by the Animal Ethics Review Board. They were given morphine sulphate $1 \mathrm{mg} / \mathrm{kg}$ i.m. and 
sodium pentobarbital $30 \mathrm{mg} / \mathrm{kg}$ i.m. one-half hour prior to surgery. An intravenous line was started, ECG leads were placed and the trachea was intubated. Ventilation was controlled with a respirator receiving $100 \%$ inspired oxygen concentration. Supplemental morphine sulphate was given in small, incremental doses by intravenous injection up to a total dose of $5 \mathrm{mg} / \mathrm{kg}$ as needed. Two-dimensional echocardiograms were performed with the dogs lying in the right lateral position and by placing a $5 \mathrm{MHz}$ transducer (focussed in narrow band) directly on the chest wall.

The chest was entered through an incision in the left 5 th intercostal space, the pericardium incised and the beating heart exposed. Five dogs served as controls (sham operated dogs). In 13 dogs undergoing intervention, a bolus injection of lidocaine $1 \mathrm{mg} / \mathrm{kg}$ was given to all dogs prior to clamping the left anterior descending coronary (LAD) artery. The LAD was isolated approximately $1 \mathrm{~cm}$ from the ostium of the left main coronary artery, proximal to the first large diagonal branch. The LAD was occluded with a vascular clamp. Following this, the dogs were maintained on lidocaine $2-4 \mathrm{mg} / \mathrm{kg}$ with a constant drip through a venous catheter. Additional bolus injections of lidocaine $(1 \mathrm{mg} / \mathrm{kg})$ were given in the event an episode of ventricular tachycardia occurred in the anesthetized dog. At the end of 3 hours of LAD Occlusion, the vascular clamp was released and reperfusion permitted for a maximum period of 1 hour.

All dogs were sacrificed at the end of the study by injecting a 5-10 $\mathrm{mg} / \mathrm{kg}$ bolus dose of sodium pentobarbital, while ventilation was concomitantly discontinued. The chest was then opened, and the hearts were removed for additional investigations as described below.

\section{Echocardiographic Data:}

Prior to any manipulation of the LAD, baseline parasternal short axis views at different levels of the left ventricle were obtained in all dogs by placing a $5 \mathrm{MHz}$ transducer directly on the chest wall. The time-gaincompensation settings (TGC) and all other controls on the echom cardiographic machine were kept identical in all studies in all dogs. Images were recorded on standard VHS video tapes.

In addition, two-dimensional echocardiograms (2DE) in the short axis view at various levels of the left ventricle were performed prior to chest incision, pre-LAD occlusion, 3 hours post-LAD occlusion and 1 houm after reperfusion. In sham operated dogs, serial $2 \mathrm{DE}$ was performed at 0 hours and at the end of 4 hours.

The 2DE videotaped images gated in the end-diastolic phase (onset of 
QRS complex) of the cardiac cycle were digitized using a Diasonics Cardio Revue Center (CRC). The CRS has a JVC Model BR-6400U VHS video cassette recorder and a Sony Model SVM-1010 video motion analyzer. The $\mathrm{CRC}$ consists of a magnetic video disk, a Polaroid camera and a 8080 -based microcomputer incorporating a 5-megabyte hard disk, a Datacube Model VG-120 digitizer and graphic display controller, dual 5-inch floppy disk drives, a dot-matrix printer, a keyboard and a cathode ray tube display. The Datacube Model VG- 120 digitizes a full field of analog video data (RS-170 ElA Standard Analog Signal) with a resolution of 320 horizontal by 240 vertical picture elements (pixels) by 64 gray levels and downloads the binary result to on-board random access memory (RAM) in real time, which simultaneously converts the binary data in the RAM back into analog video data viewable on a CRT monitor. In addition, the microprocessor has read/write access to any single pixel contained in the on-board RAM.

We performed standardization of $2 \mathrm{DE}$ because ultrasound machines and video tape recorders vary in regard to video signal level ${ }^{9}$. To negate the effects of these variations on color encoding, a standard video signal is presented to the image digitizer. This is accomplished by using a video processing amplifier and an oscilloscope. Each digitized video frame was then transmitted through a high speed serial data link to a second computer for further processing. The second computer, a Compupro Model $816 / \mathrm{B}$, is an $8085 / 8088$-based microcomputer incorporating 64 kbytes of RAM, dual 8-inch, 1.2-megabyte floppy disk drives, a Scion Microangelo ${ }^{\circledR}$ color graphic subsystem, an RGB high resolution video display monitor and a high resolution light pen. The digitized video frames are stored on floppy disks after transfer from the CRC and can be retrieved at any time thereafter for display or processing. The Microangelo ${ }^{\circledR}$ color system stored digitized color video images with a resolution of 480 Horizontal by 512 Vertical pixels by 64 user-definable collors and simultaneously converts the video data contained in the RAM into analog video signals capable of driving a high resolution color monitor.

Sixty-four selected colors indicate pixel intensity (pixel value) with purple representing a pixel value of 0 , and white representing a pixel value of 63. The pixel intensity at any given location could be ascertained by using a high resolution light pen. Two observers who were blinded to the results of histopathology, assessed and agreed on the area of wall motion abnormality which was subsequently digitized. The entire area of interest, i.e. the area of wall motion abnormality representing the area of infarction and a comparable area of adjacent normally moving 
myocardium (control region), was demarcated and the mean pixel intensity (value) obtained. When recording pixel values, we tried to avoid specular reflections from the leading and trailing edges of the myocardium.

\section{Triphenyl Tetrazolium Chloride Staining}

The slices of dog heart were incubated in a freshly prepared solution of triphenyl tetrazolium chloride (TTC) for 20 minutes at $37^{\circ} \mathrm{C}$ to delineate infarcted tissue. After staining, the slices were fixed in formaldehyde solution and photographs of all specimens were obtained for documentation purposes. Normal tissue was stained brickred, whereas necrotic zones remained unstained.

\section{Results}

\section{Echocardiographic Findings:}

The echocardiographic data are summarized in tables I and II. The number of pixels which were averaged ranged from 800-1500. In sham operated dogs, the mean pixel intensity in the latera $(22.8 \pm 4.0$ vs $23.1 \pm 3.8)$ and anteroseptal ( $23.2 \pm 3.5$ vs $22.6 \pm 3.9)$ regions showed no significant changes from 0 to 4 hours (Table I).

In dogs undergoing LAD occlusion (Table II, Figures 1,2A and 2B) there was a significant $(\mathrm{p}<0.01)$ increase at 3 hours in the mean pixel intensity $(33.7 \pm 4.5)$ in the area of wall motion abnormality (area of infarction) compared to the same area during the pre-occlusion phase $(25.4 \pm 2.7)$. There was a significant difference in the mean pixel intensity at 3 hours post-LAD occlusion, between the anteroseptal and the lateral (control) region $33.7 \pm 4.5$ vs $24.7 \pm 2.9, \mathrm{p}<0.02$ ). The mean pixel intensity in the lateral region (control region) did not change significantly from baseline to 3-hours post-LAD-occlusion. No significant change was observed in the mean pixel intensity between 3-hours post-LAD occlusion and 1-hour post-reperfusion in either the infarcted ( $33.7 \pm 4.5$ vs $33.3 \pm 4.4$ ) or lateral. (control) areas $(24.7 \pm 2.9$ vs $24.3 \pm 2.4)$. 
Table 1: Echocardiogtaphic data in sham dogs

LATERAL REGION

\begin{tabular}{|c|c|c|c|c|}
\hline Dog，梢 & $\begin{array}{l}\text { Mean Pixel } \\
\text { Intensity } \\
0 \mathrm{Hrs}\end{array}$ & $\begin{array}{l}\text { Mean Pixel } \\
\text { Intensity } \\
4 \mathrm{Hrs}\end{array}$ & $\begin{array}{l}\text { Mean Pixel } \\
\text { Intersity } \\
0 \mathrm{Hrg}\end{array}$ & $\begin{array}{l}\text { Mean Pirel } \\
\text { Intensity } \\
\quad 4 \mathrm{Hrs}\end{array}$ \\
\hline 1. & 23 & 24 & 24 & 22 \\
\hline 2. & 21 & 21 & 22 & 22 \\
\hline 3. & 22 & 23 & 21 & 20 \\
\hline 4. & 24 & 23 & 23 & 24 \\
\hline 5. & 24 & 26 & 26 & 25 \\
\hline MeantSD & $22.8 \pm 1.3$ & $23.4 \pm 1.8$ & $23.2 \pm 1.9$ & $22.6 \pm 1.9$ \\
\hline Abbreviations: & \multicolumn{4}{|c|}{$\begin{array}{l}0 \mathrm{Hrs}=\text { baseline values } \\
4 \mathrm{Hrs}=\text { At the end of } 4 \text { howrs } \\
\text { p=NS between } 0 \text { hours and } 4 \text { hours in lateral and anteroseptal } \\
\text { regions }\end{array}$} \\
\hline
\end{tabular}

ANTEROSEPTAL REGION 
Table II: Echocardiographic data pre- and post-LAD occlusion

LATERAL REGION

Mean Pixel Intensity
ANTEROSEPTAL REGION

Dog \# (Pre-Occl) (Post-Ocel) (Post-Rep) (Pre-Ocd) (Post-Occl) (Post-Rep)

\begin{tabular}{rllllll}
\hline 1. & 22 & 24 & 23 & 25 & 31 & 28 \\
2. & 24 & 24 & 24 & 23 & 28 & 33 \\
3. & 24 & 22 & 21 & 25 & 32 & 31 \\
4. & 26 & 29 & 26 & 29 & 38 & 39 \\
5. & 27 & 26 & 28 & 25 & 33 & 34 \\
6. & 31 & 31 & 23 & 30 & 45 & 44 \\
7. & 22 & 21 & 21 & 24 & 29 & 31 \\
8. & 20 & 21 & 27 & 28 & 34 & 34 \\
9. & 23. & $24^{*}$ & $\dagger$ & 23 & $29 *$ & + \\
10. & 25 & 24 & 26 & 26 & 37 & 29 \\
11. & 25 & 26 & 27 & 24 & 33 & 32 \\
12. & 22 & 24 & 22 & 25 & 34 & 31 \\
13. & 24 & 25 & 24 & 23 & 35 & 34 \\
\hline
\end{tabular}

\begin{tabular}{llllll}
\hline Mean \pm SD 24 2.7 & $24.7 \pm 2.9$ & $24.3 \pm 2.4$ & $25.4 \pm 2.7$ & $33.7 \pm 4.5$ & $33.3 \pm 4.4$
\end{tabular}

Abbreviations: Pre-Occl = pre-occlusion of the left anterior descending artery (LAD): Post-Occl $=3$ hour post-LAD occlusion; Post-Rep $=1$ hour postreperfusion, $\dagger=$ this dog died approximately 2 hrs after LAD occlusion; * $=$ post-Occl. values obtained after \pm 2 hrs of LAD occlusion.

Post-Ocel and post-Rep values in the lateral region were compared to pre-Occl values $(\mathrm{p}=\mathrm{NS}$ ). There was no significant difference between post-Occl and post-Rep values.

Post-Occl and post-Rep values in the anteraseptal region were compared to pre-Occl walues $(p<0.01)$. There was no significant difference between post-Occl and post-Rep values. 

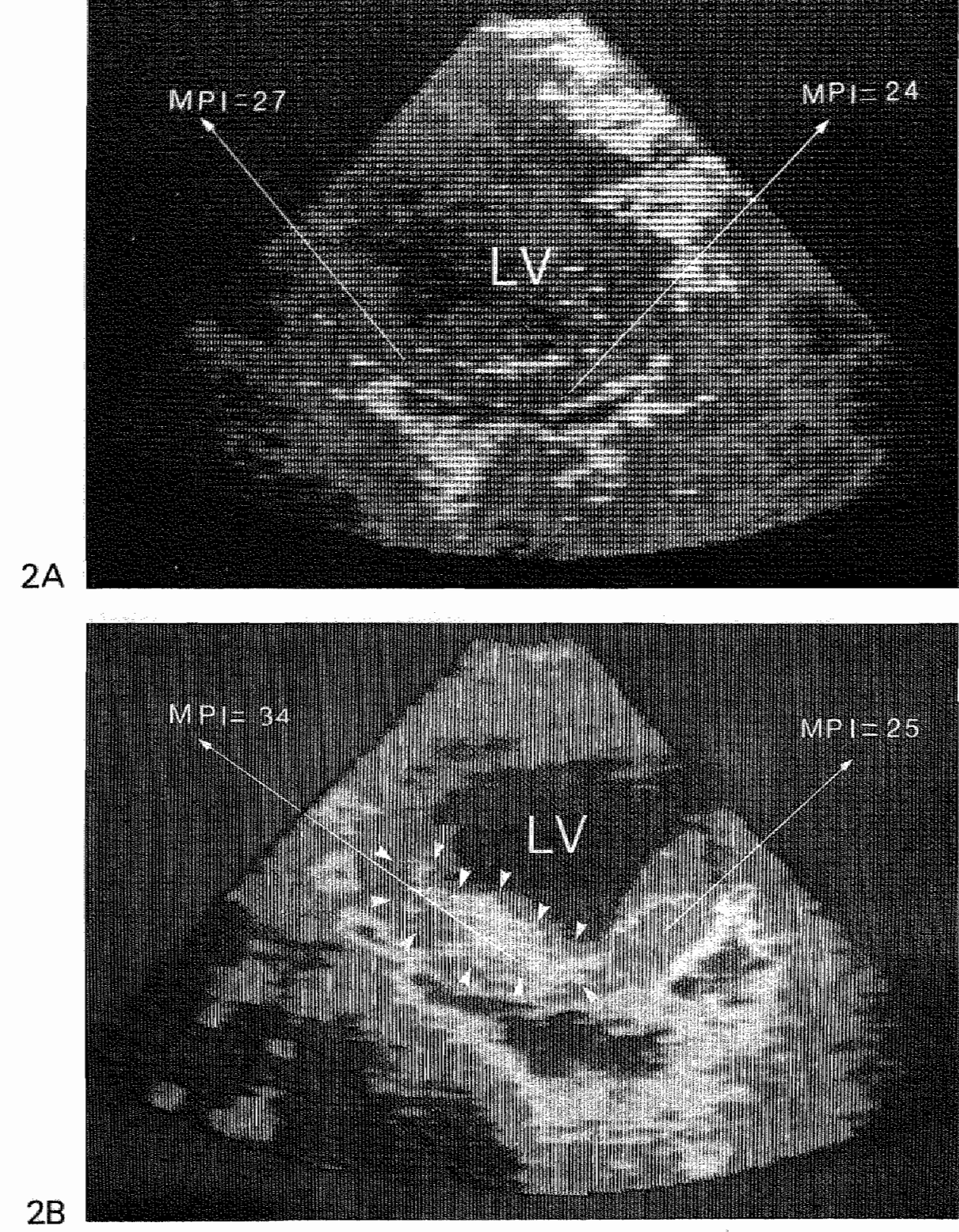

Figure 2: A representative example of $2 \mathrm{D}$ echocardiograms abtained in a dog prior to $\angle A D$ occulusion and post-LAD occlusion. Note that the mean pixel intensity prior to $\mathrm{LAD}$ occlusion (2A) in the anteroseptal area is 27 , whereas after LAD occlusion (2B) this has increased to 34 . 


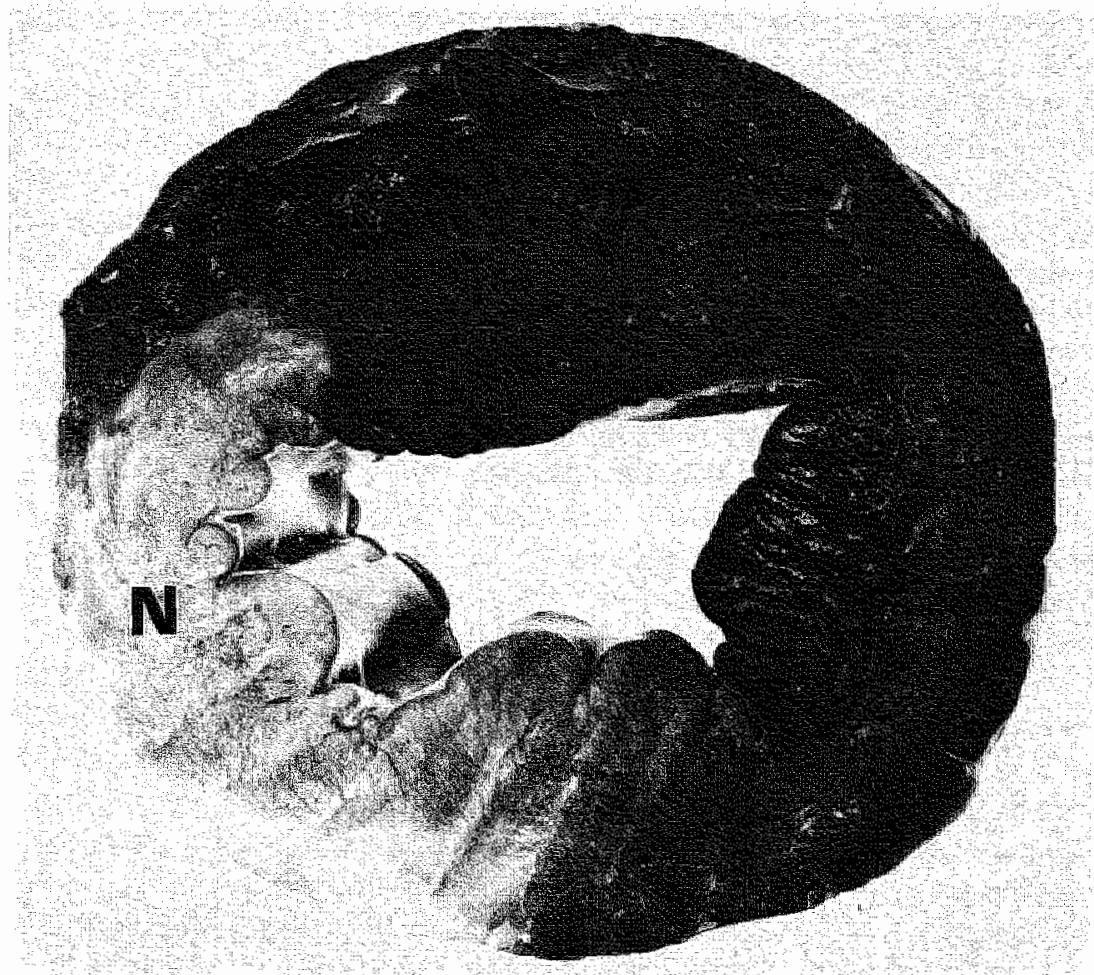

Figure 3: Cross-sectional slice of dog heart after immersion "n TTC stain. Note that the necrotic area (devoid of stain) corresponds to the a rea of LV asynergy. $N=$ Necrotic Area

\section{Triphenyl Tetrozolium Chloride Staining:}

This revealed lack of staining in the anteroseptal region of the left ventricle (area of infarction). The non-infarcted regions showed a brickred color (Fig. 3) whereas the infarcted zone was devoid of stain.

\section{Statistical Analysis:}

The mean pixel intensity of the region of left ventricular asynergy (area of myocardial infarction) and adjacent normal area were compared and a Student"s paired t-test (corrected for multiple comparisons by the Bonferroni correction) applied to evaluate significance of results. Probability-values of $<0.05$ were considered significant. 


\section{Discussion}

Experimental studies have used different indices of ultrasonic tissue characterization for diagnosing myocardial infarction. These studies thave focussed on attenuation ${ }^{10,11}$ backscatter ${ }^{12-14}$, amplitude variation of radiofrequency signal and frequency shift ${ }^{15}$, and color encoding of analog $2 \mathrm{DE}$ images ${ }^{16}$. Recent studies in patients have shown increased myocardial echo intensities or brightness in areas of chronic infarcts 9 and in several other myocardial diseases ${ }^{17}$.

Although interesting results have been obtained, both attenuation and backscatter have certain limitations. For measuring or estimating attenuation, one has to make use of transmission methods, i.e. interposing the tissue specimens between separate transmitting and receiving crystals (transducers), which is not practical in the clinical setting. Recently, techniques have been proposed for measuring attenuation from the reflected signal ${ }^{18}$, but these techniques have not as yet been applied to the study of acute myocardial infarction. To measure backscatter, the raw radiofrequency signal has to be acquired and digitized using a special data acquisition system. Skorton et $\mathrm{al}^{14}$ and Haendschen et al ${ }^{19}$ studied acute myocardial infarction in closed chest dog experiments. The former group noticed changes in gray-level distribution in areas of necrosis in dogs with 2-day old infarcts; the latter group did not notice changes in gray-level distribution in the 3 hours post-LAD occlusion period but only after reperfusion of the ischemic areas.

The detection of acute myocardial infarction within a few hours after its onset by placing the transducer directly on the chest wall and utilizing video data for analysis of results has been previously described ${ }^{20-22}$. Fraker et al used a visual analog and noted an increase in apparent brightness of myocardium quite early after acute canine myocardial infarction ${ }^{21}$. However, the measurement of mean pixel intensity and quantification of altered signal intenstity to our knowledge, thas not been previously described. In the present study, an approach using color encoding of $2 \mathrm{DE}$ to differentiate acutely infarcted myocardium from adjacent normal areas was evaluated. Since the human eye can distinguish only a limited number of gray levels, subtle variations in shades of gray may be missed. In contrast, the human eye can distinguish many more variations of the color spectrum. The use of color encoding, thus, offers a partial solution to this problem. Furthermore, equipment used in our laboratory has the ability to perform objective analysis of regional abnormalities of cardiac tissue by determining the mean pixel 
intensities (values) in any given area of digitized $2 \mathrm{DE}$ image.

In our experiments, ultrasound studies were performed prior to coronary artery occlusion, at 3 hours post-LAD occlusion and 1 hour after reperfusion. The area of wall motion abnormality on the 2DE image was assumed to be the area of infarction and the calculated mean pixel intensity of this area showed a significant increase with respect to preLAD occlusion values and values obtained from adjacent normally moving myocardium. These results are in contrast to results obtained by Haendschen et a ${ }^{19}$ who did a similar study on dogs and observed no change in mean pixel intensity at 3 hours of post-LAD occlusion, but a significant increase in mean pixel intensity was noted after reperfusion. A possible explanation for the disparity in results could be the difference in the equipment used for data acquisition.

We also utilized triphenyltetrazolium chloride (TTC) staining to confirm the location of the area of myocardial infarction which showed increased mean pixel intensity on the digitized 2DE images. TTC staining has been used extensively in vitro in delineating normal myocardium from areas of myocardial infarction. Several studies have shown that this technique is an accurate and economical method for detecting myocardial infarction (in vitro) as early as 3-6 hours after coronary artery occlusion, a time prior to the development of well defined histologic necrosis ${ }^{23,25}$. Tetrazolium dyes form colored precipitate (TTC-red) in the presence of intact dehydrogenase enzyme systems. Areas of necrosis lack dehydrogenase activity and, therefore, fail to stain. Our results showed that areas of left ventricular myocardium which were devoid of stain (abnormal areas) corresponded to the area of increased pixel intensity on the digitized 2DE image.

In summary, our data demonstrate that analysis of digitized and color encoded 2DE performed by placement of the transducer on the chest wall, provide a useful and noninvasive method for detecting acute changes in mean pixel intensity caused by myocardial infarction. Additional studies are needed to see how soon after coronary artery occlusion the textural changes are first seen and to quantitate the volume of the infarcted tissue. Should this technique become applicable to man, the ability to diagnose an acute MI early could be important.

\section{Acknowledgements}

We gratefully acknowledge the technical assistance of Steven Lin, B.S. and Nathan Rubin, M.D.; we also thank Ken Andersen of the Clinical Research Center for his help in the statistical analysis and Ms. Alice Madrid in the preparation of this manuscript. 


\section{References}

1. Stefan $G$, Bing RJ. Echocardiographic findings in experimental myocardial infarction of the posterior left wentricular wall. Am J Cardiol 1972; 30:629-634.

2. Kerber $\mathbb{R E}$, Abboud FM. Echocardiographic detection of regional myocardial infarction. An experimental study. Circulation 1973; 47:997-1005.

3. Corya BC, Rasmussen $\mathrm{S}$, Knoebel SB, Feigenbaum H. Echocardiography in acute myocardial infarction. Am I Cardiol 1975; 36:1-10.

4. Meerbaum S, Wyatt HL, Heng MU, Lang TW, Farcot JC, Corday $E$. Quantification of ischemic dysfunctioning myocardium in dogs. Circulation 1977; 56(Suppl IIII):89. (Abstr)

5. Lieberman AN, Weiss JL, Jugdutt BI, Becker LC, Buckley BH, Garrison JG, Hutchins GM, Kalimann CA, Weisfeldt MC. Two-dimensional echocardiography and infarct size: relationship of regional wall motion and tickening to the extent of myocardial infarction in the dog. Circulation 1981; 63:739-746.

6. Weiss $J L$, Bulkley BH, Hutchins GM, Mason SJ. Two-dimensional echocardiographic recognition of myocardial injury in man: Comparison with post mortem studies. Circullation 1971; 63:401-408.

7. Corya BC, Rasmussen S, Feigenbaum H, Knoebel SB, Black MJ. Systolic thickening and thinming of the septum and posterior wall in patients with coronary artery disease, congestive cardiomyopatiy and atrial septal defect. Circulation $1977 ; 55: 109-114$.

8. Pandian N, Koyanagi S, Eastham C, Skorton D, Marcus $M$, Kerber $\mathbb{R}$. Relationships between two-dimensional echocardiographic wall thickening abnormalities, infarct size and coronary risk area in dogs Circulation 1980; 62(Suppl III):186. (Abstr)

9. Chandraratna PAN, Ulene $R$, Nimalasuriya A, Reid C, Kawanishi D, Rahimtoola SH. Differentiation between acute and healed myocardial infarction by signal averaging and color encoding 2-dimensional echocardiography. Am J Cardiol 1985; 56:381-384.

10. Mimbs JW, Yuhas DE, Miller JG, Weiss AN, Sobel BE. Detection of myocardial infarction in vitro based on altered attemuation of ultrasound. Circ Res 1977; 41:192-198.

11. Mümbs JW, O'Donnel M, Miller JG, Sobel BE. Changes in ultrasonic attenuation indicative of early myocardial ischemic injury. Am J Physiol 1979; 236: $\mathrm{H} 340-\mathrm{H} 344$.

12. Mimbs JW, O'Donnel M, Bowwens, D, Miller JG, Sobel BE. The dependence of ultrasonic attenuation and backscatter on collagen content in dog and rabbit hearts. Cire Res 1980; 47:47-58.

13. Mimbs JW, Batuwens D, Cohen RD, O'Donnel M, Miller JG, Sobel BE. Effects of myocardial ischemia on quantitative ultrasonic backscatter and identification of responsible determinants. Circ Res $1981 ; 49: 89-91$.

14. Skorton DJ, Melton HE, Pandian NE, Nichols J, Koyanogi S, Marcus ML, Collins SM, Kerber RE. Detection of acute myocardial infarction in closed-chest dogs by analysis of regional two-dimensional echocardiographic gray-level distributions. Circ Res 1983; 52:36-44.

15. Schnittger I, Vieli A, Heiserman JE, Director BA, Billingham ME, Ellis SG, Kerhoff RS, Takamoto T, Popp RL. Ultrasonic tissue characterization: detection of acute myocardial ischemia in dogs. Circulation 1985; 72(1):193-199.

16. Parisi AF, Niemenen $M$, O'Boyle JE, Moynihan PF, Khuri SF, Ulsner RA, 
Folland ED, Schoen FJ. Enhanced detection of the evolution of tissue changes after acute myocardial infarction using color-encoded 2-dimensional echocardiography. Circulation 1982; 66:764-70.

17. Bhandari AK, Nanda NC. Myocardial texture characterization by 2-dimensional echocardiography. Am J Cardiol 1983;51:817-825.

18. Kumar A, Jones J, Rosin B, Chandraratna PAN. Measurement of attenuation from backscattered echo wave forms as a means of characterizing myocardial uissue. Circulation 1985; 72:III-427. (Abstr)

19. Haendschen RV, Ong K, Fishbein MC, Zwehl W, Meerbaum S, Corday E, Early differentiation of infarcted and non-infarcted reperfused myocardium in dogs by quantitative analysis of regional myocardial echo amplitudes. Circ Res 1985; $57.718-728$.

20. Chandrasekeran K, Chu A, Greenleaf JF, Bahn RC. Edwards WD, Seward JB, Tajik AJ. 2D echo quantitative texture analysis of acutely ischemic myocardium. Circulation 1985; 74:II-271. (Abstr)

21. Fraker TD Jr., Nelson D, Arthur JA, Wilkerson RD. Altered acoustic reflectance on two-dimensional echocardiography as an early predictor of myocardial infarct size. Am J Cardiol 1984; 53:1699-1702.

22. MoPherson DD, Aylward PE, Knosp BM, Bean JA, Kerber RE, Collins SM, Skorton DJ. Ultrasound characterization of acute myocardial ischemia by quantitative texture analysis. Ultrasonic Imaging 1986; 8:227-240.

23. Fishbein MC, Meerbaum S, Rit J, Lando U, Kanmatsuse K, Mercier JC, Corday E, Ganz W. Early phase acute myocardial infarct size quantification: validation of the triphenyl tetrazolium chloride tissue staining technique. Am Heart J 1981; 101:593-599.

24. Fallon JJ. Simplified method for histochemical demonstration of experimental myocardial infarct. Circulation 1979; 60:II-42.

25. Kloner RA, Darsee JR, DeBoer WV, Carlson N. Early pathologic detection of acute myocardial infarction. Arch Pathol Lab Med 1981; 105:403-406. 


\section{Chapter 5}

\section{EVIDENCE OF DECREASED TISSUE DENSITY IN MITRAL VALVES WTTH SEVERE MYXOMATOUS DEGENERATION AND INCREASED TISSUE DENSITY IN RHEUMATIC MITRAL VALVES: IN VITRO OBSERVATIONS}

Tahir Tak, M.D., P. Chandrasoma, M.D., Ronald Carlish,M.D., Arun Mittal, M.D., Shahbudin H. Rahimtoola, M.B., F.R.C.P., and P.A.N. Chandraratna, M.D., M.R.C.P.

From the Section of Cardiology, Departments of Medicine and Pathology, LAC-USC Medical Center, University of Southern California School of Medicine, Los Angeles, California, St. Vincents Medical Center, Los Angeles, California, and Torrance Memorial Hospital, Torrance, Callifornia.

\section{SUMMARY}

We have previously shown that patients with mitral valve prolapse and thickened mitral leaflets (MVP-TL) have an increased incidence of severe mitral regurgitation (MR). To assess whether digital image processing of $2 \mathrm{D}$ echocardiograms (2DE) can detect differences in tissue density between normal valves, MVP-TL and rheumatic mitral valves (RH-MV), we studied 10 normal mitral valves excised at autopsy, 10 myxomatous mitral valves and 5 surgically excised rheumatic mitral valves (RH-MV). The valwes were examined by $2 \mathrm{DE}$ in a water tank with a $2.25 \mathrm{mHz}$ transducer and all $2 \mathrm{DE}$ recording parameters were kept identical. The $2 \mathrm{DE}$ images were digitized. The thickness of the mitral valves and the mean pixel intensity (MPI) were determined in the three groups of specimens. The maximum thickness of the normal valves was significantly less than MVP-TL $[0.37 \pm 0.05$ vs $0.63 \pm 0.06 \mathrm{~cm}($ mean $\pm \mathrm{SD}), \mathrm{p}<0.05]$ and 
RH $-M V[p .37 \pm 0.05$ us $0.70 \pm 0.04 \mathrm{~cm}, \mathrm{p}<0.05]$. The MPI was significantly

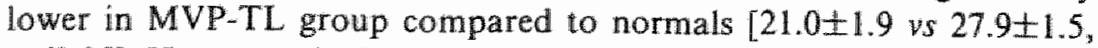
$p<0.05]$. However, the MPI of RH-MV was significantly higher than the normal mitral valves $[42.0 \pm 3.4$ vs $27.9 \pm 1.52, \mathrm{p}<0.05]$ and MVP-TL $[42.0 \pm 3.4$ ws $21.0 \pm 1.9, \mathrm{p}<0.05]$.

The MPI, which reflects tissue density, was significantly lower in MVPTL group probably because of severe myxomatous changes. In the RHMV group, the MPI was significantly higher than controls and MVP-TL. Thus, digital image processing of echocardiograms enables further characterization of the thickened leaflets in MVP and RH-MV and provides a method for distinguishing thickened mitral leaflets due to myxomatous changes from that due to rheumatic mitral valve disease.

Key Words: Echocardiography, Mitral Valve Prolapse, Digital Image Processing.

\section{INTRODUCTION}

Mitral valwe prolapse, which frequently affects young adults, in particular young women and girls, is a common abnormality, and its prevalence ranges between 5-20\%..$^{1-4}$ Significant cardiac arrhythmias, progressive mitral regurgitation, infective endocarditis and neurologic impairment may occur in association with mitral valve prolapse. ${ }^{5}$ However, the incidence of these complications is small, thus, it is important to identify subgroups of patients that are at high-risk for developing complications. ${ }^{6}$

We and others have shown that patients with mitral valve prolapse and thickened mitral leaflets have an increased incidence of cardiovascular abnormalities. ${ }^{5,7}$ However, thickening of mitral valves also occurs in rheumatic mitral valves. Thickening of the mitral leaflets in mitral valve prolapse is due to severe myxomatous degeneration, whereas, in rheumatic mitral valve disease increased mitral valve thickness is the result of fibrosis and calcification of the valve. The present in-vitro study was undertaken to determine whether the thickened leaflets of patients with mitral valve prolapse and rheumatic mitral valve disease have textural characteristics which are different from each other and from those of normal valves.

\section{MATERIALS AND METHODS}

\section{Control Popularion}

Ten patients with a mean age of 47.0 years (range $22-78$ years) who had no history of cardiovascular disease and had a noncardiovascular death 
were selected as controls. The mitral valve was excised at autopsy and histology rewealed a normal mitral valve.

\section{Patient Population}

Ten patients included in this study, had a mean age of 61.7 years, (range 47-78 years) and had clinical and echocardiographic evidence of mitral valve prolapse and severe mitral regurgitation on physical examination and noninvasive testing. The diagnosis was confirmed by cardiac catheterization with angiography and by histological examination of the excised valwes at time of valve replacement for severe mitral regurgitation.

The valves were stained with hematoxylin and eosin, the Verhoff's Van Gieson stain for elastin and collagen and the colloidal iron stain for acid mucopolysaccharides. Patients who had all 3 of the following criteria were considered to have myxomatous degeneration of the mitral valve: (1) Disruption of the zona fibrosa layer; (2) Expansion of the zona spongiosa layer with acid mucopolysaccharides; and (3) $>50 \%$ of the valve involved with acid mucopolysaccharide deposition as shown by the colloidal iron stain.

Five patients with a mean age of 40 years (range $36-55$ years) with rheumatic heart disease (mitral stenosis and mitral regurgitation) who had mitral valve replacement were studied. The diagnosis was confirmed by noninvasive tests, cardiac catheterization with angiography and histologic examination which showed thickening, fibrosis and calcification.

\section{Echocardiographic Data}

The thickness and mean pixel intensity of the mitral valves were studied in the in-vitro situation.

The valves or portions of the valvular leaflets were suspended horizontally (with Catgut) in a water bath at $32^{\circ} \mathrm{C}$. The transducer was allowed to touch the surface of the water and images obtained a depth of $4 \mathrm{~cm}$ and recorded on standard VHS videocassette tapes. An IREX Meridian echo machine and a $2.25 \mathrm{mHz}$ transducer was used to obtain echocardiographic images. The gain settings in the echo machine were kept constant for all the studies. The images were digitized (see data acquisition system) and the mean pixel intensity calculated. Tho maximum thickness of the mitral valve was measured (with calipers) from the echocardiographic image.

Image Acquisition System:

The $2 \mathrm{DE}$ vidiotaped images were digitized using a Diasonics Cardio 
Revue Center (CRC). The CRC has a JVC model BR-6400U VHS videocassette recorder and a Sony model SVM-1010 video motion analyzer. The CRC consists of a magnetic video disk, a Polaroid camera and an 8080-based microcomputer incorporating a 5-megabyte hard disk, a Datacube model VG-120 video frame digitizer and a graphic display controller, dual 5-inch floppy disk drives, a dot-matrix printer, a keyboard and a cathode ray tube display. The Datacube model VG-120 digitizes a full field of analog video data (RS-170 EIA standard analog signal) with a resolution of 320 horizontal by 240 vertical picture elements (pixels) by 64 gray levels and downloads the binary result of on-board random access memory (RAM) in real time, while simultaneously converting the binary data in the RAM back into analog video data viewable on a CRT monitor. In addition, the microprocessor has $\mathrm{read} /$ write access to any single pixel contained in the on-board RAM.

We performed standardization of $2 \mathrm{D}$ echocardiograms because ultrasound machines and video tape recorders vary in regard to video signal level. To negate the effects of these variations, a standard video signal was presented to the image digitizer. It was accomplished using a video processing amplifier and an oscilloscope.

Each digitized video frame was transmitted through a high-speed serial data link to a second computer for further processing. This computer, a Compupro model $816 / \mathrm{B}$, is an $8085 / 8088$-based microcomputer incorporating 64 kbytes of RAM, dual 8-inch 1.2-megabyte floppy disk drives, a Scion Microangelo ${ }^{\circledast}$ color graphics subsystem, an RGB highresolution video display monitor and a high-resolution light pen. The digitized video frames were stored on floppy disks after transfer from $\mathrm{CRC}$ and could be retrieved at any time thereafter for display or processing. The Microangelo system stored digitized video images with a resolution of $480 \mathrm{H}$ by $512 \mathrm{~V}$ pixels.

The pixel intensity at any given location could be ascertained using a high-resolution light pen. The computer had the capability of average pixels at any given area of interest. The number of pixels averaged and the mean pixel walue of the areas studied could be displayed. When pixel averaging, we avoided specular reflections from the leading and trailing edges of the valve. The MPI of the mitral valve was obtained by painting a $2 \mathrm{D}$ image (blow-up) of the mitral valve with the light pen. The entire mitral leaflet was taken into account for measurement of MPI.

Analysis of variance was used to evaluate significance of results. Pvalues of $<0.05$ were considered significant. 
Table II: Summary of findings

\begin{tabular}{lcccc}
\hline $\begin{array}{c}\text { No. of } \\
\text { Pts }\end{array}$ & $\begin{array}{c}\text { Mean Age } \\
\text { (Yrs) }\end{array}$ & $\begin{array}{c}\text { Maximum } \\
\text { Thickness of } \\
\text { MV (cm) } 5 \text { SD* }\end{array}$ & $\begin{array}{c}\text { Mean Pixel } \\
\text { Intensity of } \\
\text { MVtSD }\end{array}$ \\
\hline Normals & 10 & 47.2 & $0.37 \pm 0.05$ & $27.9 \pm 1.5$ \\
MVP-TL & 10 & 61.7 & $0.63 \pm 0.06$ & $21.0 \pm 1.9$ \\
RH-MV & 5 & 40.0 & $0.70 \pm 0.04$ & $42.0 \pm 3.4$ \\
\hline
\end{tabular}

MVP-TL=mitral valve prolapse with thickened mitral leaflets; RH-MV=rlheumatic mitral valves; $M V=$ Mitral Valve; ${ }^{*}=$ mean values; $p t s=$ patients; Yrs=Years

\section{RESULTS}

The data are summarized in Table 1 . The histological appearance of a prolapsing mitral valve is shown in figure 1 . The maximum thickness (mean $\pm \mathrm{SD}$ ) of the excised mitral leaflets of control subjects was

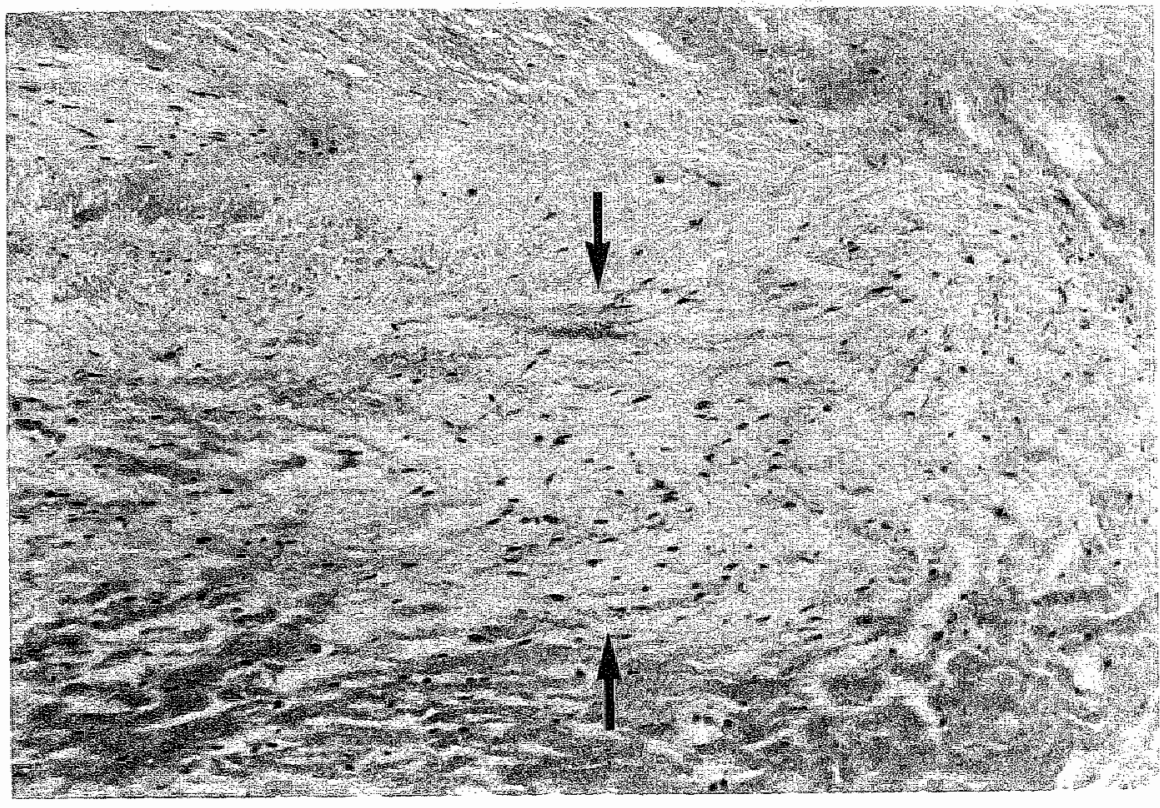

Figure 1: Histological appearance of a prolapsing mitral valve in a 47 year old man. Note the area of myxomatous degeneration between arrows (magnification ×25). 


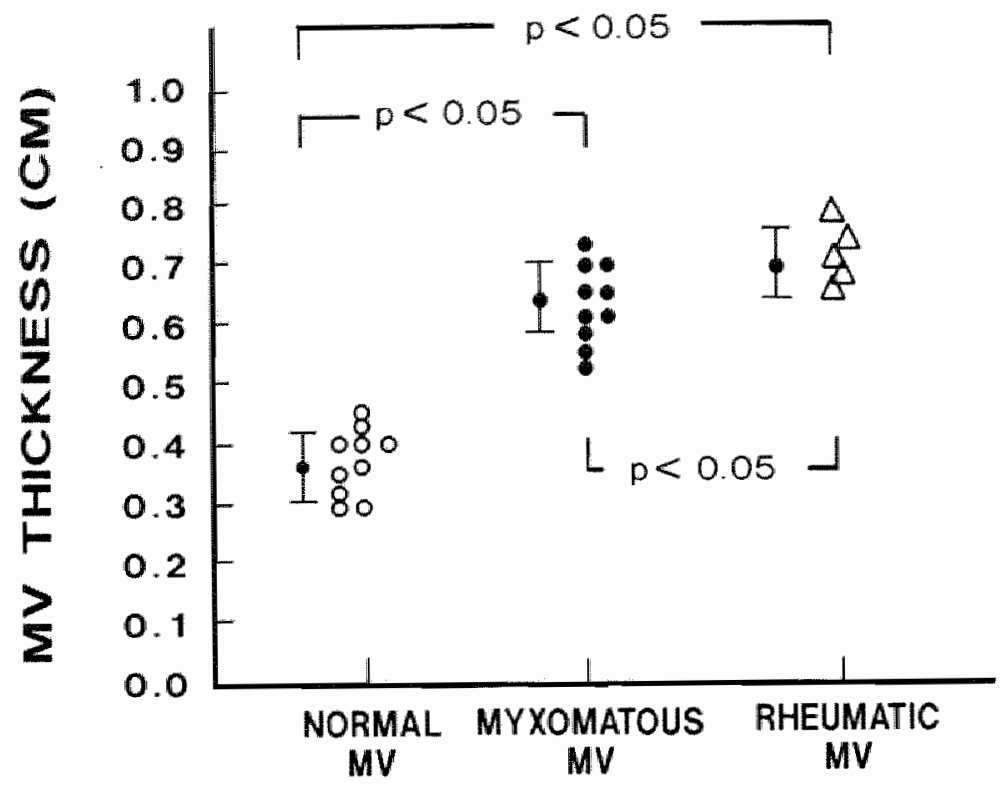

Figure 2: Maximum mitral valve (MV) thickness in $\mathrm{cm}$ in normal, myxomatous and rheumatic mitral valves. The difference was significant $(p<0.05)$.

$0.37 \pm 0.05 \mathrm{~cm}$ (range $0.30-0.45 \mathrm{~cm}$ ). The maximum thickness (mean $\pm \mathrm{SD}$ ) of mitral leaflets in the myxomatous mitral valves was $0.63 \pm 0.08 \mathrm{~cm}$ (range $0.53-0.70 \mathrm{~cm}$ ) and was significantly higher than normals $(\mathrm{p}<0.05)$. The maximum thickness of the rheumatic mitral valves was $0.70 \pm 0.04 \mathrm{~cm}$ (range: $0.65 \sim 0.78 \mathrm{~cm}$ ) and was significantly thicker than normals $(\mathrm{p}<0.05)$ (Figure 2). The mean pixel intensity $\pm \mathrm{SD}$ of the normal valves was $27.9 \pm 1.5$ (range $26.0-31.0 \mathrm{~cm}$ ). The mean pixel intensity in the myxomatous mitral valve group was $21.0 \pm 1.9$ (range $18.0-23.0 \mathrm{~cm}$ ) and was significantly lower than normals $(p<0.05$ ); in the rheumatic mitral valve group, it was $42.0 \pm 3.4$ (range $38.0-47.0 \mathrm{~cm}$ ) and was significantly higher than normals $(p<0.05)$. There was no overlap of values for mean pixel intensity in normal valves, myxomatous valves, and rheumatic mitral valves (Figure 3 ). There was a statistically significant difference $(p<0.05)$ between rheumatic, myxomatous and normals in mean pixel intensity and mitral valve thickness (Figure 3). 


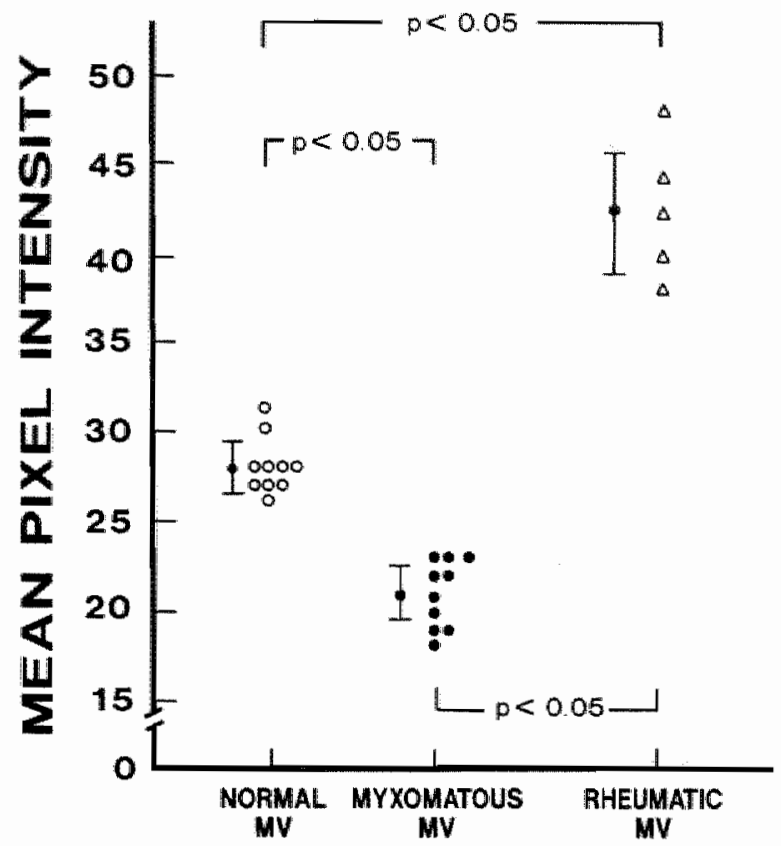

Figure 3: Mean pixel intensity in normal, myxomatous and rheumatic mittal valves (MV). The difference was significant $(\mathrm{p}<0.05)$.

\section{DISCUSSION}

Previous investigators have shown that myxomatous degeneration of the mitral valve is a common cause of mitral valve prolapse. ${ }^{8}$ Although the majority of patients with mitral valve prolapse have a benign prognosis, serious complications may occur in some patients. We have shown that patients with mitral valve prolapse and thickened mitral leaflets have a high incidence of cardiovascular complications when compared to patients who have mitral valve prolapse and normal leaflet thickness. ${ }^{7,9}$ Nishimura and his colleagues noted that patients with mitral valve prolapse and thickened mitral leaflets have a much higher incidence of progressive mitral regurgitation, sudden death, cerebral embolic events and infective endocarditis as compared to patients with mitral walve prolapse and normal mitral leaflet thickness. ${ }^{5}$ Barletta and his coworkers observed that patients with multiple valve prolapse or diffuse valvular thickening have an increased incidence of neurological complications. ${ }^{10}$ Thus, patients with mitral valve prolapse and thickened mitral leaflets, 
are more likely to have serious complications.

We have previously reported that the mitral valves (studied in-vivo) of patients with mitral vair o prolapse and severe mitral regurgitation had textural abnormalities and lower mean pixel intensity in addition to thickening of the valve leaflets. "Since values for mean pixel intensity in-wiwo are influenced by a variety of factors, such as gain settings, the present in-vitro study was undertaken. This in-vitro study confirms that myxomatous mitral valves have a significantly lower mean pixel intensity than normal mitral valves. These data are consonant with findings of King and associates who noted that the density of myxomatous valves was less than that of normal valves. ${ }^{8}$ Extensive myxomatous degeneration of the mitral valve is the probable cause of the decreased tissue density that we noted. The mean pixel intensity of the rheumatic mitral valves was significantly higher $(\mathrm{p}<0.05)$ than normal mitral valves and myxomatous mitral valves. This is probably attributable to the extensive fibrosis and calcification present in these valves.

In summary, patients with mitral valve prolapse and severe mitral regurgitation had mitral leaflet thickness which was greater than that of normal valves. The thickened mitral valves with MVP showed a mean pixel intensity which was less than that of normal valves. The reduction in mean pixel intensity of the valves in patients with mitral valve prolapse is probably attributable to reduced tissue density resulting from extensive myxomatous degeneration of the valve. The thickened rheumatic mitral valves in contrast to normals and prolapsing mitral valves, showed increased mean pixel intensity, which is probably due to extensive fibrosis and calcification of these valves.

\section{REFERENCES}

1. Procacci PM, Savran SV, Schreiter SL, et al: Clinical frequency and implications of mitral valve prolapse in the female population. Circulation $1975 ; 5 \|$ and 52;Suppl 2:11-78 (abstr).

2. Markiewicz W, Stoner J, London E, et al: Mitral valve prolapse in 100 presumably healthy young femalles. Circulation 1976;53(3):464-473.

3. Savage DD, Garrison RJ, Devereux RB, et al: Mitral valve prolapse in the general population I. Epidemiological features: The Framingham Study. Am Heart J 1983; $106: 571-576$.

4. Procacci PM, Savran SV, Schreiter SL, et al: Prevalence of clinical mitral valve prolapse in 1169 young women. N Engl J Med 1976; 294:1086m8.

5. Nishimura RA, McGoon MD, Shub C, et al: Echocardiographically documented mitral valwe prolapse: Long-term follow-up of 237 patients. N Engl J Med 1985; 313:1305-9.

6. Tresch DD, Doyle TP, Broncheck LI, et al: Mitral valve prolapse requiring surgery: Clinicul and pathologic study. Am J Med 1985; 78:245-250. 


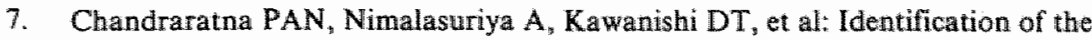
increased frequency of cardiovascular abnormallities associated with mitral valve prolapse by 2-dimensional echocardiography. Am J Cardiol 1984; 54;1283-1285.

8. King $\mathrm{BD}$, Clark MA, Baba $\mathrm{N}$, et al: Myxomatous mitral valves: Collagen dissolution as the primary defect. Circulation 1982; 66(2):288-296.

9. Tak $T$, Gamage $N$, Lin $S L$, et al: Identification of textural differences of the mitral leaflets in subsets of patients with mitral valve prolapse. An $\mathrm{J}$ Cardiol $1987 ; 60: 917-919$.

10. Barletta GA, Gagliardi $R$, Benwenuti $L$, et al: Cerebral ischemic attacks as a complication of aortic and mitral valve prolapse. Stroke 1985;16:219-223. 



\section{Chapter 6}

\section{ULTRASONIC TISSUE CHARACTERIZATION METHODS IN THE DIAGNOSIS OF CORONARY ARTERY DISEASE}

Tahir Tak, M.D., Joie P. Jones Ph.D., Shahbudin H. Rahimtoola, M.B., F.R.C.P., and Premindra A.N. Chandraratna, M.D., M.R.C.P.

From the Section of Cardiology, Department of Medicine, Los Angeles Count-University of Southern California, Medical Center University of Southern California School of Medicine, Los Angeles, Callifornia.

During the last decade, echocardiography has become increasingly popular and is currently one of the most widely used tools in cardiovascular diagnosis. ${ }^{1-3}$ Ultrasound examination of the heart is a fairly simple process and, in comparison to other imaging techniques, the instrumentation is relatively inexpensive. With the development of new and far more expensive imaging techniques, such as computerized tomography and nuclear magnetic resonance, the comparison of costbenefit ratios has become even more obvious.

The first in vivo ultrasound measurement for the purposes of tissue differentiation and characterization was made by Wild and Reid in $1952 .{ }^{4}$ They observed distinct quantifiable differences between $\mathrm{A}$ mode waveforms of normal breast tissue and malignant and benign breast lesions. Subsequent widespread use of these and other techniques now associated with ultrasonic tissue characterization was delayed for over 25 years. Even today, our knowledge of the propagation of ultrasound in tisue and the development of ultrasound technology, which serves as the basis for ultrasonic tissue characterization, is still a major rescarch topic.

This chapter reviews the role of cardiac tissue characterization in the evaluation of coronary artery discase. To accomplish this task, the feasibility of ultrasonic tissue characterization is discussed, present techniques undergoing evaluation are reviewed, and future developments are assessed.

Published in: C. Visser, Kan, G. and Meltzer, R. (eds.) Echocardiography in Coronary Artery Disease 1988: 235-354. Kluwer Academic Publishers. Boston/Dordrecht/ Lancaster. Reproduced by permission. 


\section{Acoustic properties of tissue}

Major factors that describe the prapagation of ultrasound in tissue include the density, the elasticity, and the velocity of sound in tissue, the specific acoustical impedance (ratio of pressure to particle velocity at the point of interest), the absorption of sound by tissue, and the scattering of sound by tissue structure inhomogeneites. ${ }^{2,5,6}$ Absorption refers to energy loss as a result of a transformation to other energy forms. Various relaxation, viscous, and thermal mechanisms are responsible for absorption in tissue.

Absorption in tissues is primarily related to the protein content, although there is a component of absorption that is apparently related to other constituents. ${ }^{7}$ In general, it appears that acoustic absorption in tissue can be described by a relaxation process, which is defined by the molecular properties of the material. ${ }^{7-10}$

Since live human tissue is generally at a constant normal body temperature of $37^{\circ} \mathrm{C}$, there is little need in present diagnostic regimens to consider effects of temperature on the acoustic properties of tissue. This is not to imply that such temperature effects should be ignored, since interesting possibilities utilizing temperature changes have been suggested for experimental studies with the aim of possible future medical applications. ${ }^{11,12}$

\section{Attenuation}

When an ultrasonic pulse propagates in tissue, some of the energy is lost via absorption or the transformation to other energy forms, and some of the energy is scattered and/or redirected along alternative paths. Attenuation refers to energy loss in the propagation of sound as a result of both scattering and absorption. From in vitro and in vivo studies spanning over 60 years, it is clear that attenuation is an important parameter for the description of the propagation of ultrasound in tissuc. ${ }^{13-16}$ Significant and medically useful correlations have already been demonstrated between attenuation and pathology, and it seems likely that the in vivo measurement of attenuation will play a major role in any ultrasonic tissue characterization scheme. ${ }^{11,14}$ The attenuation of sound in tissue is a frequency-dependent process. Thus, as the ultrasound pulse propagates, less energy is available to penetrate deep into the body. The penetration of ultrasound decreases as the frequency increases, ${ }^{17}$ and attenuation increases almost linearly with increasing frequency. A term used to express the amount of absorption and attenuation of ultrasound in tissue is the half-value layer or half-power distance. ${ }^{18}$ These terms refer to the distance that ultrasound will travel in a particullar tissue before its 


\section{7}

Table 1: Acoustic properties of several common materials: these represent averaged values from the literature which were measured in vitro by transmission methods

\begin{tabular}{|c|c|c|c|c|}
\hline Material & $\begin{array}{l}\text { Propagation } \\
\text { velocity } \\
\left(\mathrm{m} \mathrm{s}^{-1}\right.\end{array}$ & $\begin{array}{l}\text { Characteristic } \\
\text { impedance } \\
\left(10^{5} \mathrm{kgm}^{-2} \mathrm{~s}^{-1}\right)\end{array}$ & 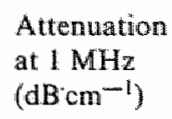 & $\begin{array}{l}\text { Frequency } \\
\text { dependence } \\
\text { of attenuation }\end{array}$ \\
\hline Water $\left(20^{\circ} \mathrm{C}\right)$ & 1480 & 1.48 & 0.0022 & $\mathbb{1}^{2}$ \\
\hline Aluminum (bulk) & 6300 & 17.0 & 0.018 & r \\
\hline Air (at standard & 343 & 0.000415 & 12 & $f^{2}$ \\
\hline Blood & 1570 & 1.61 & 0.18 & $f^{2}$ \\
\hline Brain & 1541 & 1.58 & 0.85 & $\sim f$ \\
\hline Fat & 1450 & 1.38 & 0.63 & $\sim 1$ \\
\hline $\begin{array}{l}\text { Human soft tissue } \\
\text { (mean value) }\end{array}$ & 1540 & 1.63 & 0.81 & $\sim f$ \\
\hline Muscle & 1585 & 1.70 & $1.3-3.3$ & $\sim f$ \\
\hline Skull bone & 4080 & 7.80 & 13 & $\mathrm{f}^{2}$ \\
\hline Lung & 650 & 0.26 & 41 & $1 / \mathrm{f}$ \\
\hline
\end{tabular}

Reproduced by permission from Jones and Leeman [1].

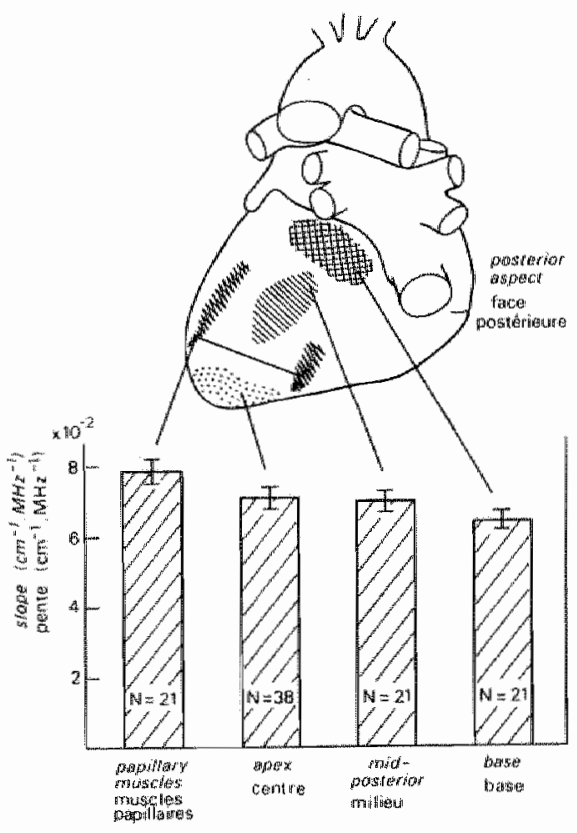

Figure 1: Regional variation of the slope of the attenuation (between 2 and $10 \mathrm{MHz}$ ) in normal dog myocardium. $\mathrm{N}$, number of samples. Reproduced by permission from O'Donnel et al. [35] 
energy is attenuated to half its original value. Table 1 shows the characteristic acoustic properties of several common materials. Atttenuation at $1 \mathrm{MHz}$ is lowest in water, relatively higher in blood and brain tissue, and highest in the lung.

Different investigators have used various methods of measuring or estimating attenuation. $13,14,19-22$ Such measurements are important to cardiac tissue characterization because changes in frequency dependence of attenuation in dog myocardium are correlated with regional creatine kinase (CK) depletion associated with myocardial infarction. ${ }^{23,24}$ The measurement of CK depletion is a standard biochemical marker of the infarction process.

Figures 1 and 2 show the slope of the ultrasonic attenuation for normal and for normal versus ischemic dog myocardial tissues determined at specified intervals following coronary occulusion. Although significant differences are noted between normal and ischemic tissues, the behavior of the attenuation slope suggests a complex biological process and a complex relationship between the tissue state and tissue acoustic properties.

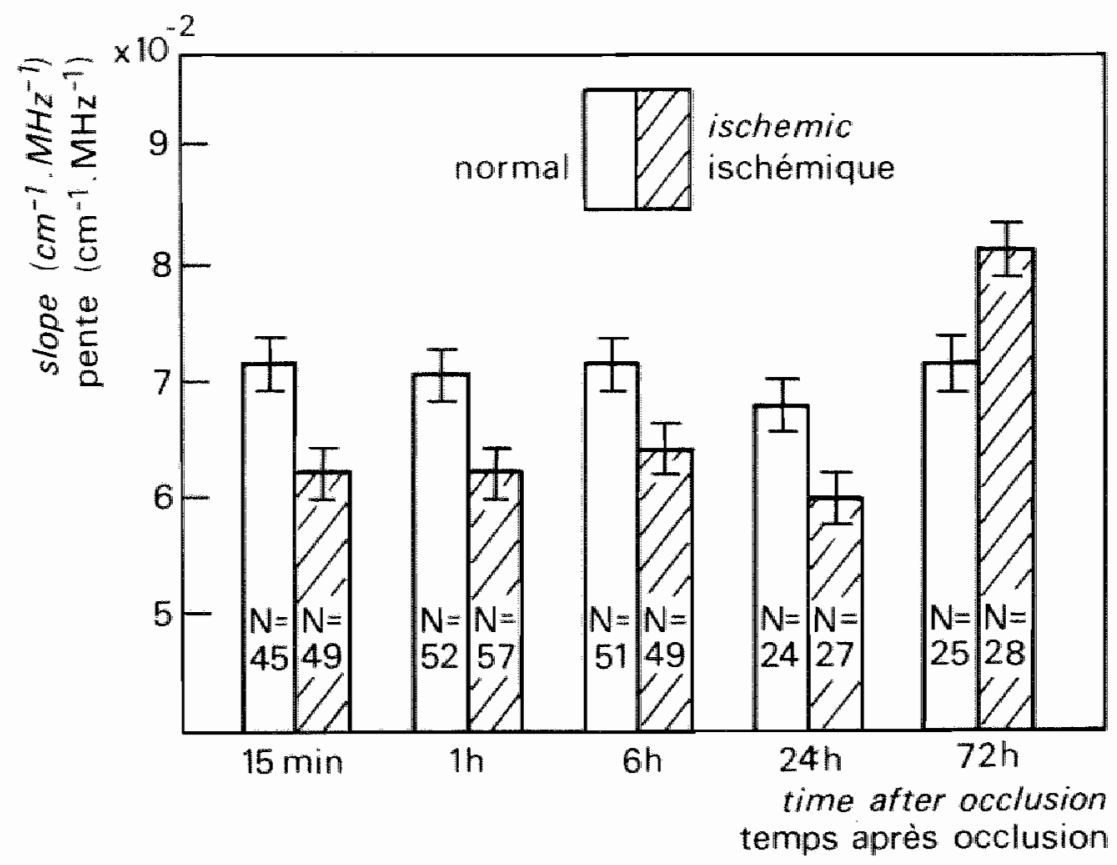

Figure 2: Slope of the ultrasonic attenuation (between 2 and $10 \mathrm{MHz}$ ) for normal and ischemic dog myocardial tissue determined at specified intervals following coronary occlusion. N, number of samples. Reproduced from O'Donnel et all. [35] 


\section{Backscatter}

When discussing ultrasonic echoes, it is important to distinguish between specular reflections and scattering. Specular reflections are produced by objects that are large with respect to the wavelength of sound and present a relatively smooth surface to the ultrasonic beam. ${ }^{2,3}$ Such objects reflect the ultrasonic energy in accordance with geometric acoustics (which is equivalent to Snell's Law in optics). With specular reflection, there exists a wide range of angles for which virtually none of the ultrasound energy returns to the transducer. The angles of reflection are predicted by the spatial orientation and shape of the reflecting object or interface. To date, echocardiography has been principally concerned with specular echoes originating from cardiac valves and walls. ${ }^{3}$ Specular reflectors are angle dependent, e.g., when imaging a cardiac structure, such as the posterior wall of the left ventricle, the endocardium will appear unusually bright during a certain phase of the cardiac cycle and less bright in another phase when surface angles change with respect to the incident beam.

When ultrasound waves impinge on surfaces or structures that are much smaller than their wavelength, the incident energy is scattered in all directions. Although scattered echoes are more difficult to record because of their lower amplitude, they are ever-present and, in contrast to specular reflections, are not angle dependent. In addition, scattering from tissue or parenchyma is important for visualizing objects essentially parallel to the ultrasonic beam. It is now generally acknowledged that, by studying the pattern of ultrasound echoes that are backscattered to the transducer, certain cellular structures or pathologically altered tissue states can be adequately differentiated.

\section{Basic concepts of digital computation in echocardiography image digitiza- tion}

The term image processing refers to the manipulation and analysis of pictorial data. There are three general methodologies that have been emplloyed for image processing:

1. Optical processing, as the name implies, uses lenses and other, less familiar optical components to manipulate optical images. This method of processing has the advantage of being extremely fast.

2. Analog processing refers to the processing of image data by analog electronic circuitry; therefore, this method can only be applied to images that are in analog electronic form. The electronic processing of video images is the most common example of analog image processing.

3. Digital image processing. With the advances in computer technology, digital processing has become the dominant method for manipulating 
and analyzing pictorial data. Digital processing employs general or specialpurpose digital computers, or computer peripherals, to process discrete images. Such an image is represented as a discrete matrix of picture elements (pixels), with each element having one of a finite number of values (gray levels or intensities).

The process of digitization can be described as dividing an image into a grid or matrix of discrete positions (pixels), each position located by a pair $(x, y)$ of position coordinates. At each pixel position, an attribute of the image is measured (sampled) and assigned a discrete value (quantized). In ultrasound imaging, the attribute of interest is the local echo amplitude, which is displayed as a particular gray level (or a particular color). Thus, the digitized echocardiogram may be described as a matrix of pixels, each pixel having a discrete gray levell or echo amplitude value. ${ }^{25}$

There are two important questions to be addressed when designing the echocardiographic digitization process. First, how many pixels should the image be partitioned into and, second, how should one measure gray level or echo amplitude?

Digitizing an image into a fine matrix of several (small) pixels will tend to produce a more visually pleasing digital image, whereas fewer (larger) pixels cause a" blocky" or "pixelated" appearance. ${ }^{25}$

The number of gray levels necessary for optimal visualization will probably be less than that necessary for quantitative analysis, in particular those aimed at ultrasound tissue characterization. Commonly available digitalbased echocardiographs quantize gray levell (echo amplitude) into four bits (16 gray levels), six bits (64 gray levels), and eight bits (256 gray levels).

\section{Image storage}

The analog two-dimensional images have usually been stored on videotape cassettes. This method provides for relatively inexpensive storage of large numbers of images and for convenient review (slow speed, fast speed, real time, stop frame) of the recorded image data. The quality of stored data when played back on the videotape is adversely affected by two factors. The first is a loss in image quality that occurs when recording images on videotape, especially when viewing images in the stop-frame mode. The second is the relatively poor temporal stability of the playback mechanism in the videotape recorder.

An alternative approach is to store the image in digital form within the scanner itself. Commercially available echocardiographic instruments typically have enough internal digital memory to store one or two images. Il $\leqslant$ thus possible to transfer into digital memory a systolic and a diastolic 
image from the same cardiac cycle. With this arrangement, however, it is not possible to acquire a large number of echocardiographic images in real time.

\section{Image display and enhancement}

Digitized echocardiographic images are displayed on a high-resolution video monitor, similar to an ordinary television set. A video monitor is a faster display device in the sense that horizontal lines are displayed (left to right) one after the other from the top to the bottom of the screen. Following scan conversion, each pixel is displayed on the video monitor with an intensity corresponding to the value of the pixel (i.e., echo amplitude).

Enhancement refers to the application of one or more processing steps to an image for purposes of improving the quality by reducing noise or, in some other fashion, making features of the image easier to appreciate.

Image enhancement can be further subdivided into image smoothing and contrast enhancement.

\section{Image smoothing}

The most straightforward approach to image smoothing is to replace each pixel in an echocardiographic image with the average of the value of the pixels in its immediate surrounding neighborhood. For instance, the area of interest might consist of the center pixel in question and its eight immediately adjacent and clearly defined neighbors. Thus, each pixel would be replaced by the average of nine pixels.

\section{Contrast enhancement}

The rationale behind contrast enhancement is to make some image features, such as endocardial or epicardial borders, more visually apparent. The simplest way to achieve this is to perform background subtraction, i.e., subtracting a fixed gray level from the value of all pixels in the image. This background gray level may be selected arbitrarilly or may correspond to the average gray level of some region of the image. If this region is selected within the cavity, background subtraction will have the effect of improving contrast between myocardium and cavity.

\section{Edge detection}

Edge detection is the process of identifying borders or edges of interest in an image; this enables determination of all pixels encompassed by an edge. The converse in also possible. Several edge-detection algorithms have been devised and applied to both medical and other types of images, 
the two most important being parallel and sequential edge-detection algorithms. As the names imply, parallel edge detection attempts to find complete object borders simultaneously, while sequential techniques search for one point on the border at a time. An image edge can be defined as a transition in gray level. Two important factors that complicate edge detection are the presence of image noise and gray level transitions that do not correspond to desired borders.

\section{COMMONLY USED GEOMETRIC TRANSFORMATIONS IN ANALY- ZING TWO-DIMENSIONAL IMAGES}

\section{Image zoom}

The simplest geometric transformation is image zoom, in which the image (or portion of the image) is magnified, usually by a factor that is a multiple of 2 . The most straightforward procedure for performing image zoom by a factor $N$ is referred to as pixel replication and consists of replacing each pixel with an " $X$ " block of pixels of the same gray level. $A$ disadvantage of this system is that it tends to produce "blocky" images.

An alternative procedure employs interpolation to produce a more pleasing image. Image interpolation is the process of calculating a gray level value for a point whose gray level is not defined from the gray level values of the neighboring pixels.

\section{Pixel histogram}

This gives the relative frequency of occurrence of gray levels (pixels) in a particular area being studied. The area can be delineated with a highresolution light pen by painting the desired area into the image on the monitor screen.

\section{Pixel map}

This gives a three-dimensional reproduction of the number of pixels in a desired area on the picture screen. The area of interest is painted into the picture or demarcated by a line by using a high-resolution light pen.

\section{Pixel averaging}

The entire area of interest (several pixels) on the picture screen can be included for pixel averaging by demarcating it with a high-resolution light pen. 
Image acquisition/processing system

We now describe the methods that we use at the Los Angeles CountyUniversity of Southern California Medical Center for color encoding and signal processing of two-dimensional echorcardiograms.

Videotaped images are digitized using a Diasonics Cardio Revue Center (CRC). The CRC has a JVC model BR-6400U VHS videocassette recorder and a Sony model SVM-1010 video motion analyzer. The CRC consists of a magnetic video disk, a Polaroid camera, and an 8080-based microcomputer incorporating a 5-megabyte hard disk, a Datacube model VG-120 digitizer and graphic display controller, dual 5-inch floppy disk drives, a dot matrix printer, a keyboard, and a cathode ray tube (CRT) display. The Datacube model VG-120 digitizes a full field of analog video data (RS-170 EIA standard analog signal) with a resolution of 320 horizontal $(\mathrm{H})$ by 240 vertical (V) picture elements (pixels) by 64 gray levels, and downloads the binary result to on-board random access memory (RAM) in real time, which simultaneously converts the binary data in the RAM back into analog video data viewable on a CRT monitor. In addition, the microprocessor has read/write access to any single pixel contained in the on-board RAM.

The two-dimensional echoes have to be standardized because ultrasound machines and videotape recorders vary in regard to video signal level. To negate the effects of these variations on color encoding, a standard video signal is presented to the image digitizer. This is accomplished by using a video-processing amplifier and an oscilloscope. Each digitized video frame is then transmitted through a high-speed serial data link to a second computer for further pracessing. The second computer, a Compupro model $816 / \mathrm{B}$, is an $8085 / 8088$-based microcomputer incorporating 64 kilobytes of RAM, dual 8-inch 1.2-megabyte floppy disk drives, a Scion Microangelo color graphics subsystem, an RGB high-resolution video display monitor, and a high-resolution light pen. The digitized video frames are stored on floppy disks after transfer from the CRC and can be retrieved at any time thereafter for display or processing. The Microangelo color system stores digitized color video images with a resolution of $480 \mathrm{H}$ by $512 \mathrm{~V}$ pixels by 64 user-definable colors and simultaneously converts the video data contained in the RAM into analog video signals capable of driving a high-resolution color monitor.

Three to five gated video frames from each patient can be averaged to produce a smooth image. Pixel intensity (pixel value) is indicated by 64 selected collors. The pixel intensity at any given location can be ascertained by using a high-resolution light pen. The entire area of 
interest (several pixels) is demarcated and the mean pixel value obtained. When recording pixel values, we try to avoid specular reflections from the leading and trailing edges of the structure being imaged.

\section{Ultrasonic tissue characterization}

As indicated carlier, ultrasonic tissue characterization encompasses a wide variety of techniques and methods that seek to extract and separate from an interrogating ultrasonic wave the medically significant features of ultrasound interactions and to display ultrasonic tissue signatures appropriate for a differential diagnosis or some other medical purpose.

To be useful and significant, such signatures or measures must be related to tissue pathology or physiology. Tissue characterization is broad in scope and, in certain cases, can include aspects of qualitative and quantitative imaging. At its simplest, tissue characterization involves merely a redisplay or recombination of ultrasound information in a way that is more pathology specific.

\section{CARDIAC TISSUE CHARACTERIZATION}

\section{Importance of standardization}

The influence of changes in gain setting on echo intensity must be borne in mind when analyzing echocardiograms. An unusually high gain setting may result in an artifactual increase in echo intensity, especially in anteriorly situated structures such as the interventricular septum. This phenomenon is unlikely to be important when comparing structures at the same depth such as different areas of the posterior wall of the left ventricle in the parasternal long-axis view. It should be emphasized that, in order to compare serial studies in the same patient, the same gain settings have to be used for all of the studies. This can be achieved by noting the gain settings used for the first study and using the same settings for subsequent studies.

\section{Problems with cardiac tissue characterization}

Cardiac tissue characterization can be achieved with the use of specially modified equipment in order to extract and analyze echo signals that have not been subjected to the gross distortions common in commercial $\mathrm{M}$ - and B-scan equipment. Even given that such technical problems are resolved, there are some difficulties associated with the heart itself that demand a more careful design of a tissue characterization investigation than is required for most other organs in the body. These are briefly reviewed here. 


\section{Motion}

The heart, by its very nature, is constantly in rapid motion. This makes it difficult (and with standard methods, impossible) to track a particular tissue segment to ensure that echoes from that region only are being analyzed. The difficulty may be overcome to some extent, in most patients, by simultaneously monitoring the electrocardiogram, for example, and ensuring that echoes acquired only during a particular phase of the cardiac cycle are analyzed. Such a procedure clearly simplifies the comparison of results between different patients, observers, and even from the same patient, if the time course of some condition is being investigated.

\section{Cycling}

Even if a specified segment of cardiac tissue could be tracked throughout the cardiac cycle, it is highly unlikely (as experiments with canine hearts confirm) that its measurable acoustic properties and tissue signatures would remain constant throughout the contraction and relaxation phases of the muscle. ${ }^{17,26}$ Here again, utilizing the electrocardiogram as a "clock" in order to analyze data from only known phases of the cardiac cycle would be advantageous. A direct consequence of this approach is to compare results throughout the cardiac cycle in order to follow the changes in measured properties. Significance is then attached also to the time variation of the tissue characterization indices rather than only to their absolute value at a particular cardiac phase. Necrotic or ischemic regions would be expected to show considerably less time variation than normal regions - due to lack of thickening! It is also very difficult, in such a dynamic tissue characterization approach, to distinguish between the significant cycling and the less-important motion effects. In practice, it may be more convenient to compare results in two phases only (e.g., end diastole and end systole) rather than mapping the full-time course throughout the cardiac cycle. Olshansky et al. ${ }^{26}$ have studied the variation of left ventricular myocardial gray level on two-dimensional echocardiograms as a result of cardiac contraction. These investigators found a significant decrease in gray level from parasternal shortaxis images digitized at end diastole $(175 \pm 58.0)$ to end systole $(59 \pm 2.5, p<$ $0.005)$. These cyclic changes were observed in the left ventricular posterior wall; findings in the ventricular septum were less consistent.

\section{Acoustic window}

The human heart may be ultrasonically viewed invivo only through a limited number of relatively small acoustic windows. This restricts the 
full range of information that can be acquired for tissue characterization and may well exclude some cardiac regions from such investigations.

\section{Cardiac size}

Some tissue characterization methods, which are of potential value in cardiac studies such as attenuation estimation from backscattered echoes, require fairly long tissue segments for implementation. Such techniques, developed for relatively large organs such as the liver, need considerable refinement before they can be implemented on the short data sets obtainable from the myocardium.

\section{QUALITATIVE METHODS USED IN CARDIAC TISSUE CHAR- ACTERIZATION}

\section{Visual methods}

Textural abnormalities on visual inspection of echocardiograms have been described in a variety of disease states in humans. A characteristic granular appearance to the interventricular septum has been described in hypertrophic obstructive cardiomyopathy (HOCM) ${ }^{28}$ Highly refractile echoes (HREs) have been noted in other infiltrative and noninfiltrative cardiac disease. ${ }^{28-30}$ Myocardial scar tissue produces a dense echo pattern. ${ }^{31}$ However, the process of directly imaging acoustically abnormal tissue is somewhat unpredictable, due to the several image manipulations routinely performed during the echocardiographic image acquisition process. Such instrument controls as gain and time-gain compensation substantially alter the image appearance masking or mimicking "diagnostic" changes in the reflective properties of the tissue. ${ }^{32}$ Further, the variability of chest wall and other tissue intervening between the transducer and the region of interest will often alter the echocardiographic appearance of even normal myocardium. Thus, the appearance of the myocardium on standard echocardiograms may not always be a reliable indicator of abnormal cardiac tissue structure.

\section{M-mode echocardiograms}

Some investigators have used M-mode echocardiograms to study myocardial scar tissue characteristics. Rasmussen et al. ${ }^{31}$ and others ${ }^{29}$ noted increased signal intensity in the interventricular septum several weeks after anteroseptal myocardial infarction. They also demonstrated a high degree of correlation between the presence of highintensity echoes and the presence or absence of scar at surgery and at autopsy. 


\section{Two-dimensional echocardiography}

Several studies indicate that cardiac tissue changes can be detected by two-dimensional echocardiography in certain disease states and in patients with acute myocardial infarction. ${ }^{27,33-38}$ Two-dimensional echocardiographic examination has revealed highly refractile HREs in infiltrative and noninfiltrative disorders of the heart. ${ }^{30,311}$ Rogers et all. ${ }^{40}$ showed that useful information about the ultrasonic reflectivity of atherosclerotic coronary artery lesions can be extracted from twodimensional echo-imaging systems by digital processing of the twodimensional echocardiographic images.

\section{Color encoding of the analog images}

Color processing can increase the dynamic range of echo information because the eye can distinguish colors more easily than shades of gray. While color encoding has been accomplished with $M$ mode echocardiography, two-dimensional echocardiograms allow a spatial integration difficult to achieve with M-mode echocardiography.

Parisi et $a{ }^{41}$ produced actue myocardial infarction in 26 dogs by ligation of the left anterior descending artery. Two-dimensional echocardiograms were performed through the chest wall before and serially after coronary ligation. The dogs were then killed in four groups at intervals from $24 \mathrm{~h}$ to 8 weeks. Each two dimensional echo was processed through a video quantizer, which encoded echo amplitudes progressively into eight regions of color. The myocardium was graded with respect to color composition in regions that showed any abnormally contracting segment (ACS). The ACS exhibited a progressive increase in echo intensity that became maximal 6-8 weeks following coronary ligation. However, in ten of 13 dogs, myocardial echo intensity increased to some degree within $48 \mathrm{~h}$ after coronary ligation.

\section{Color encoding digitized echocardiograms}

Recent advancement in computer sciences have made digital image processing of two-dimensional echocardiograms possible. In our laboratory, the analog two-dimensional image is digitized by one computer and then the digitized data are transmitted to a second computer for color encoding (see Image acquisition/processing system). Each pixel is assigned a value from 0 to 63 , corresponding to 64 colors. The area of interest can be demarcated by a light pen and can subsequently be analyzed by determining the mean pixel intensity, kurtosis, and skewness. Data generated in our own laboratory indicate that scar tissue resulting from old myocardial infarction can be detected 


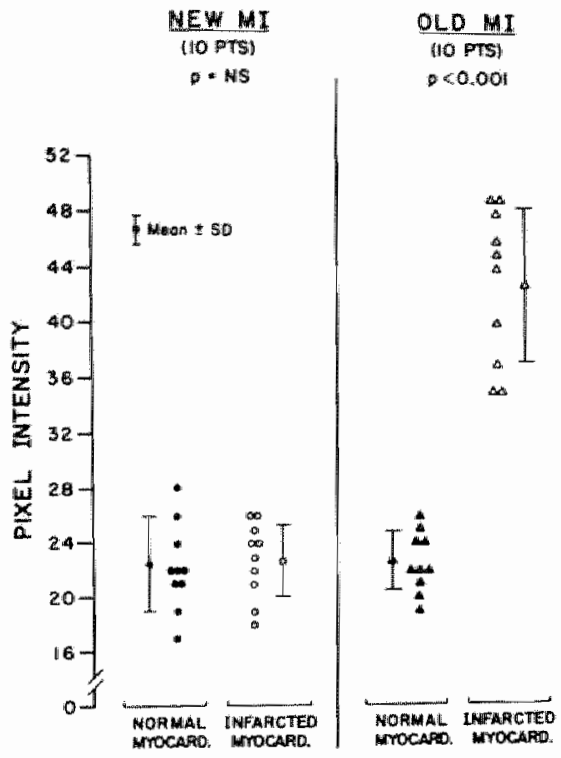

Figure 3: Parasternal long-axis view of patient with inferior myocardial infarction (chronic stage) and adjacent normal myocardium. Note the increase in mean pixel intensity at the site of infarction. Reproduced by permission from Chandraratna et al. ${ }^{42}$

by color encoding and signal averaging of two-dimensional echocardiograms. ${ }^{42}$ The processed image showed clear demarcation of the area of infarction as shown by a color difference in the area of wall motion abnormality (area of infarction) as compared with adjacent normally moving muscle (figure 3 ). This subjective impression of a color change in the area of infarction was confirmed by objective determination of pixel intensity in the infarcted area and comparing it with adjacent muscle. Areas of infarction in the "chronic" phase exhibited higher pixel intensities than did adjacent normal muscle (figure 4).

\section{QUANTITATIVE METHODS USED IN CARDIAC TISSUE CHAR- ACTERIZATION}

\section{Analysis of video image}

Several studies ${ }^{42-44}$ have used digital image processing of echocardiograms in differentiating cardiac structure and for quantitative analysis of cardiac abnormalities in man. The video image was digitized and each gray level was assigned a finite pixel value. 


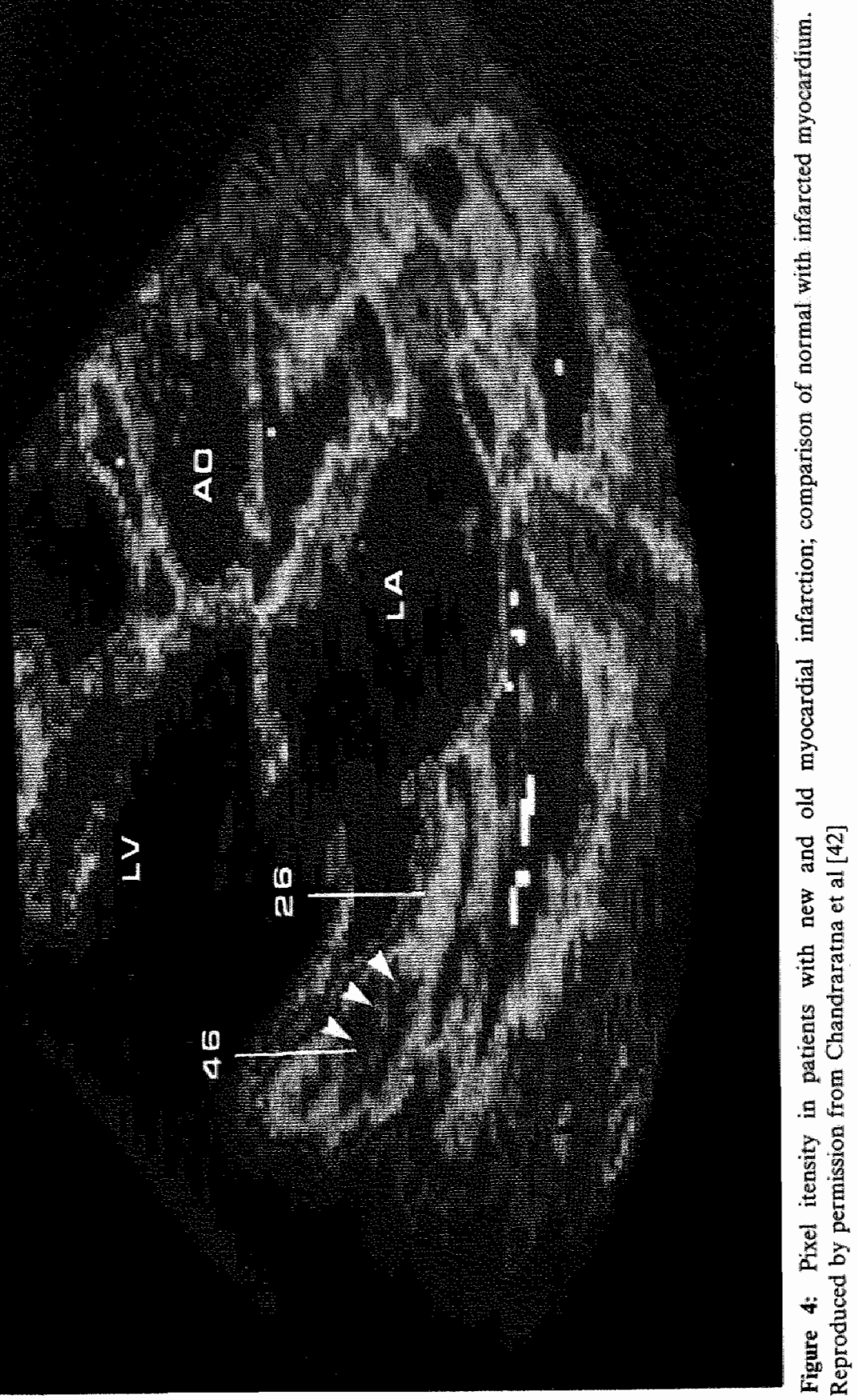


In other studies related to (experimental) acute myocardial infarction in dogs, ${ }^{45}$ the mean pixel intensity of the area with wall motion abnormality (area of infarction) was compared with an adjacent normal area. Statistically significant differences in the mean pixel intensity were noted between the region with wall motion abnormality and adjacent normally moving myocardium. Skorton and co-workers ${ }^{46}$ analyzed twodimensional echo images of dogs (closed-chest experiment) prior to and 2 days after occluding the circumflex artery. These investigators observed quantitative changes as depicted by a significant decrease in kurtosis (i.e., peakedness of gray-level distribution) in the infarcted region in comparison to adjacent normal areas. The distribution of gray level present in each region of interest was displayed as a gray-level histogram, showing the frequency of occurrence of each gray level within that region. Before and 2 days after coronary artery occlusion, 256 gray-level histograms were generated. Average gray level increased significantly from preocclusion to postocclusion images in the infarcted regions, but not in the controll regions. Average gray level was calculated for each region of interest, and the shape of the gray-level distribution was analyzed by calculation of skewness and kurtosis, and by qualitative features of shape of gray-level histograms. Skewness measured the symmetry and kurtosis measured the peakedness of gray-level distribution. A decrease in kurtosis indicates flattening and broadening of the gray-level distribution, whereas reduced skewness values are seen in lessskewed histograms.

Another group has investigated the pattern of echoes from within the myocardium in order to arrive at a tissue characterization index. Joynt et al. ${ }^{47}$ have analyzed the distribution of echo amplitudes obtained from normal human subjects and patients with myocardial infarction. Although the number of subjects was very small, these authors felt that the analysis provided a differentiation between normal and affected myocardium.

\section{Analysis of radiofrequency signal}

The radiofrequency (RF) signal, produced by the transducer when it transforms the ultrasonic echoes into an electrical waveform, must be subjected to simple processing such as envelope detection in order to produce an image on the video screen. More extensive processing and filtering are used to produce a visually pleasing image. This process of manipulation of the RF signal results in a loss of phase information and, therefore, a loss of much information regarding tissue signature. Thus, for purposes of tissue characterization, analysis of the RF signal prior to 
processing is important for many applications. To utilize the RF sigmals effectively, the echocardiographic machine must be specially modified and interfaced to an appropriate data acquisition system that digitizes and stores the RF signals. ${ }^{48}$ Digitization rates of $20-30 \mathrm{MHz}$ are typical. Very fast memory, 1-2 megabytes in size, is required for recording the digitized data; larger but slower memory is required for data storage and analysis.

An example of the application of statistical signal analysis to RF data can be found in the work of Joynt and co-workers, ${ }^{36,49}$ who digitized portions of single A lines (corresponding to single lines from twodimensional echocardiograms) and analyzed the amplitude distributions of the RF signal from a selected region of myocardium. This relatively simple evaluation of the distribution of echo amplitudes in a local region allowed the investigators to differentiate cardiac thrombus from artifact. Using a somewhat similar approach, Dines and co-workers ${ }^{50}$ were able to identify acutely infarcted myocardium based on a set of statistical descriptors of the RF waveforms; a further statistical analysis of these RF signals also allowed some estimation of the relative scatterer spacing within the myocardium. It is also of note that several groups have shown that analysis of RF signal patterns is an efficacious approach to tissue characterization in other organs ${ }^{13,51-53}$ (e.g., liver and eye), adding credence to the use of these techniques in the myocardium.

Although the use of RF data is attractive and has many advantages, it also has significant drawbacks. Radiofrequency data must be sampled at a very rapid rate (usually $20 \mathrm{MHz}$ ). The amount of data stored and processed when using RF data is thus much larger than that manipulated when using image or video data. Moreover, standard echocardiographic instruments do not allow direct access to the ultrasound signal in its RF form.

\section{MEASUREMENT OF ACOUSTIC PROPERTIES OF THE MYO- CARDIUM}

The measurement of the acoustic properties of the myocardium has proved to be a sensitive method for detecting pathologic abnormalities. The acoustic parameters that have most often been measured include attenuation, $34-36,56$ attenuation coefficient, and integrated ultrasonic backscatter. ${ }^{59-63}$ Such may be derived from the RF signal.

In one of the early studies of myocardial tissue characterization, Namery and Lele ${ }^{36}$ noted a change in acoustic impedance in excised hearts $30 \mathrm{~min}$ after acute experimental myocardial infarction. Thus, changes in elastic properties may prove to be a useful measure for characterizing the myocardium. ${ }^{64,65}$ 


\section{Measurement of attenuation}

Mimbs and co-workers found a significant decrease in attenuation of ultrasound passing through acutely infarcted myocardium when compared with normal tissue. ${ }^{34}$ Interestingly, the acoustic alterations were noted as soon as $15 \mathrm{~min}$ after acute experimental coronary occlusion in open-chest dog studies. The measurements in this study were performed in vitro using excised tissue specimens. The attenuation remained less than normal in the infarcted region for the first $24 \mathrm{~h}$ after infarction. Measurements performed more than 3 days after coronary occlusion, however, showed an increase in attenuation through the infarcted tissue relative to the normal myocardium. ${ }^{15}$ Thus, not only did the acoustic analysis allow very early identification of ischemic tissue, but the age of the ischemic injury affected the direction of the change in attenuation. Although of great theoretical and physiologic interest, these initial excised tissue studies of attenuation were performed in transmission mode, i.e., by interposing tissue specimens between separate transmitting and receiving crystals. Such studies would clearly not be done in vivo. Although techniques have recently been developed for measuring attenuation in reflection mode, i.e., using the same crystal as transmitter and receiver, ${ }^{67}$ these latter techniques have only recently been applied to myocardial studies.

\section{Measurement of backscatter}

Many promising studies in ultrasound tissue characterization have been based upon the measurement of the backscatter coefficient or the integrated backscatter, parameters that may be derived from the echo signal.

O'Donnel et al, ${ }^{611}$ using in part a concept discussed by Siegelmann and Reid ${ }^{68}$ introduced the measurement of integrated backscatter, which in an estimation of the energy within an ultrasound signal returning from a portion of tissue, compared with the energy in a signal returning from a "perfect" reflector. Measurement of integrated backscatter as early as $1 \mathrm{~h}$ after acute occlusion of a coronary artery in an open-chest dog allowed identification of an increase of backscatter from infarcted compared with normal myocardium. ${ }^{62}$ Therefore, this presumably clinically applicable measurement was able to identify acute infarction. In a subsequent study, the authors were able to use integrated backscatter to identify myocardium that was rendered abnormal by administration of the cytostatic agent doxorubicin. ${ }^{60}$

One of the problems that has limited the development of clinical methods of ultrasound myocardial tissue characterization is a method of accounting for alterations in the ultrasound beam as it passes through 
tissues that are interposed between the transducer and the region of interest. This intervening tissue absorbs and scatters ultrasound, acts as a low-pass filter (since attenuation of ultrasound is directly related to frequency), and causes diffraction effects. At least three methods have recently been reported that have attempted to correct for the effects of intervening tissue and thus set the stage for clinical measurements of myocardial acoustic properties. Cohen and co-workers measured the acoustic properties of excised chest-wall specimens ${ }^{69}$ and utilized these measurements to derive a correction factor for use in adjusting backscatter measurements for the effect of the chest wall. Using this correction factor, these investigators were able to identify acute ischemia through the chest wall in an animal model and showed a high correlation between measurements of backscatter through the chest wall in an animal model and showed a high correlation between measurements of backscatter through the chest wall and and those obtained directly from the epicardium over the site of injury. O'Donnel has attempted to correct for the effects of intervening tissue by developing quantitative volume backscatter images. ${ }^{63}$ Melton and Skorton have reported a hardware-based method of altering the gain-compensation profile individually along each ultrasound line of site within a two-dimensional echocardiographic frame, based on differential amplification of signals of varying amplitude ${ }^{58}$ These and other methods of accounting for intervening tissue will probably in the near future allow reasonable estimates of integrated backscatter to be made through the chest wall in a clinically relevant fashion.

Mimbs and co-workers ${ }^{62}$ studied a series of open-chest dogs and observed that integrated backscatter was increased by $200 \%$ compared with values in control regions within $1 \mathrm{~h}$ after coronary occlusion, and by $400 \%$ within $6 \mathrm{~h}$. Factors responsible for alteration of ultrasonic properties in the acute phase of myocardial infarction include the development of interstitial and intracellular edema, changes in concentration of cytoplasmic proteins, differences in tissue volume between ischemic and nonischemic regions, and changes in concentration of potential ultrasonic contrast agents such as blood and calcium content. Although characteristic histologic changes are not seen in the very early phases of myocardial infarction by light microscopy, swollen organelles, mitochondrial densities, and myofibrillar relaxation are evident within $1 \mathrm{~h}$ of coronay occlusion by electron microscopy. ${ }^{62}$ In addition, the authors noted an increase in cardiac fluid content as reflected by an increase in wet to dry weight ratio in the acute phase of infarction and they felt that this was an important determinant of increased ultrasonic backscatter that was observed. Mimbs and co-workers ${ }^{36}$ did a series of experiments in which 
hearts from 21 rabbits were studied for 5-7 weeks after coronary occhusion. Ultrasonic attenuation and ultrasonic backscatter were increased significantly when compared with nonischemic regions from the same rabbits. An increase in the collagen content within the infarcted tissue was considered to be an important determinant of the increase in attenuation and backscatter.

\section{SUMMARY AND FUTURE EXPECTATIONS}

There is now sufficient laboratory evidence that various indices of ultrasonic tissue characterization can provide adequate information in the diagnosis of myocardial infarction. With some modification of existing equipment, it may be possible to acquire data for tissue characterization during routine echocardiographic examinations without causing any inconvenience to the patient. ${ }^{48}$

It is conceivable that the widespread use of real-time gray-scale scanners and color-encoded images, and the availability of powerful lowcost computers, will aid the further development of ultrasonic tissue characterization.

\section{REFERENCES}

1. Jones JP, Leeman S. Ultrasonic tissue characterization: a rewiew. Acta Electron 1984;26:1.

2. Erikson UR, Fry FJ, Jones JP. Ultrasound in medicine: a review. IEEE Trans Sonics Ultrason 1974;SU-21:144.

3. Feigenbaum H. Echocardiography, 4th edn. Philadelphia: Lea and Febiger, 1986:1.

4. Wild JJ, Reid JM. Further pilot echographic studies on the histologic structures of tumors of the living intact human breast. Am J Pathol 1952;28:839.

5. Reid JM, Sikov MR. Interaction of ultrasound and biological tissues. Proc workshop, Battele Seattle Research Center (1971). DHEW Publ 1972:FDA-73-8008.

6. Hussey M. Diagmostic ultrasound: an introduction to the interactions between ultrasound and biollogical tissues. New York: John Wiley and Sons, 1975.

7. Dunn F, Edmunds P, Fry W. Absorption and dispersion of ultrasound in biological media. In: Schwan H (ed) Biological engineering. New York: McGraw-Hill, 1969-205.

8. Beyer RT, Letcher SV. Physical ultrasonics. New York: Academic Press, 1969:96.

9. Beyer RT, Letcher SV. Physical ultrasonics. New York: Academic Press, 1969:118.

10. Bhatia AB, Ultrasonic absorption. London: Oxford, 1967:174.

11. Fry WJ, Fry FJ. Ultrasonic visualization of soft tissue structure based on gradients in absorption characteristics. J Acoust Soc Am 1963;35:1788.

12. Sachs TD, Welt A, Slayton PW. Thermo-acoustic sensing technique: TAST. In: Proceedings of the 1972 IEEE Ultrasonics Symposium. New York, 1972:54.

13. Kuc R, Schwartz M. Estimating the acoustic attenuation coefficient slope for liver from reflected ultrasound signals. IEEE Trans Sonics Ultrasound Signals $1979 ; \mathrm{SU}-26: 353$. 
14. Leeman S, Jones JP. Attenuation estimation for tissue characterization. In: Prom ceedings of the 1983 IEEE Ultrasonics Symposium. IEEE Publ 83-CH, 1947\%, $1983: 847$.

15. Mimbs JW, Yuhas DE, Miller JG, Weiss AN, Sobel BE. Detection of myocardial infaretion in vitro based on altered attenuation of ultrasound. Cire Res $1977 ; 41: 192$.

16. Harvey $\mathbb{E}$, Loomis $A$. High frequency sound waves of small intensity and their biological effects. Nature 1928;F622:121.

17. Wells PNT. Biomedical ultrasonics. London: Academic Press, 1977:509.

18. Goldman DE, Hueter TF. Tabular data of the velocity and absorption of high frequency sound in mammalian tissues. J Acoust Soc Am 1956;28:35.

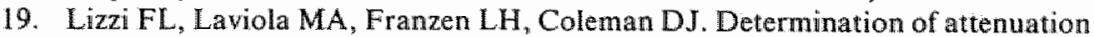
spectra in ophthalmic ultrasonography. Ultrasound Med 1977;3:2077.

20. Kuc R. Statistical estimation of the acoustical attenuation slope for liver disease. PhD thesis, Columbia University, 1977;78-2331.

21. Fink M, Hottier F, Cardoso JF. Ultrasonic signal processing for in vivo attenuation measurements: Short term Fourier analysis. Ultrasonic Imaging. $1983 ; 5 ; 117$.

22. Ferrai L, Jones JP, Conzalez V, Behrens M. In vivo measurement of attenuation based on the theory of Gaussian pulse propagation. Ultrasonic Imaging $1982 ; 4: 42$.

23. Miller JG, Yuhas DE, Mimbs JW, Dierker SB, Busse LJ, Laterra JJ, Weiss AN, Sobel BE. Ultrasonic tissue characterization: correlation between biochemical and ultrasonic indices of myocardial injury. In: Proceedings of the 1976 IEEE Ultrasonics Symposium. IEEE Publ 76-CH-1120-5SU, 1976:33.

24. Yuhas DE, Mimbs JW, Miller JG, Weiss AN, Sobel BE. Changes in ultrasonic attenuation indicative of regional myocardial infarction. U].trasound Med $1977,3: 1883$.

25. Collins SM, Skorton DJ. Cardiac imaging and image processing. New York: McGraw Hill, 1986 .

26. Olshansky B, Collins SM, Skorton DJ, Prasad NV. Variation of left ventricular myocardial gray level on two-dimensional echorcardiograms as a result of cardiac contraction. Circulation 1984;70:972.

27. Mimbs JW, Bauwens D, Cohen R, O'Donnell M, Miller JG, Sobel B. Effects of myocardial ischemia on quantitative ultrasonic back-scatter and identification of responsible determinants. Circ Res 1981;49:89.

28. Martin PR, Rakowski H, French J, Popp RL. Idiopathic hypertrophic subaortic stenosis viewed by wide angle phased array echocardiography. Circulation 1979;59:1206.

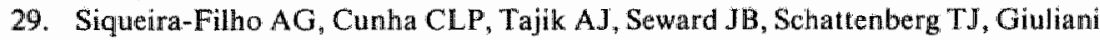
ER. M mode and 2-dimensional echocardiographic features in cardiac amyloidosis. Circulation $1981 ; 63: 188$.

30. Bhandari AK. Nanda NC. Myocardial texture characterization by 2 dimensional echocardiography. Am J Cardiol 1983;51:817.

31. Rasmussen $\mathrm{S}$, Corya $\mathrm{BC}$, Feigenbaum $\mathrm{H}$, Knoebel SB. Detection of myocardial scar tissue by $\mathrm{M}$-mode echocardiography. Circulation 1978;57:230.

32. Jaffe CC, Harris DJ. Physical factors influencing numerical echo amplitude data extracted from B-scan ultrasound images. J Clin Ultrasound 1980;8:327.

33. Chandrasekaran K, Chu A, Greenleaf JF, Bahn RC, Edwards WD, Seward JB 
Tajik AJ: $2 D$ echo quantitative texture analysis of acutely ischemic myocardium [abstr.] Circulation 74 (Suppl. II): 11-271, 1986.

34. Mimbs JW, O'Donnel $M$, Miller JG, Sobel BE. Changes in ultrasonic attenuation indicative of early myocardial ischemic injury. Am I Physiol $1979 ; 236 ; 4340$.

35. O'Donnel M, Mimbs JW, Sobel BE, Miller JG. Ultrasonic attenuation in normal and ischemic myocardium. In: Linzer $M$ (ed) Ultrasonic tissue characterization II. National Bureau of Standards, Spec Publ, Washington DC:US Government Printing Office, 1979,525:63.

36. Mimbs J, O'Donnel M, Bauwens D, Miller JG, Sobel BE. The dependence of ultrasonic attenuation and backscatter on collagen content in dog and rabbit hearts. Circ Res 1980,47:49.

37. Rasmussen S, Lovelace E, Knoebel SB, Ransburg R, Corya BC. Echocardiographic detection of ischemic and infarcted myocardium. I Am Coll Cardiol 1984;3:733.

38. Logan-Sinclair R, Wong CM, Gibson DG. Clinical application of amplitude processing of echocardiographic images. Br Heart $\mathrm{J}$ 1981;45:621.

39. Chiaramida SA, Goldman MA, Zema MJ. Pizzarello RA, Goldberg HM. Real cross sectional echocardiographic diagnosis of inflitrative cardiomyopathy due to amylloid. J Clin Ultrasound 1980;8:58.

40. Rogers EW, Feigenbaum $\mathrm{H}$, Weyman AE, Codley RW, Johniston KW, Eggleton $\mathrm{RC}$. Possible detection of atherosclerotic coronary calcification by twodimensional chocardiography. Circulation 1980;52:1046.

41. Parisi AF, Nieminen M, Boyle JE, Moynihan PF, Khuri SF, Kloner RA, Folland ED, Schoen FJ. Enhanced detection of the evolution of tissue changes after acute myocardial infarction using color encoded two-dimensional echocardiography. Circulation $1982 ; 66: 764$.

42. Chandraratna PAN, Ulene $R$, Nimalasuriya $A$, Reid $C L$, Kawanishi $D$, Rahimtoola, SH. Differentiation between actue and healed myocardial infarction by signal averaging and color-encoding 2-dimensional echocardiography. Am J Cardiol 1985;56:381.

43. Chandraratna PAN, Minagoe S, Nimalasuriya A, Rosin B, Rahimtoola SH. Quantitative estimation of textual differences in thickened mitral leaflets of rheumatic mitral stenosis and mitral valve prolapse by digital image processing of echocardiograms [abstr]. Circulation 1984;70:11-405.

44. Skorton DJ, McNary CA, Child IS, Newton FC, Shah PM. Digital image processing of 2-dimensional echocardiograms: identification of the endocardium. An J Cardiol 1981:48:479.

45. Tak $T$, Gamage $N$, Lin $S L$, Gerbaudo $V$, Colletti $P$, Rahimtoola $S H$, Chandraratra PAN. Echocardiographic textural changes and nuclear magnetic resonance parameters in acute canine myocardial infarction [abstr]. Circulation 1986:74 (suppl II): II-270.

46. Skorton DJ, Melton HE, Pandian NG, Nichols J, Koyaragi S, Marcus ML, Collins SM, Kerber RE. Detection of acute myocardial infarction in closed-chest dogs by analysis of regional two-dimensional echocardiographic gray-level distribution. Circ Res 1983;52:36.

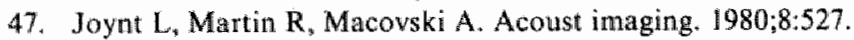

48. Jones JP. Computers in ultrasound, Radiographic 1985;5:105.

49. Joynt $\mathbb{L}$, Boyle DL, Rakowski $H$, Popp $\mathbb{R}$, Beaver $W$. Identification of tissue 
parameters by digital processing of real time ultrasonic clinical cardiac data. In: Linzer M (eds) Ultrasonic tissue characterization II. National Bureau of Standards, Spec Publ 525. Washington DC: US Government Printing Office, 1979:267.

50. Dines KA, Weyman AE, Franklin TD Jr, Cuđdenback JK, Sanghvi NT, Avery US, Baird Al, Fry FJ. Quantitation of changes in mycoardial fibre bundling spacing with acute infarction, using pulse-echo ultrasound signals [abstr]. Circulation 1979;60:11-17.

51. Jones JP, Gonzalez V, Kovach R. Differentiation of abdominal organs and pathologies by the analysis of A mode ultrasound waveforms. In: Proceedings of the 1980 IEEE ultrasonics symposium. IEEE Publ 80Ch 102-2, 1980.

52. Maklad NF, Ophir J, Balsara V. Attenuation of ultrasound in normal liver and diffuse liver diseases in vivo. Ultrasonic Imaging 1984;6:117.

53. Ophir J, Shawker TH, Maklad NF, Miller FW, Flax FW, Narayana PA, Jones JP. Attenuation estimation in reflection: progress and prospects Ultrasonic Imaging 1984;6:349.

54. Lizzi FL, Coleman DJ, Franzen L, Feleppa E. Use of a spectrum analysis stystem for characterization of malignant melanoma. Ultrasound Med 1978;4:559.

55. Jones JP, Cole-Beuglet $\mathrm{C}$. In vivo characterization of several lesions in the eye using ultrasound impediography. Acoust Imaging 1980;8:539.

56. Namery J, Lele PP. Ultrasonic detection of myocardial infarction in dog. In: Proceedings of the IEEE Ultrasonics Symposium, 1972:491.

57. Leeman S, Ferrari L, Jones JP, Fink M. Perspectives on attenuation estimation from pulse echo signals. IEEE Trans Sonics Ultrasonics 1984;SU-31:352.

58. Melton $\mathrm{HE} \mathrm{Jr}$, Skorton DJ. Rational gain compensation for attenuation in cardiac ultrasonography. Ultrasonic Imaging 1983;5:214.

59. O'Donnel M, Miller JG. Quantitative broadband ultrasonic backscatter: an approach to non-destructive evaluation in acoustically inhomogeneous materials. J Appl Physiol 1981;52:1056.

60. Mimbs JW, O'Donnel M, Miller JG. Sobel BE. Detection of cardiomyopathic changes induced by doxyrubicin based on quantitative analysis of ultrasonic backscatter. Am J Cardiol 1981;47:1056.

61. O'Donnel M, Bauwens D, Mimbs JW, Miller JG. Broadband integrated backscatter: an approach to spatially localized tissue characterization in vivo. In: Proceedings of the IEEE Ultrasonics Symposium ( $\mathrm{CH}$ 1482), 1979:175.

62. Mimbs JW, Bauwens D, Cohen RD, O'Donnell M, Miller JG, Sobel BE. Effects of myocardial ischemia on quantitative ultrasonic backscatter and identification of response determinants. Circ Res $1981 ; 49: 89$.

63. O'Donnel M. Quantitative volume backscatter imaging. IEEE Trans Sonics Ultrasonics 1983;30:26.

64. Jones JP. Ultrasonic impediography and its application to tissue characterization. Recent Advances Biomed 1977;1:131.

65. Jones JP, Holasek E, Purnell EW, Sokollu A. Tissue characterization using spectral analysis of ultrasound wave forms. In: Proceedings of the 91 st meeting of the Acoustical Society of America, April $1976: 143$.

66. Kuc R. Feasibility of attenuation images from reflected ultrasound signals [abstr]. Ultrasonic Imaging $1984 ; 6: 213$.

67. Kumar A, Jones J, Rosin B, Chandraratna PAN. Measurement of attenwation from backscattered echo wave forms as a means of characterizing myocardial tissue [abstr]. Circulation 1985; 72: III-427. 
68. Siegeimann RA, Reid JM. Analysis and measurement of ultrasound backscattering from an ensemble of scatterers excited by sinewawe bursts. I Acoust Soc Am 1973:53:1351.

69. Cohen RD, Mottley JG, Miller JG, Kurnik PB, Soble BE. Detection of ischemic myocardium in wivo through the chest wall by quantitative ultrasonic tissue characterization. Am J Cardiol 1982;50;838. 


\section{Chapter 7}

\section{DETECTION OF EARLY MYOCARDIAL TISSUE CHANGES IN ACUTE CANINE MYOCARDIAL INFARCTION BY ULTRASONIC TISSUE CHARACTERIZATION METHODS}

Tahir Tak, M.D., Nimal Gamage, M.D., Shoa-Lin Lin, M.D., Corry Mahler, M.D., Stephen N. Steen, M.D., Sc.D., Patrick Coletti, M.D., Shahbudin H. Rahimtoola, M.B., F.R.C.P., and P. Anthony N. Chandraratna, M.D., M.R.C.P.

From the Section of Cardiology, Departments of Medicine, Anesthesiology and Radiology, Los Angeles County-University of Southern California Medical Center, University of Southern California School of Medicine, Los Angeles, California.

\section{ABSTRACT}

To determine the time after left anterior descending artery (LAD) occlusion that changes in myocardial texture first occur, we performed 2-D echocardiograms (2DE) on 5 sham operated dogs and 8 dogs before and after proximal LAD occlusion. Serial $2 \mathrm{DE}$ were performed every 15 minutes by placing a $5 \mathrm{MHz}$ transducer directly on the chest wall. The dogs were sacrificed at the end of the study, and the area of myocardial infarction was confirmed by triphenyl tetrazolium chloride staining. The $2 \mathrm{DE}$ images were digitized. The mean pixel intensity (MPI) $\pm S D$ in the area of myocardial infarction (region of asynergy) and a normally (control region) moving area equidistant from the transducer were calculated; thus each dog served as its own control.

In sham operated dogs, no significant change in MPI, skewness, or kurtosis were observed. There was a significant increase in MPI in the infarcted regions (anteroseptal) compared to values obtained in the normally moving (lateral) regions at 30 minutes (MPI $=25.2 \pm 23.1 \mathrm{ws}$ $23.0 \pm 0.7, \mathrm{p}<0.05$ ), and this difference persisted at 45 minutes (MPI $=$

Presented at the 61st Annual Scientific Sessions of the American Heart Association, Washington D.C. November 1988. Submitted for publication. 
$25.8 \pm 0.9$ vs $22.6 \pm 0.5, p<0.01), 60$ minutes (MPI $=27.2 \pm 1.4$ vs $22.8 \pm 0.8$, $\mathrm{p}<0.01), 90$ minutes (MPI $=28.6 \pm 1.6$ vs $22.5 \pm 0.9, \mathrm{p}<0.01)$ and 180 minutes (MPI $=28.7 \pm 1.8$ ws $21.3 \pm 1.4, p<0.01$ ). In addition, kurtosis showed a statistically significant decrease between infarcted (anteroseptal) and normal (lateral) regions starting at 45 minutes $(-0.256 \pm 0.3 \mathrm{vs}$ $0.280 \pm 0.6, p<0.05)$ and persisting to 180 minutes $(0.090 \pm 0.4$ vs $0.030 \pm 0.2, \mathrm{p}<0.05$ ).

We conclude that digital image processing of $2 \mathrm{DE}$ obtained through the chest wall enables the early detection of myocardial infarction, that is, at 30 minutes.

Key Words: Echocardiography, Myocardial Infarction, Ultrasonic Tissue Characterization.

\section{INTRODUCTION}

Chronic myocardial infarction has been occasionally detected by noting areas of increased brightness on $\mathrm{M}$-mode ${ }^{\mathrm{d}}$ and $2 \mathrm{D}$ echocardiography. ${ }^{2,3}$ Fraker et $\mathrm{al}^{4}$ noticed an increase in apparent brightness of infarcted areas of dog hearts after acute myocardial infarction; however, their findings were subjective in nature and no objective quantification of acoustic reflectance was attempted in their study. Other investigators have analyzed radiofrequency signal ${ }^{5}$ and gray level run-lengths ${ }^{6}$ from acutely infarcted canine myocardium to identify acute myocardial ischemia. Color encoding of ultrasound amplitudes (i.e. replacing gray-level variations with variations in color intensity and hue) has proved useful in studying the evolution of myocardial infarction ${ }_{3,7}$ Skorton et al ${ }^{8}$ have evaluated the quantitative statistical characteristics of echocardiographic intensities (gray-levels) from standard echocardiograms of canine myocardium before and two days after experimental coronary occlusion. The distribution of gray-levels (shape of the gray-level histograms) changed significantly with acute infarction. In another study, a significant increase in mean pixel intensity was noted at the end of 3 hours of coronary artery occlusion in the anteroseptal region (infarcted) compared to noninfarcted regions. ${ }^{y}$ Since the naked eye cannot detect subtle changes in gray-levels, a digital image processing method developed in our laboratory was utilized to determine how early after coronary artery occlusion a myocardial infarction could be diagnosed in dogs. 


\section{Methods}

\section{Animal Preparation}

Thirteen adult mongrel dogs weighing between $25-50 \mathrm{~kg}$ were used in this study. The study protocol was approved by the Institutional Review Board of the University of Southern California School of Medicine. They were given morphine sulphate $1 \mathrm{mg} / \mathrm{kg}$ i. $\mathrm{m}$. and sodium pentobarbital $30 \mathrm{mg} / \mathrm{kg}$ i.m. one-half hour prior to surgery. An intravenous line was started, ECG leads were placed and the trachea intubated. Ventilation was controlled with a respirator and the dogs received $100 \%$ inspired oxygen. Supplemental morphine sulphate was given in small, incremental doses by intravenous injection up to a total dose of 5 $\mathrm{mg} / \mathrm{kg}$. Two-dimensional echocardiograms were performed with the dogs lying in the right lateral decubitus position by placing a $5 \mathrm{MHz}$ transducer directly on the chest wall.

The chest was entered through an incision in the left fifth intercostal space, the pericardium incised and the beating heart exposed. Five dogs served as controls (sham operated dogs). In 8 dogs undergoing intervention, a bolus injection of lidocaine $1 \mathrm{mg} / \mathrm{kg}$ was given prior to clamping the left anterior descending coronary artery (LAD). The LAD was isolated approximately $1 \mathrm{~cm}$ from its origin proximal to the first large diagonal branch. The LAD was occluded with a vascular clamp. Following this, the dogs were maintained on lidocaine $2-4 \mathrm{mg} / \mathrm{kg}$ with a constant drip through a venous catheter. Additional bolus injections of lidocaine $(1 \mathrm{mg} / \mathrm{kg})$ were given in the event an episode of ventricular tachycardia occurred in the anesthetized dog.

All dogs were sacrificed at the end of the experiment by injecting a 5-10 $\mathrm{mg} / \mathrm{kg}$ bolus dose of sodium pentobarbital, while ventilation was concomitantly discontinued. The chest was then fully opened, and the hearts were removed for additional investigations as described below.

\section{Echocardiographic Data}

Prior to any manipulation of the LAD, baseline parasternal short axis views at different levels of the left ventricle were obtained in all dogs by placing a $5 \mathrm{MHz}$ transducer (narrow band, focussed) directly on the chest wall. The time-gain-compensation setting (TGC) and all other controls on the echocardiographic machine were kept identical in all studies. Images were recorded on standard VHS video tapes. Image analyses were performed on videotaped studies. 


\section{Standardization of $2 D$ Echocardiograms}

In order to enable comparison of serial studies, standardization of $2 \mathrm{D}$ echocardiograms was performed. This was done 1) By noting the time-gain compensation (TGC) settings and other controls on the echo machine at the time of the first study; 2) By keeping these settings identical in subsequent studies; and 3) By presenting a standard video signal to the image digitizer using a video processing amplifier and an oscilloscope.

\section{Data Analysis System}

Selected series of videotaped images were digitized using a Diasonics Cardio Revue Center (CRC). The CRC has a JVC Model BR-6400U VHS video cassette recorder and a Sony Model SVM-1010 Video Motion Analyzer. The $\mathrm{CRC}$ consists of a magnetic video disk, a Polaroid camera and an 8080-based microcomputer incorporating a 5-megabyte hard disk, a Datacube Model VG-120 video frame digitizer and a graphic display controller, dual 5-inch floppy disk drives, a dot-matrix printer, a keyboard and a cathode ray tube (CRT) display. The Datacube Model VG-120 digitizes a full field of analog video data (RS-170 E1A standard analog signal) with a resolution of 320 horizontal (H) by 240 vertical (V) picture elements (pixels) by 64 gray levels and downloads the binary result of on-board random access memory (RAM) in real time, while simultaneously converting the binary data in the RAM back into analog video data viewable on a CRT monitor. In addition, the microprocessor has $\mathrm{read} /$ write access to any single pixel contained in the on-board RAM. Standardization was accomplished using a video processing amplifier and an oscilloscope.

Each digitized video frame obtained at end-diastole (beginning of $\mathbf{R}$ wave on ECG) was transmitted through a high-speed serial data link to a second computer for further processing. This computer, a Compupro Model $816 / \mathrm{B}$, is an $8085 / 8088$-based microcomputer incorporating 64 kbytes of RAM, dual 8-inch 1.2-megabyte floppy disk drives, a Scion Microangelo ${ }^{*}$ color graphics subsystem, an RGB highresolution video display monitor and a high-resolution light pen. The digitized video frames were stored on floppy disks after transfer from the CRC and could be retrieved at any time thereafter for redisplay or processing. The Microangelo ${ }^{\circledast}$ system stored digitized video images with a resolution of $480 \mathrm{H}$ by $512 \mathrm{~V}$ pixels.

The pixel intensity of any given location could be ascertained using a high-resolution light pen. The computer had the capability to average pixels at any given area of interest such as valvular leaflets or the 
myocardium. The number of pixels averaged and the mean pixell value of the areas studied could be displayed. The entire area of interest i.e. the area of wall motion abnormality representing the area of infarction and a comparable area of adjacent normally moving myocardium (control region) was demarcated and the mean pixel intensity obtained. When pixel averaging, we tried to avoid specular reflections from the leading and trailing edges of the myocardium.

"Skewness" measured the asymmetry of the shape of the distribution and "kurtosis" measured the peakedness of the distribution relative to the length and size of its tails.

The calculations of skewness and kurtosis were done as follows:

Values for skewness and kurtosis of the pixel distributions were calculated using the standard statistical definitions and incorporating them in our computer software package. First a standardization variable, $\mathrm{Z}$, is computed

$$
\mathrm{Z}=(\mathrm{x}-\overline{\mathrm{x}}) / \mathrm{S}
$$

where $\bar{x}=$ mean of the distribution and $S=$ standard deviation of the distribution.

The following calculations are then performed:

$$
\text { Skewness }=\quad \frac{\mathrm{N}}{(\mathrm{N}-1)(\mathrm{N}-2)} \Sigma \mathrm{Z}^{3}
$$

$$
\text { Kurtosis }=\frac{N(N+1)}{(N-1)(N-2)(N-3)} \Sigma Z^{4} \frac{3(N-1)(N-1)}{(N-2)(N-3)}
$$

\section{Triphenyl Tetrazolium Chloride Staining}

After sacrificing, the heart was rapidly excised and sliced into $1 \mathrm{~cm}$. thick transverse sections from apex to base parallel to the atrioventricular groove. The slices of dog heart were immersed in a freshly prepared solution of triphenyl tetrazolium chloride (TTC) for $10-15$ minutes at $32^{\circ} \mathrm{C} .^{10,11}$ After staining, the slices were fixed in formaldehyde solution and photographs of specimens were obtained for documentation purposes and for later comparison with ultrasound images. 
Statistical Analysis

The mean pixel intensity of the region of left ventricular asynergy (area of myocardial infarction) and a normally moving area were compared and a Student's paired $t$-test applied to evaluate significance of results. Probability values of $<0.05$ were considered significant.

\section{RESULTS}

\section{Echocardiographic Data}

The mean pixel intensity, kurtosis, skewness were calculated in all dogs. The results are shown in figure I and tables I to IV.

In sham operated dogs, no significant change in mean pixel intensity was

\section{MEAN PIXEL INTENSITY IN SHAM OPERATED DOGS AND DOGS UNDERGOING LAD OCCLUSION MEAN VALUES $\pm S D$ ARE DISPLAYED}

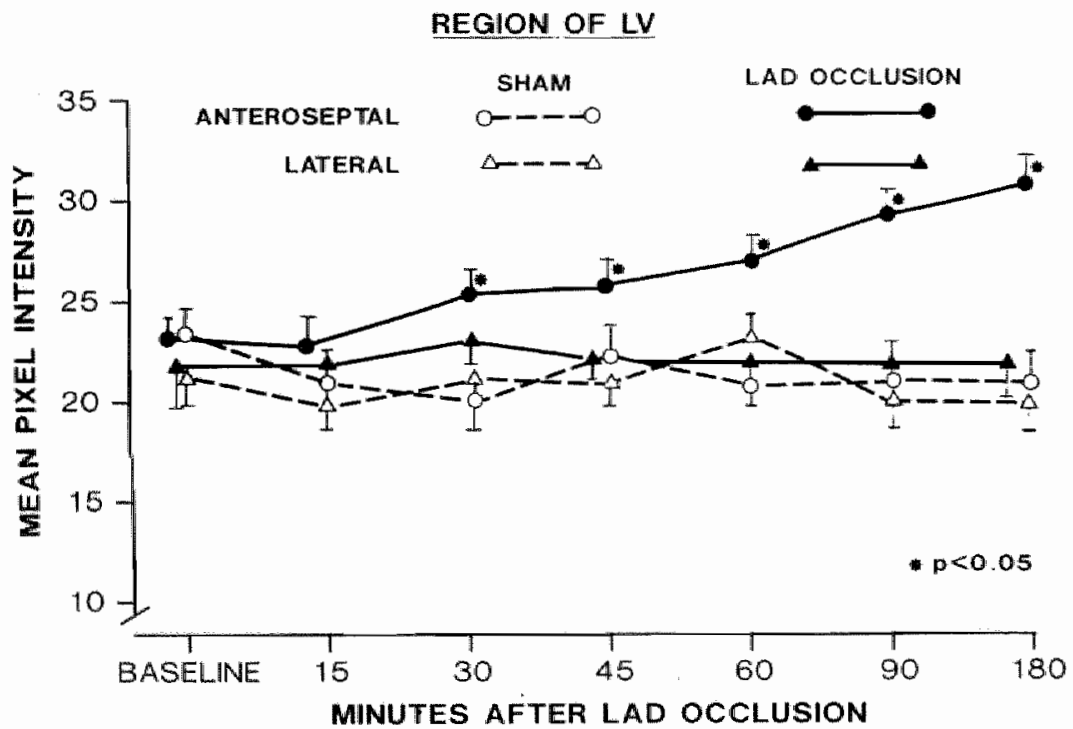

Figure 1: Mean pixel intensity in 5 sham operated dogs and 8 dogs undergoing left anterior descending artery occhusion. MeantSD are displayed. AS = anteroseptal area; Lat. $=$ lateral area.

Asterisks indicate values that differ from the corresponding time intervals at $p<0.05$ between the anteroseptal (infarcted) and the lateral (normal) regions. 
noted (at each point in time) from baseline values to 30, 45, 60, 90 and 180 minutes between the anterosepral region and lateral regions. In addition, skewness and kurtosis were measured and showed no statistically significant difference in sham operated dogs.

However, in dogs undergoing LAD occlusion, a statistically sugnificant difference was noted in mean pixel intensity between the infarcted (anteroseptal) and normal (lateral) regions of the myocardium at 30 minutes $(\mathrm{MPI}=25.2 \pm 2.1$ vs $23.0 \pm 0.7, \mathrm{p}<0.05)$ and this difference

Table I: Kurtosis in sham operated dogs

Mean Values $\pm S D$

\begin{tabular}{llcc}
\hline Time & Kurtosis (AS) & Kurtosis (LAT) & P Value \\
\hline Baseline & $0.81 \pm 0.01$ & $0.75 \pm 0.08$ & NS \\
$15 \mathrm{~min}$ & $0.59 \pm 0.38$ & $0.41 \pm 0.43$ & NS \\
$30 \mathrm{~min}$ & $0.47 \pm 0.68$ & $0.34 \pm 0.92$ & NS \\
$45 \mathrm{~min}$ & $0.74 \pm 0.09$ & $0.55 \pm 0.84$ & NS \\
$60 \mathrm{~min}$ & $0.70 \pm 0.23$ & $0.87 \pm 0.05$ & NS \\
$90 \mathrm{~min}$ & $0.73 \pm 0.16$ & $0.51 \pm 0.59$ & NS \\
$180 \mathrm{~min}$ & $0.38 \pm 0.26$ & $0.23 \pm 0.37$ & NS \\
\hline
\end{tabular}

$\mathrm{NS}=$ not significant; $\mathrm{AS}=$ anteroseptal region, $\mathrm{LAT}=$ lateral region

Table II: Skewness in sham operated dogs

Mean Values $\pm S D$

\begin{tabular}{lrrl}
\hline Time & Skewness (AS) & Skewness (LAT) & P Value \\
\hline Basseline & $-0.17 \pm 0.28$ & $-0.41 \pm 0.71$ & NS \\
$15 \mathrm{~min}$ & $-0.40 \pm 0.82$ & $-0.21 \pm 0.43$ & NS \\
$30 \mathrm{~min}$ & $-0.39 \pm 0.54$ & $0.11 \pm 0.31$ & NS \\
$45 \mathrm{~min}$ & $-0.47 \pm 0.56$ & $0.24 \pm 0.34$ & NS \\
$60 \mathrm{~min}$ & $-0.29 \pm 0.23$ & $0.07 \pm 0.31$ & NS \\
$90 \mathrm{~min}$ & $-0.20 \pm 0.40$ & $0.15 \pm 0.51$ & NS \\
$180 \mathrm{~min}$ & $0.11 \pm 0.30$ & $0.25 \pm 0.31$ & NS \\
\hline
\end{tabular}

$\mathrm{NS}=$ not significant; $\mathrm{AS}=$ anteroseptal region, $\mathrm{LAT}=$ =lateral region 
persisted at 45 minutes (MPI $=25.8 \pm 0.9$ vs $22.6 \pm 0.5, \mathrm{p}<0.01$ ), 60 minutes $(\mathrm{MPI}=27.2 \pm 1.4$ vs $22.8 \pm 0.8, \mathrm{p}<0.01), 90$ minutes $(\mathrm{MPI}=28.6 \pm 1.6 \mathrm{ws}$ $22.5 \pm 0.9, \mathrm{p}<0.01)$ and 180 minutes (MPI $=28.7 \pm 1.8$ vs $21.3 \pm 1.4, \mathrm{p}$ $<0.01$ ) (Figure I).

In addition, in dogs undergoing LAD occlusion, kurtosis showed a statistically significant decrease between infarcted (anteroseptal) and normal (lateral) regions; starting from 45 minutes $(-0.256 \pm 0.3$ vs $0.289 \pm 0.6, \mathrm{p}<0.05)$ to 180 minutes $(0.090 \pm 0.4$ vs $0.300 \pm 0.2, \mathrm{p}<0.05)$.

Table III: Kurtosis in dogs undergoing LAD occlusion

Mean Values $\pm S D$

\begin{tabular}{lrrc}
\hline Time & Skewness (AS) & Skewness (L.AT) & P Value \\
\hline Baseline & $1.26 \pm 1.16$ & $0.59 \pm 0.74$ & NS \\
$15 \mathrm{~min}$ & $0.32 \pm 0.38$ & $0.40 \pm 0.40$ & NS \\
$30 \mathrm{~min}$ & $0.14 \pm 0.75$ & $-0.01 \pm 0.42$ & NS \\
$45 \mathrm{~min}$ & $-0.25 \pm 0.32$ & $0.28 \pm 0.64$ & 0.03 \\
$60 \mathrm{~min}$ & $-0.59 \pm 0.33$ & $0.58 \pm 1.08$ & 0.01 \\
$90 \mathrm{~min}$ & $-0.37 \pm 0.34$ & $0.34 \pm 0.61$ & 0.04 \\
$180 \mathrm{~min}$ & $0.09 \pm 0.43$ & $0.30 \pm 0.23$ & 0.04 \\
\hline
\end{tabular}

$\mathrm{NS}=$ not significant; $\mathrm{AS}=$ amteroseptal region, $\mathrm{LAT}=$ =lateral region

Table IV: Skewness in dogs undergoing LAD occlusion

Mean ValuestSD

\begin{tabular}{lrrl}
\hline Time & Skewness (AS) & Skewness (LAT) & P Value \\
\hline Baseline & $-0.82 \pm 0.43$ & $-0.62 \pm 0.24$ & NS \\
$15 \mathrm{~min}$ & $0.29 \pm 0.43$ & $0.21 \pm 0.36$ & NS \\
$30 \mathrm{~min}$ & $-0.24 \pm 0.35$ & $0.23 \pm 0.38$ & NS \\
$45 \mathrm{~min}$ & $-0.12 \pm 0.35$ & $0.00 \pm 0.64$ & NS \\
$60 \mathrm{~min}$ & $-0.03 \pm 0.28$ & $0.01 \pm 0.45$ & NS \\
$90 \mathrm{~min}$ & $-0.11 \pm 0.37$ & $0.40 \pm 0.40$ & NS \\
$180 \mathrm{~min}$ & $0.25 \pm 0.35$ & $0.16 \pm 0.75$ & NS \\
\hline
\end{tabular}

NS=not significant; $A S=$ anteroseptal region, $\mathrm{LAT}=$ =lateral region 
Changes in skewness showed no statistically significant difference in dogs undergoing LAD occlusion.

\section{Triphenyl Tetrazolium Chloride Staining}

This revealed lack of staining in the anteroseptal region of the left ventricle (area of infarction). The noninfarcted regions showed a brick-red color.

\section{DISCUSSION}

Ischemic myocardium changes the nature of the reflected ultrasound signal, and this change is detectable..$^{9,11-17}$ In canine preparations, Mimbs et al ${ }^{16,17}$ showed increased integrated backscatter in ischemic myocardium in-vivo as early as one hour after coronary occlusion. Several studies have shown that integrated backscatter undergoes variation throughout the cardiac cycle with a decrease in backscatter from diastole to systolle. ${ }^{18-20}$

Madlaras et $a^{21}$ have recently reported that integrated ultrasonic backscatter measured in open-chest dogs varies with the phase of cardiac contraction in normal myocardium. Olshansky et $\mathrm{al}^{22}$ have shown that left ventricular myocardial gray-levels obtained by 2-dimensional echocardiograms vary from end-diastole to end-systole. Fraker et al ${ }^{4}$ noted an increase in apparent brightness of infarcted areas of dog hearts after acute myocardial infarction; however, their findings were subjective in nature and no quantification of acoustic reflectance was attempted.

Skorton et al ${ }^{8}$ have evaluated the (quantitative) statistical characteristics of echocardiographic intensities (gray-levels) from standard echocardiograms of canine myocardium before and two days after experimental coronary occlua.. The distribution of gray-levels (shape of the gray-level histograms) changed significantly with acute infarction. Utilizing quantitative measures of echocardiographic image texture which were previously used in the analysis of nonmedical images, $\mathrm{McPherson}$ et $\mathrm{al}^{23}$ have identified acutely ischemic myocardium 1-2 hours after coronary occlusion in dogs.

Results of the present study indicate that measurement of mean pixel intensity of digitized $2 \mathrm{DE}$ images can detect myocardial ischemia as early as 30 minutes after coronary artery occlusion in dogs. Our findings corroborate those of some other investigators ${ }^{5,16,24}$ who, while using more cumbersome approaches which involved acquiring radiofrequency data, found significant changes at an early stage following occlusion of the coronary circulation in experimental studies. The current data 
were obtained by placing a $5.0 \mathrm{mHz}$ transducer directly on the chest wall. In this study, the first significant increase in mean pixel intensity in the infarcted region was observed at 30 minutes following $\mathrm{LAD}$ occlusion. The mean pixel intensity in the infarcated region continued to increase over time after occllusion and further significant differences were noted between 30 to 180 minutes post-occlusion between the infarcted and normal regions. No significant difference in mean pixel intensity between anteroseptal and lateral regions was seen in the sham operated dogs in the three hour study period. Kurtosis (peakedness of mean pixel intensity) showed a significant decrease at 45 minutes between the anteroseptal and lateral regions following LAD occlusion, and this difference remained significant until 180 minutes. In sham operated dogs, no difference in kurtosis was observed between the lateral and anteroseptal regions. Our observations that the MPI in the region of the wall motion abnormality at 15 minutes was not significantly different when compared to a control region, indicate that the changes in MPI observed at subsequent times was probably not caused by the wall motion abnormality per se, because wall motion abnormalities occur immediately after coronary occlusion.

Although the current data are expressed as mean $\pm \mathrm{SD}$, and our method required a fair amount of averaging of data, the measurement 30 minutes after coronary artery occlusion was statistically significantly different from normally moving areas for mean pixel intensity and at 45 minutes for kurtosis. The explanation for the altered mean pixel intensity and kurtosis in infarcted regions of the myocardium is not entirely clear. Mimbs et al $^{17}$ noted an increase in myocardial fluid content reflected by the wet-to-dry weight ratio in their experiments involving ultrasonic backscatter. Schnittger et al ${ }^{s}$ observed changes by electron microscopic slides at the subcellular level, and this may alter scattering properties. Myocardial cells or bundle of cells can be looked upon as individual scatterers, and as found by others using erythrocytes, ${ }^{25}$ when the density of scatterers changes, the backscatter may change.

In conclusion, the results of the present study demonstrate that digital image processing of 2-dimensional echocardiograms is an additional useful tool in diagnosing myocardial infarction in its very early stages in dogs. Its applicability to man remains to be further explored.

\section{REFERENCES}

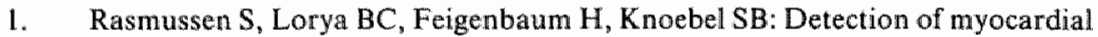
scar tissue by M-mode echocardiography. Circulation 1978; 57:230-237. 
2. Chandraratna PAN, Ulene $R$, Nimalasuriya $A$, Reid $C L$, Kawanishi $D$, Rahimtoola SH: Differentiation between acute and healed myocardial infarction by signal averaging and color encoding two-dimensional echocardiography. Am J Cardiol $1985 ; 56: 381-3,84$.

3. Parisi AF, Nieminen M, O'Boyle JE, Moynihan PF, Khuri SF, Kloner RA, Folland Ed, Schoen FJ: Enhanced detection of the evaluation of tissue changes after acute myocardial infarction using color-encoded 2-dimensional echocardiography. Circulation $1982 ; 66: 764-770$.

4. Fraker TD Jr, Nelson D, Arthur JA, Wilkerson RD: Altered acoustic reflectance on two-dimensional echocardiography as an early predictor of myocardial infarct size. Am J Cardiol 1984; 53:1699-1702.

5. Schnittger I, Vieli $A$, Heiserman JE, Director $B A$, Billingham $M E$, Ellis $\mathrm{SG}_{\text {, }}$ Kernoff RS, Takamoto T, Popp RL: Ultrasonic tissue characterization: Detection of acute myocardial ischemia in dogs. Circulation 1985; 72(1):193.

6. Chandrasekaran K, Chu A, Greenleaf JF, Bahn RC, Edwards WD, Seward JB, Tajik $\mathrm{AJ}$ : $2 \mathrm{D}$ echo quantitative texture analysis of acutely ischenic myocardium. (abstr.) Circulation 1986; 74:II-271.

7. Logan-Sinclair R, Wong CM, Gibson DG: Clinical application of amplitude processing of echocardiographic images. Br Heart J 1981; 45:621-627.

8. Skorton DJ, Melton HE Jr., Pandian NG, Nichols J, Koyanagi S, Marcus ML, Collins SM, Kerber RE: Detection of acute myocardial infarction in closed chest dogs by analysis of regional 2-dimensional echocardiographic gray-level distributions. Circ Res 1983; 52:36-44.

9. Tak, Gamage N, Lin SL, Gerbaudo V, Coletti P, Rahimtoola SH, Chandraratna PAN: Echocardiographic textural changes and nuclear magnetic resonance parameters in acute canine myocardial infarction. (abstr) Circulation 1986; 74 II -270

10. Kloner RA, Darsee JR, De Boer WV, Carlson N: Early pathologic detection of acute myocardial infarction. Arch Path Lab Med 1981; 105:403-406.

11. Fishbein MC, Meerbaum S, Rit J et al: Early phase acute myocardial infarct size quantification: Variation of the triphenyl tetrazolium chloride tissue staining technique. Am Heart J 1981; 101:593-599.

12. Skorton D, Melton H Jr., Pandian N et al: Identification of acutely infarcted myocardium in closed-chest dogs by analysis of regional 2-dimensional echo gray-level histograms. (abstr.) Circulation 1981; 64:IV-205.

13. Mimbs JW, O'Donnel M, Bauwens D, Miller JW, Sobel BE: The dependence of ultrasonic attenuation and backscatter on collagen content in dog and rabbit hearts. Circ Res 1980; 47:49-58.

14. Mimbs JW, Yuhas DE, Miller JG, Weiss AN, Sobel BE: Detection of myocardial infarction in vitro based on altered attenuation of ultrasound. Circ Res 1977; 41:192-198.

15. O'Donnel M, Mimbs JW, Miller JG: The relationship between collagen and ultrasonic attenuations in myocardial tissue. J Acoust Soc Am 1979; 65:512-5 17 .

16. Mimbs JW, O'Donnel M, Miller JG, Sobel BE: Changes in ultrasonic attenuation indicative of early myocardial ischemia injury. Am Phys Soc 1979; 236: $\mathrm{H} 340-44$.

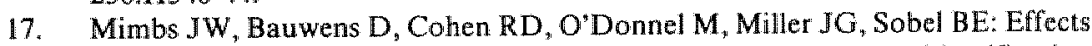
of myocardial ischemia on quantitative ultrasonic backscatter and identification of responsible determinants. Circ Res 1981; 49:89-96.

18. Mottley JG, Glueck RM, Perez JE, Sobel BE, Miller JG: Regional differences in 
the cyclic variation of myocardial backscatter that parallel regional differences in contractile performance. I Acoust Soc Am 1984; 76:1617-23.

19. Wickline $\mathrm{SA}$, Thomas III LJ, Miller JG, Sobel BE, Perez JE: A relationship between ultrasonic integrated backscatter and myocardial contractile function. $J$ Clin Invest $1985 ; 76: 2151-60$.

20. Wickline SA, Thomas III LJ, Miller JG, Sobel BE, Perez JE: The dependence of myocardial ultrasonic integrated backscatter on contractile performance. Circulation $1985 ; 72$; $183-92$.

21. Barzilai B, Madaras EI, Sobel BE, Miller JG, Perez JE: Effects of myocardial contraction on ultrasonic backscatter before and after ischemia. Am J Physiol $1984 ; 247: \mathrm{H} 478-83$.

22. Olshansky B, Collins SM, Skorton DJ, Prasad NV: Variation of left ventricular niyocardial gray-level on 2-dimensional echocardiograms as a result of cardiac contraction. Circulation 1984; 70:972-77.

23. McPherson DD, Aylward PE, Knosp BM et al: Ultrasound characterization of acute myocardial ischemia by quantitative texture analysis. Ultrasonic Imaging $1986 ; 8(4): 227-40$.

24. Rasmussen S, Lovelace E, Knoebel SB, Ransburg R, Corya BC: Echocardiographic detection of ischemic and infarcted myocardium. J Am Coll Cardiol $1984 ; 3: 733-743$.

25. Yaun YW, Shung KK, Fei $\mathbb{D}$. Effects of flow disturbance and erythrocyte aggregation on ultrasonic backscatter from blood. J Acoust Soc Am 1984; $75: 1265$. 


\section{Chapter 8}

\section{APPRAISAL OF THE RESEARCH PERFORMED}

The present research was conducted from September 1985 to June 1988 , at the Echocardiographic Laboratory of the Section of Cardiology, Department of Medicine, Los Angeles County - University of Southern California School of Medicine, Los Angeles, under the supervision of Dr. P.A.N. Chandraratna (Professor of Medicine, Director of Echocardiography and Graphics).

Two dimensional echocardiography provides a great deal of information about the size and volume of various cardiac chambers and about regional and global left ventricular function. In addition to the above, information regarding the structure of the cardiac tissue (e.g. myocardium and valves) can sometimes be obtained by analysis of 2 dimensional echocardiograms, for instance, when gross calcification and fibrosis can be seen by the naked eye. However, in other instances when mild and subtle abnormalities are present, a more sophisticated diagnostic approach is needed.

A relatively new area of endeavor in cardiac ultrasound is the attempt to evaluate myocardial tissue composition and/or structure based on the acoustic properties of the heart. The rationale for this area of study termed "Ultrasonic Tissue Characterization", is that ultrasound interacts (is absorbed or reflected) differently with abnormal myocardium than with normal myocardium. This rationale stems from the common clinical observation that certain abnormalities of the heart (calcification, myocardial ischemia, amyloidosis and others) affect the appearance of echocardiographic images. Several approaches to the evaluation of tissue composition with ultrasound include the display of acoustically abnormal tissue using gray scale or color encoding, the measurement of classic acoustic variables, and computer based analysis of ultrasound signals and images. Promising results have been obtained through the use of ultrasound tissue characterization methods to identify acute ischemia, acute and chronic myocardial infarction, cardiomyopathies, myocardial contusion and intracardiac masses.

The purpose of this research was to investigate the ability of a 
computer based image digitizing system developed in our laboratory to: 1) quantitate textural abnormalities of valvular leaflets in patients with mitral valve prolapse and rheumatic mitral valves; 2) differentiate "active" from "chronic" vegetations in patients with infective endocarditis; and 3) differentiate normal from infarcted myocardium in dogs. To realize this goal, our computer system was designed to measure mean pixel intensity $\pm \mathrm{SD}$, kurtosis and skewness in a given area of interest in the normal and abnormal tissue. In addition, it has the capability of drawing pixel histograms and pixel maps of desired areas on the picture screen and perform certain other functions such as image zoom, signal averaging, edge detection, etc. Sixty-four colors indicated pixell intensity or pixel value; e.g. blue and green color represented low pixel values, while yellow and red color represented high pixel values. Using this methodology, we were able to detect (early) infarcted from normal myocardium in dogs in two separate studies, differentiate "active" from "chronic" vegetations of infective endocarditis and establish that a subset of patients with severe myxomatous degeneration have a lower mean pixel intensity than normal mitral valves, whereas, patients with rheumatic mitral valves have a higher mean pixel intensity than mormal and myxomatous mitral valves.

There is now ample laboratory evidence, based on in vitro and in vivo animal studies, together with some confirmatory studies in humans, to suggest that cardiac tissue characterization is feasible. With some modification to existing equipment, it is possible to acquire data for tissue characterization during routine echocardiographic examinations without causing any inconvenience to the patient. Unfortunately,such modified equipment is unavailable commercially at the present time and research instruments provided by some companies have proven inadequate to the task. Thus, all tissues characterization studies carried out to date have been performed with equipment either constructed or modified by individual investigators.

The future development of cardiac tissue characterization is clearly tied to the availability of appropriate instrumentation. The widespread use of real time, gray-scale instruments and the availability of powerful, lowcost microcomputers will almost certainly kindle enthusiasm amongst cardiologists and scientists alike and will lead to a new generation of ultrasound systems that are appropriate for tissue characterization studies. Such studies have the potential for making a substantial contribution to diagnostic medicine, in general, and to echocardiography, in particular. It is conceivable that, in the not too distant future, ultrasonic tissue characterization will become one of the more powerful and routine applications of echocardiography. 


\section{SUMMARY}

The first chapter gives an introduction to the basic principles and applications of ultrasonic tissue characterization in the detection of cardiovascular diseases. Three modalities of this technique are discussed:

1. Visual methods.

2. Measurement of acoustic variables.

3. Digital image/signal analysis.

A more detailed description of the qualitative and quantitative methods used in cardiac tissue characterization is discussed in chapter 6. The methods of two-dimensional echocardiographic recordings are also described in this chapter. The aim of this thesis was to investigate the ability of a computer based image digitizing system developed in our laboratory to differentiate normal from abnormal cardiac tissue by digital image processing of two-dimensional echocardiographic images.

In Chapter 2, two groups of patients with mitral valve prolapse, one with thickened mitral leaflets (MVP-TL), and the other with normal leaflet thickness (MVP-NTL) were compared to each other and with a normal control group. The two-dimensional echocardiographic images were digitized and the mean pixel intensity of the mitral leaflets (PI-ML) and the posterior wall of the aorta (PI-Ao) was determined. The mean pixel intensity in the MVP-TL and ratio PI-ML/PI-Ao was compared to the MVP-NTL group; the mean pixel intensity in the MVP-TL group was significantly lower than that of MVP-NTL group. In addition, the mitral leaflets of the MVP-TL group were significantly thicker than those of the MVP-NTL group and normal controls. The lower mean pixel intensity in the MVP-TL group is probably attributable to more extensive myxomatous change in this group of patients.

In Chapter 3, the ability of a computer based image digitizing system to differentiate active from chronic vegetations of infective endocarditis by digital image processing of two-dimensional echocardiograms was evaluated. This study was performed on a prospective basis on 22 patients who were studied serially for a mean period of 8 weeks (range 4-22 weeks) after initiation of antibiotic therapy. This method enabled us to reliably differentiate "active" from "chronic" vegetations; the first significant 
increase in mean pixel intensity occurred at 4 weeks following therapy. Vegetation size decreased in only $73 \%$ of the patients, whereas in the remaining $27 \%$ of the patients the vegetation size did not change significantly from the active to the chronic stage.

In Chapter 4, experimental myocardial infarction was induced in 13 dogs by ligation of the left anterior descending coronary artery (LAD). Five sham operated dogs served as controls. The mean pixel intensity measured in the anteroseptal region (infarcted region) was significantly higher in dogs undergoing LAD occlusion for 3 hours, as compared to a normaliy moving (lateral) region. Triphenyl tetrazolium chloride staining confirmed the region of myocardial infarction suspected on two dimensional echocardiograms and digitized two dimensional images. In sham operated dogs no change in mean pixel intensity was noted at 4 hours.

In Chapter 5, the results of an in-vitro study which was performed on excised mitral valves with myxomatous degeneration and severe mitral regurgitation, rheumatic mitral valves, and normal mitral valves of persons with a negative cardiovascular history are presented. Mitral valve thickness and mean pixel intensity were determined in all three groups. The mitral valve thickness in the excised rheumatic and myxomatous valves were both significantly higher than that of normal valves. The mean pixel intensity in the myxomatous valves was significantly less than that of rheumatic mitral valves and normal mitral valves. The decrease in the mean pixel intensity in myxomatous valves with severe mitral regurgitation is probably due to decreased tissue density in these valves. The increased mean pixel intensity found in rheumatic mitral valves when compared to myxomatous mitral valves and normal mitral valves reflects increased tissue density probably as a result of fibrosis, and calcification.

Chapter 6, reviews the present knowledge of the application of ultrasonic tissue characterization methods in the diagnosis of coronary artery disease. This technique has been used both in the experimental and clinical setting and some very promising results have been obtained. The importance of image standardization in ultrasonic tissue characterization is also discussed in detail. It appears from the literature that this technique of ultrasonic tissue characterization is sensitive in detecting ischemic changes in the myocardium. 
In the study described in chapter 7 the feasibility of digital image processing in the very early stages of acute myocardial infarction in an animal model is discussed. The mean pixel intensity, kurtosis, and skewness were measured in 8 dogs who were subjected to left anterior descending artery occlusion. Five sham operated dogs serwed as controls. Serial. 2-dimensional echocardiographic studies were performed every 15 minutes for the first hour and every 30 minutes thereafter for the remaining 2 hours of the study. There was a significant increase in mean pixel intensity between infarcted and non-infarcted regions beginning at 30 minutes which persisted until the end of 3 hours of LAD occlusion. Kurtosis showed a significant decrease in the infarcted versus noninfarcted regions beginning at 45 minutes and continued until the end of the study in dogs undergoing LAD occlusion. Kurtosis did not change significantly in sham operated dogs. There was no change in skewness between the anteroseptal and lateral regions in dogs undergoing LAD occlusion or in sham operated dogs.

In Chapter 8 , the institution where the research was performed, purpose of research, methodology used, as well as a general background of ultrasonic tissue characterization are described. In addition, an appraisal of the work performed and the future of this noninvasive diagnostic method is presented. 


\section{SAMENVATTING}

Hoofdstuk 1: Inleiding.

In dit hoofdstuk wordt de theoretische achtergrond alsmede de waarde van ultrasonore weefseltypering beschreven bij de opsporing van cardiovasculaire ziekten. Een literatuuroverzicht van deze techniek en de algemene toepassing van M-Mode en tweedimensionale echocardiografie wordt aangegeven. Drie modaliteiten van ultrasonore weefseltypering worden besproken.
A. Visuele methoden
B. Meting van acoustische variabelen
$C_{n}$ Digitaal beeld/Signaal analyse.

Een uitgebreide beschrijving van de qualitatieve en quantitatieve methoden die gebruikt worden in ultrasonore weefseltypering is gegeven in hoofdstuk 6. Het doel van dit promotieonderzoek is om een nieuw computersysteem dat ontwikkeld is in ons laboratorium te gebruiken en te proberen hiermee cardiovasculaire aandoeningen te diagnostiseren.

\section{Hoofdstuk 2:}

Twee groepen patiënten met mitralisklepprollaps: 1. met verdikte klepslippen (MVP-TL) en 2. met niet-verdikte klepslippen (MVP-NTL) werden vergeleken met een controle groep (normalen). De tweedimensionale beelden werden gedigitaliseerd en de gemiddelde pixelintensiteit (MPI) van de mitralisklepslip (PI-ML) en de achterwand van de aortawortel (PI-Ao) werden gemeten. De MPI en de ratio PI-ML/PI-Ao in de drie onderzoeksgroepen werden vergeleken. De MPI en de ratio PIML/PI-Ao in de MVP-TL groep waren significant lager dan in beide andere groepen.

De verlaagde MPI in de MVP-TL groep is waarschijnlijk toe te schrijven aan de myxomateuze veranderingen van de mitralisklep.

\section{Hoofdstuk 3:}

In dit hoofdstuk wordt de waarde van ons computersysteem t.a.v. het onderscheiden van actieve en chronische vegetaties bij infectieuze endocarditis geëvalueerd. Deze studie werd verricht op een prospectieve wijze bij 22 patiënten over een gemiddelde periode van 8 weken (range 4 tot 18 weken) na het instellen van antibiotische therapie. De gemiddelde pixe】 intensiteit (MPI) van de actieve en chronische vegetaties op verschillende 
kleppen werd seriaalsgewijs gemeten. Deze techniek stelde ons in staat om bij infectieuze endocarditis actieve van chronische vegetaties te onderscheiden. De MPI toonde een significante toename met klinische verbetering. Deze toename in MPI werd voor het eerst gezien vier weken na het instellen van antibiotische therapie. De grootte van de vegetaties verminderde significant bij $73 \%$ van de patiënten; bij de overige $27 \%$ van de patiënten werd geen significant verschil gemeten in grootte tussen het actieve en het chronische stadium.

\section{Hoofdstuk 4.}

Hierin worden de resultaten beschreven van een experimentele studie bij 18 proefdieren (honden). Bij 13 honden vond kunstmatige afsluiting van de ramus descendens anterior plaats (LAD); de overige 5 honden werden als controls gebruikt. De gemiddelde pixel intensiteit (MPI) werd gemeten in het abnormaal bewegend gebied (anteroseptaal) en werd vergeleken met de MPI in het normaal bewegend gebied(lateraal). Er was een significante toename van MPI gemeten drie uur na afsluiting van de LAD in het geïnfarceerde t.o.w. het normaal bewegend gebied $(p<0.05)$. In de controle groep werd geen significant verschil in MPI gezien tussen het anteroseptaal en lateraal gebied. Triphenyl tetrazolium chloride kleuring bevestigde het geïnfarceerde gebied en hielp in het onderscheid maken tussen normaal en abnormaal weefsel.

\section{Hoofdstuk 5.}

Dit hoofdstuk geeft de bevindingen weer van een in vitro verrichte studie van mitraliskleppen met: 1. myxomateuze degeneratie gepaard gaande met ernstige mitralisklepinsufficiëntie; 2 . rheumatische mitraliskleppen en 3. gezonde mitraliskleppen (normaalgroep). Histopathologisch onderzoek bevestigde deze bevindingen. De gemiddelde pixel intensiteit (MPI) en de dikte van de klepslippen werden gemeten in de drie groepen. De rheumatische en myxomateuze klepslippen waren beide dikker dan de normale klepslippen $(p<0.05)$. De MPI van de rheumatische klepslippen was significant hoger dan die van de normale klepslippen. Daarentegen hadden de myxomateuze klepslippen een significante lagere MPI $(p<0.05)$ dan de normale klepslippen.

\section{Hoofdstuk 6.}

Hierin wordt een literatuuroverzicht gegeven van de waarde van ultrasonore weefseltypering bij de diagnose van coronairlijden. Deze techniek heeft toepassing zowel op het experimentele gebied als in de klinische praktijk. De resultaten wan de diverse studies zijn in het algemeen gunstig. Verder wordt in dit hoofdstuk de noodzaak van standaardizatie 
van de echocardiografische beelden en de verwachtingen m.b.t. de bruikbaarheid van deze techniek besproken.

\section{Hoofdstuk 7.}

Digitalisatie van tweedimensionale echocardiografische beelden bij proefdieren (honden) hielp ons met het opsporen van vroege ischemie. De gemiddelde pixelintensiteit (MPI), kurtosis en skewness werden gemeten in 8 honden bij wie de ramus descendens anterior (LAD) was afgesloten. Vijf honden werden gebruikt als controle groep. Bij alle honden werd tweedimensionale echocardiografie seriaalsgewijs verricht iedere 15 minuten gedurende het eerste uur, daarna eens per 30 minuten gedurende de overige twee uur van het onderzoek. Er werd een significante toename van MPI gevonden in de geïnfarceerde gebieden t.o.v. de normaal bewegende gebieden (lateraal) na 30 minuten LAD afsluiting en dit bleef aanwezig gedurende de rest van de tijd van het onderzoek. De kurtosis vertoonde een significant verschil na 45 minuten in de geïnfarceerde gebieden t.o.v. de normaal bewegende gebieden (lateraal). Daarentegen vertoonde de skewness geen significante veranderingen. Er werden geen significante verschillen gevonden m.b.t. deze drie parameters bij de controles wanneer het anteroseptaal gebied vergeleken werd met het laterale gebied.

\section{Hoofdstuk 8.}

Hierin wordt het instituut waar het onderzoek plaats wond vermeld en worden doel van research, de gebruikte methodologie, en een algemene achtergrond van ultrasonore weefseltypering beschreven. Daarnaast worden waarde en toekomstperspectief van deze non-invasieve onderzoeksmethode besproken. 


\section{ACKNOWLEDGEMENTS}

First of all, I am thankful to Dr. H.J.J, Wellens (Professor and Head of the Department of Cardiology, University of Limburg, Maastricht) for giving me the opportunity to defend this thesis in Maastricht, in order to obtain a doctorate degree in The Netherlands.

I am grateful to Dr. C.A. Visser (University of Amsterdam) for not only teaching me the basics of echocardiography during my "Fellowship" years, but also for stimulating my interest in the field of Ultrasonic Tissue Characterization.

I wish to express particular thanks to Dr. Shahbudin H. Rahimtoola (George C. Griffith Professor of Cardiology, Professor of Medicine, Chief, Section of Cardiology, University of Southern California School of Medicine, Los Angeles) and Dr. P.A.N. Chandraratna (Professor of Medicine, Director of Echocardiography and Graphics, University of Southern California School of Medicine, Los Angeles) who contributed much of their time in review of all the papers. Dr. Rahimtoola's academic brilliance, inspiring personality, his constant encouragement, and above all his support to me during the three years helped enormously in the completion of this thesis.

I also wish to thank Dr. J.P. Jones, Ph.D. (Professor of Radiology, University of California, Irvine) for his careful review of chapter 2 of this thesis.

I acknowledge the stimulation of all colleagues who, in many ways, helped me to question the validity of my hypotheses. I am also grateful to the technicians of the Echocardiographic Laboratory, LAC-USC Medical Center, who tolerated my presence in the Laboratory and performed follow-up studies on patients when needed.

Last but not least, I would like to express my appreciation and thanks to Ms. Alice Madrid, Ms. Lorine Villanueva and Ms. Corine Legdeur for their secretarial assistance in the preparation of the manuscripts of this thesis. 


\section{CURRICULUM VITAE}

The author of this thesis was born in Lahore (Pakistan) on July 18, 1951. After finishing High School, he graduated from the Government College, Lahore, with a Bachelor of Science degree in Biology and Chemistry. In September 1972, he started Medical School at the University of Nijmegen (The Netherlands) and completed his M.D. in 1977. During his medical training, the author completed a medical externship (Department of Medicine) from the Marymount Hospital, Garfield Heights, Ohio. From February 1978 to January 1980, the author completed his medical internship in the University Hospital in Nijmegen. Hereafter, from 1980-1982, he did his residency in Internal Medicine at the Mariastichting Haarlem (The Netherlands). From February 1982 to July 1985, a Cardiology Fellowship was completed in the University Hospital (Program Directors: Professor Dr. Dirk Durrer and Professor Dr. A.J. Dunning) in Amsterdam, The Netherlands. He was registered as a Cardiologist in The Netherlands on August 1, 1985. From September 1985 to June 1988, the author worked as a "Research Fellow" at the Section of Cardiology, (Chief: Dr. S.H. Rahimtoola) Department of Medicine, Los Angeles County-University of Southern California Medical Center, University of Southern California School of Medicine, Los Angeles, California. The author was supported in part by the Group Investigator Award of the American Heart Association, Greater Los Angeles Affiliate.

The present research was conducted at the Echocardiographic Laboratory of the Los Angeles County/University of Southern California School of Medicine, Los Angeles, under the supervision of Dr. P.A.N. Chandraratna, Professor of Medicine and Director of Echocardiography and Graphics.

The author is a Fellow of the American College of Chest Physicians, Member of the American College of Cardiology, Member of the American Heart Association, Associate of the American College of Physicians, Member of the American Society of Echocardiography, Member of the Los Angeles Society of Echocardiography, Member of the American Federation for Clinical Research and Member of the Dutch Society of Cardiology. 